\title{
INFLUÊNCIA DA CARGA ALCALINA NO PROCESSO DE POLPAÇÃO Lo-Solids@ PARA MADEIRAS DE EUCALIPTO
}

\section{FÁBIO SÉRGIO DE ALMEIDA}

\begin{abstract}
Dissertação apresentada à Escola Superior de Agricultura "Luiz de Queiroz", Universidade de São Paulo, para obtenção do título de Mestre em Recursos Florestais, com opção em Tecnologia de Produtos Florestais.
\end{abstract}

PIRACICABA

Estado de São Paulo - Brasil

Agosto - 2003 


\section{INFLUÊNCIA DA CARGA ALCALINA NO PROCESSO DE POLPAÇÃO Lo-Solids® PARA MADEIRAS DE EUCALIPTO}

\section{FÁBIO SÉRGIO DE ALMEIDA}

Bacharel em Ciência da Computação

Orientador: Prof. Dr. FRANCIDES G. DA SILVA JÚNIOR

Dissertação apresentada à Escola Superior de Agricultura "Luiz de Queiroz", Universidade de São Paulo, para obtenção do título de Mestre em Recursos Florestais, com opção em Tecnologia de Produtos Florestais.

PIRACICABA

Estado de São Paulo - Brasil

Agosto - 2003 


\section{Dados Internacionais de Catalogação na Publicação (CIP)}

DIVISÃO DE BIBLIOTECA E DOCUMENTAÇÃO - ESALQ/USP

Almeida, Fábio Sérgio de
Influência da carga alcalina no processo de polpação Lo-Solids®
para madeiras de eucalipto / Fábio Sérgio de Almeida. - - Piracicaba, 2003.

$115 \mathrm{p}$.

Dissertação (mestrado) - - Escola Superior de Agricultura Luiz de Queiroz, 2003.

Bibliografia.

1. Celulose 2. Densida de da madeira 3. Madeira de euc alipto 4. Polpa da madeira 5. Polpação 6. Química da madeira I. Título

CDD 674.142

"Permitida a cópia total ou parcial deste documento, desde que citada a fonte - $\mathrm{O}$ autor" 
À minha esposa Andréa, pelo carinho, compreensão e incentivo.

Ao meu pai Natalino e a minha mãe Elmira, que através do amor, carinho e simplicidade transmitiram os verdadeiros ensinamentos.

A Deus pela minha existência e por tornar tudo isso possível. 


\section{AGRADECIMENTOS}

À Escola Superior de Agricultura "Luiz de Queiroz" e ao Departamento de Ciências Florestais que permitiram a realização desse estudo.

Ao Professor Dr. Francides Gomes da Silva Júnior, pelos ensinamentos e orientação.

Aos Professores Luiz Ernesto George Barrichelo, Celso Edmundo Bochetti Foelkel, Cláudio Angeli Sansígolo e José Mangoline Neves pelas sugestões e colaboração para o enriquecimento do trabalho.

Ao Professor Marcelo Alves pelo auxílio na análise estatística.

À Vera Maria Sacon pela confiança, incentivo e amizade.

Ao amigo Alexandre Bassa pelas sugestões e colaboração ao longo do desenvolvimento do trabalho.

A bibliotecária da VCP Cleusa Maria Machado pela paciência e colaboração nas pesquisas de bibliografia.

Aos amigos do Laboratório de Pesquisa e Desenvolvimento da VCP/LA: Valter, Rogério, Sérgio, Alessandra, Vinicius, Carol, Juliana, Paula, Henrique.

Aos amigos do Laboratório de Química, Celulose e Energia da ESALQ: Regina, Camila, Talita, Camila Sarto, Francismara, Udemilson.

Aos amigos da ESALQ: Winter, Marcelino, Percy, Antonio, Wirifran, Maria Cláudia, Ana Clara, Gláucia, Ana Maria, Sila, Andréa Mosca, Viviane.

A todos que de forma direta ou indireta contribuíram para execução deste trabalho. 


\section{SUMÁRIO}

\begin{tabular}{|c|c|}
\hline LISTA DE TABELAS & $\begin{array}{r}\text { Página } \\
\text { vii }\end{array}$ \\
\hline STA DE FIGURAS. & ix \\
\hline STA DE QUADRO & \\
\hline ZESUMO.. & $x i i$ \\
\hline UMMARY... & xiv \\
\hline INTRODUÇÃO .. & 1 \\
\hline 2 REVISÃO DE LITERATURA ............... & 3 \\
\hline 2.1 Densidade básica da madeira................... & 3 \\
\hline 2.2 Propriedades químicas da madeira.......... & 6 \\
\hline 2.3 Propriedades anatômicas da madeira.... & 7 \\
\hline 2.4 Carga alcalina ....................... & 9 \\
\hline 2.5 Processo de polpação Kraft modificado... & 12 \\
\hline 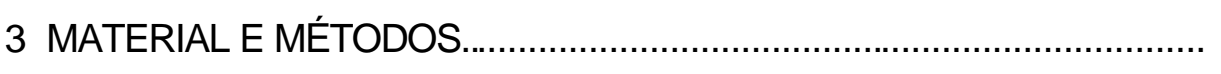 & 15 \\
\hline 3.1 Materiais.................... & 15 \\
\hline 3.1.1 Amostragem........ & 15 \\
\hline 3.2 Métodos... & 16 \\
\hline 3.2.1 Madeira....... & 16 \\
\hline 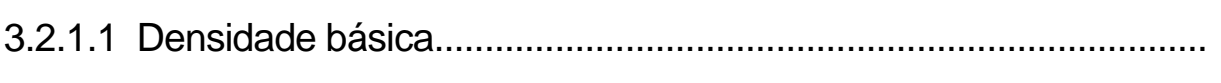 & 16 \\
\hline 3.2.1.2 Composição química da madeira..... & 16 \\
\hline 3.2.1.3 Pentosanas......... & 17 \\
\hline 3.2.1.4 Carboidratos da madeira....... & 17 \\
\hline 3.2.1.5 Dimensões das fibras.. & 17 \\
\hline 2.1.6 Classificação granulométrica. & 18 \\
\hline
\end{tabular}




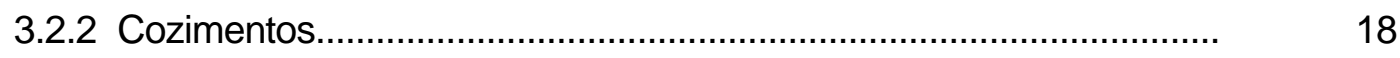

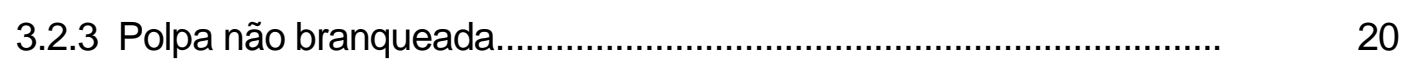

3.2.3.1 Rendimento bruto, depurado e teor de rejeitos............................... 20

3.2.3.2 Número kappa ........................................................................... 20

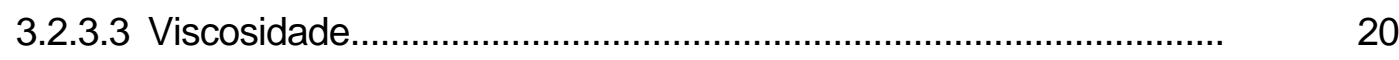

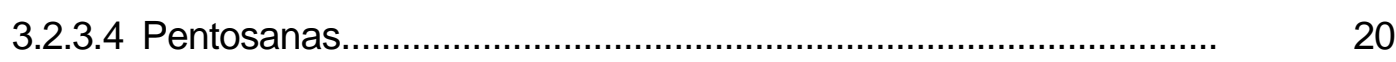

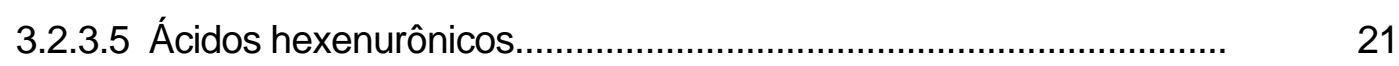

3.2.3.6 Dimensão de fibra...................................................................

3.2.3.7 Solubilidade em $\mathrm{NaOH} 5 \%$ - S5 ...................................................

3.2.3.8 Carboidratos........................................................................

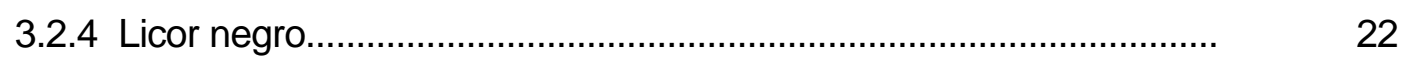

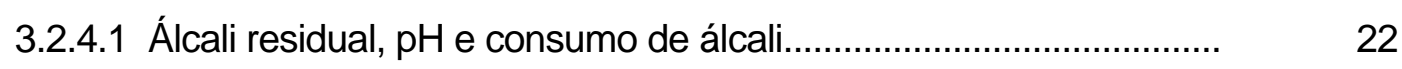

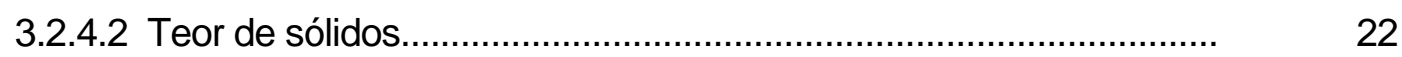

3.2.4.3 Teor de sólidos secos................................................................

3.2.5 Delineamento experimental e análise estatística................................. 23

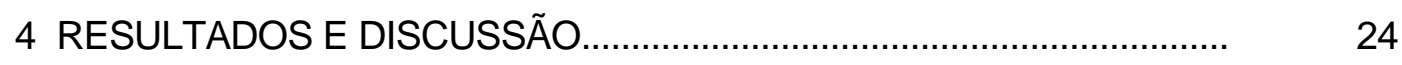

4.1 Madeira

4.1.1 Densidade básica da madeira............................................................ 24

4.1.2 Composição química da madeira........................................................ 25

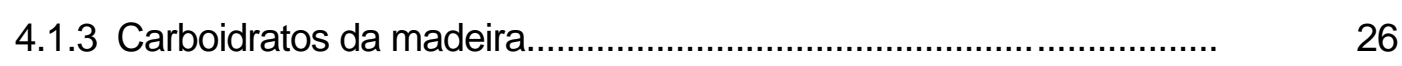

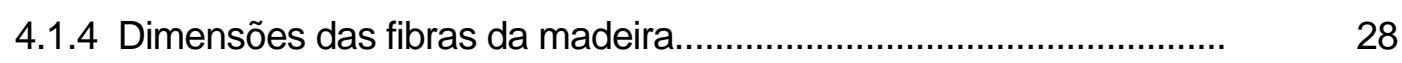

4.1.5 Classificação granulométrica dos cavacos de madeira........................ 29

4.2 Cozimentos.....................................................................................

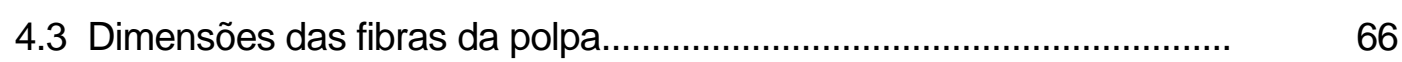

4.4 Características dos licores negros........................................................ 83

4.5 Carga alcalina consumida..................................................................... 94

4.6 Estimativa do consumo específico de madeira...................................... $\quad 96$

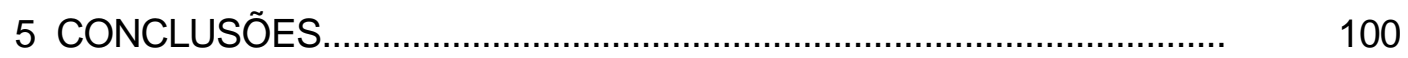

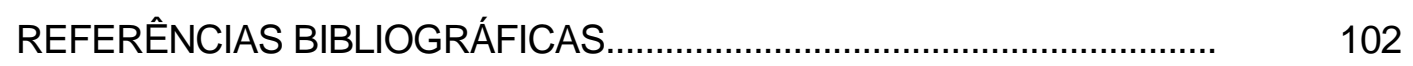

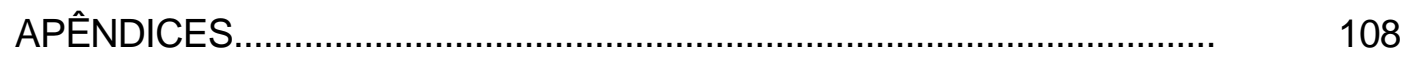




\section{LISTA DE TABELAS}

\section{Página}

1 Dados de silvicultura dos materiais.

2 Condições dos cozimentos: quantidade de cavacos, relação licor madeira, carga alcalina, sulfidez e fator $\mathrm{H}$..

3 Tempo, temperatura e distribuição da carga alcalina nas fases do cozimento.

4 Densidade básica da madeira................................................................ 24

5 Teor de lignina total, solúvel e insolúvel, teor de holocelulose, teor de extrativos e teor de pentosanas............................................................. 25

6 Grupos acetis, ácidos glicurônicos, glucanas, xilanas e arabinanas......... 27

7 Comprimento, largura, espessura da parede, diâmetro do lume, fração parede, coeficiente de flexibilidade, índice de Runkel e índice de enfeltramento.

8 Distribuição granulométrica do comprimento dos cavacos, após eliminação dos "overs" e finos..

9 Distribuição em espessura dos cavacos, após eliminação dos "overs" e finos.

10 Análise de variância e teste $\mathrm{F}$ para o parâmetro número kappa................. 37

11 Análise de variância e teste $\mathrm{F}$ para o parâmetro rendimento depurado.... 42

12 Análise de variância e teste $\mathrm{F}$ para o parâmetro teor de rejeitos............... 46

13 Análise de variância e teste $\mathrm{F}$ para o parâmetro viscosidade..................... 50

14 Análise de variância e teste $\mathrm{F}$ para o parâmetro ácido hexenurônico....... 55

15 Análise de variância e teste $\mathrm{F}$ para solubilidade em $\mathrm{NaOH}$ 5\% - S5......... 59

16 Análise de variância e teste $\mathrm{F}$ para o parâmetro comprimento de fibra..... 69

17 Análise de variância e teste $\mathrm{F}$ para o parâmetro teor de finos................... 72

18 Análise de variância e teste F para o parâmetro largura de fibra.............. 73 
19 Análise de variância e teste $\mathrm{F}$ para o parâmetro espessura de parede..... 75

20 Análise de variância e teste $\mathrm{F}$ para o parâmetro coarseness de fibra.......

21 Consumo de madeira em $\mathrm{m}^{3}$ de madeira por tonelada de polpa celulósica seca produzida...

22 Consumo de madeira em tonelada de madeira por tonelada de polpa celulósica seca produzida...... 


\section{LISTA DE FIGURAS}

Página

1 Dimensão dos cavacos - classificação por tamanho................................... 30

2 Dimensão dos cavacos - classificação por espessura ................................. 31

$3 \quad$ Número kappa x álcali ativo........................................................................ 38

$4 \quad$ Número kappa corrigido $x$ álcali ativo......................................................... 40

5 Percentual de lignina total removido $x$ álcali ativo.......................................... 41

6 Rendimento depurado $x$ álcali ativo........................................................... 43

$7 \quad$ Rendimento depurado x número kappa....................................................... 44

8 Relação rendimento depurado/número kappa x álcali ativo........................... 45

$9 \quad$ Teor de rejeitos $x$ álcali ativo................................................................... 47

10 Teor de sólidos secos (tss) $x$ álcali ativo.................................................... 48

11 Teor de sólidos secos (tss) x número kappa............................................... 49

12 Viscosidade da polpa $x$ álcali ativo............................................................. 51

13 Viscosidade da polpa $x$ rendimento depurado............................................. 52

14 Viscosidade da polpa $x$ número kappa...................................................... 53

15 Relação viscosidade/número kappa x álcali ativo......................................... 54

16 Teor de ácidos hexenurônicos da polpa x álcali ativo................................... 56

17 Teor de ácidos hexenurônicos da polpa x número kappa............................. 58

18 Solubilidade da polpa em $\mathrm{NaOH} 5 \%$ (S5) x álcali ativo................................. 60

19 Solubilidade da polpa em $\mathrm{NaOH} 5 \%$ (S5) x rendimento depurado.................. 61

20 Solubilidade da polpa em $\mathrm{NaOH}$ 5\% (S5) x número kappa ........................... 62

21 Teor de pentosanas da polpa x álcali ativo...................................................... 63

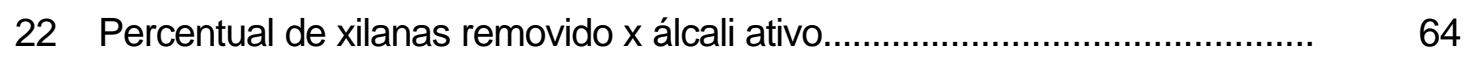

23 Percentual de glucanas removido $x$ álcali ativo............................................ 65

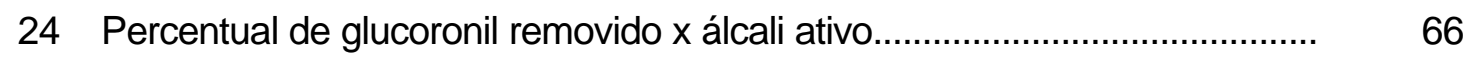

25 Comprimento médio de fibras $x$ álcali ativo................................................. 70 
26 Comprimento médio ponderado de fibras $x$ teor de finos da polpa................ 71

27 Teor de finos da polpa $x$ álcali ativo........................................................... 72

28 Largura de fibra $x$ álcali ativo................................................................ 74

29 Espessura de parede da fibra $x$ álcali ativo.................................................. 76

30 Diâmetro do lume da fibra $x$ álcali ativo.......................................................... 77

31 Coarseness de fibra $x$ álcali ativo.............................................................. $\quad 79$

32 Coarseness de fibra $x$ rendimento depurado.............................................. 80

33 Número de fibras por grama de polpa ativo............................................... 81

34 Número de fibras por grama de polpa $x$ teor de finos.................................... 82

35 Álcali efetivo residual no licor negro $x$ álcali ativo aplicado - E. grandis $x E$. urophylla P4299............................................................................ 88

36 Álcali efetivo residual no licor negro $x$ álcali ativo aplicado - E. grandis $x E$. urophylla C085...................................................................................... 89

$37 \mathrm{pH}$ do licor negro $x$ álcali ativo - E. grandis $x$ E. urophylla P4299................. 90

$38 \mathrm{pH}$ do licor negro $x$ álcali ativo - E. grandis $x$ E. urophylla C085.................. 91

39 Teor de sólidos dissolvidos no licor negro $x$ álcali ativo - E. grandis $x E$.

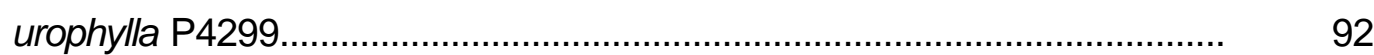

40 Teor de sólidos dissolvidos no licor negro $\mathrm{x}$ álcali ativo - E. grandis $x E$. urophylla C085..................................................................................... 93

41 Consumo de álcali por tonelada de polpa produzida $x$ álcali ativo................. 95

42 Consumo específico de madeira em $\mathrm{m}^{3}$ por tonelada de polpa produzida $\mathrm{x}$ álcali ativo.

43 Consumo específico de madeira em tonelada por tonelada de polpa produzida $x$ álcali ativo 


\section{LISTA DE QUADROS}

\section{Página}

1 Resultados dos cozimentos para o híbrido E. grandis x E. urophylla P4299.

2 Resultados dos cozimentos para o híbrido E. grandis x E. urophylla C085.

3 Composição química da polpa não branqueada híbrido $E$. grandis x $E$. urophylla P4299.

4 Composição química da polpa celulósica não branqueada híbrido $E$. grandis x E. urophylla C085...

5 Dimensões de fibras da polpa celulósica não branqueada híbrido $E$. grandis $\times$ E. urophylla P4299...

6 Dimensões de fibras da polpa celulósica não branqueada híbrido $E$. grandis $\times$ E. urophylla C085.

7 Teor de sólidos, $\mathrm{pH}$, e residual de álcali híbrido E. grandis x E. urophylla C085: fase de substituição.

8 Teor de sólidos, $\mathrm{pH}$, e residual de álcali híbrido E. grandis $\times$ E. urophylla P4299: fase de substituição.

9 Teor de sólidos, $\mathrm{pH}$, e residual de álcali híbrido E. grandis x E. urophylla P4299: fase de lavagem.

10 Teor de sólidos, $\mathrm{pH}$, e residual de álcali híbrido E. grandis x E. urophylla C085: fase de lavagem.

11 Álcali ativo aplicado, consumido, residual e quantidade necessária para produzir uma tonelada de polpa seca - Material P4299.

12 Álcali ativo aplicado, consumido, residual e quantidade necessária para produzir uma tonelada de polpa seca-Material C085. 


\title{
INFLUÊNCIA DA CARGA ALCALINA NO PROCESSO DE POLPAÇÃO Lo-Solids® PARA MADEIRAS DE EUCALIPTO
}

\author{
Autor: FÁBIO SÉRGIO DE ALMEIDA \\ Orientador: Prof. Dr. FRANCIDES GOMES DA SILVA JÚNIOR
}

\section{RESUMO}

O presente trabalho teve por objetivo estudar a influência da carga alcalina no processo de polpação kraft modificado Lo-Solids ${ }^{\circledR}$ para madeiras de eucalipto, considerando parâmetros como rendimento, teor de rejeitos, geração de sólidos e características da polpa tais como número kappa, viscosidade, composição polissacarídica e morfologia de fibras. Híbridos de E. grandis x E. urophylla com 7 anos e densidade básica de 500 e $560 \mathrm{~kg} / \mathrm{m}^{3}$ foram avaliados e os cozimentos Lo-Solids ${ }^{\circledR}$ foram realizadas aplicando-se álcali ativo (como $\mathrm{Na}_{2} \mathrm{O}$ ) de 13\%, 15\%, 17\%, 19\%, 21\%, $23 \%, 25 \%, 27 \%$ e sulfidez de $30 \%$. O delineamento experimental adotado foi o inteiramente casualizado. Os resultados obtidos indicam que variando a carga alcalina no processo de polpação é possível obter polpa não branqueada apresentando valores de kappa de 8 a 30, rendimento depurado de 46 a 53\%, viscosidade de 10 a $80 \mathrm{cP}$, solubilidade em $\mathrm{NaOH} 5 \%$ (S5) de 7 a 13\%, teor de pentosanas de 11 a 16\% e ácidos hexenurônicos de 10 a $65 \mu \mathrm{mol} / \mathrm{g}$. O aumento da carga alcalina nos cozimentos proporcionou maior geração de finos e, consequentemente, menor comprimento médio ponderado de fibras e espessura de parede. Embora os materiais estudados apresentassem diferentes densidade básica, os resultados de polpação foram semelhantes indicando que ambas matérias-primas podem ser empregadas na obtenção de polpa celulósica utilizando o processo de cozimento Lo-Solids®, o qual não se mostrou sensível a densidade básica, o que possivelmente está associado a boa impregnação dos cavacos correspondente à etapa de impregnação. O híbrido de 
maior densidade produziu polpa com fibras de maior espessura de parede, maior coarseness e menor número de fibras por grama que o híbrido de menor densidade básica. As análises do licor negro mostraram que o de $\mathrm{pH}$, o álcali efetivo residual e o teor de sólidos dissolvidos apresentam maiores valores para dosagens de álcali também superiores, porém observa-se um perfil uniforme para essas variáveis, evidenciando a homogeneidade do processo de polpação Lo-Solids ${ }^{\circledR}$. 


\title{
THE INFLUENCE OF ALKALI CHARGE ON Lo-Solids® PULPING PROCESS FOR EUCALYPTUS WOODS
}

\author{
Author: FÁBIO SÉRGIO DE ALMEIDA \\ Adviser: Prof. Dr. FRANCIDES GOMES DA SILVA JÚNIOR
}

\section{SUMMARY}

The main objective of this work was to study the influence of the alkali charge on Lo-Solids $\AA$ modified kraft pulping process for eucalyptus, considering parameters as yield, rejects content, total dissolved solids materials and the pulp characteristics as kappa number, viscosity, carbohydrate composition and fibers dimensions. Woods from hybrids of Eucalyptus grandis $x$ Eucalyptus urophylla 7 years old and presented basic density of 0,499 and $0,559 \mathrm{~g} / \mathrm{cm}^{3}$ were evaluated and the pulping process was conducted applying active alkali charge (as $\mathrm{Na}_{2} \mathrm{O}$ ) of $13 \%, 15 \%, 17 \%, 19 \%, 21 \%, 23 \%$, $24 \%, 25 \%, 27 \%$ and sulfidity of $30 \%$. The results showed that varying the alkali charge is possible to obtain unbleached pulp with kappa number from 8 to 30 , pulp yield from 46 to $53 \%$, viscosity from 10 to $80 \mathrm{cP}$, alkali solubility (S5) from 7 to $13 \%$, pentosans content from 11 to $16 \%$ and hexenuronic acids content from 10 to $65 \mu \mathrm{mol} / \mathrm{g}$. It was verified that the higher is the alkali charge the higher is the fines generation leading to a decreased of fiber length and the cell wall thickness. Although the hybrids studied presented different wood basic density, the pulping results obtained were not different showing that both raw-materials could be used to pulp production with Lo-Solids $\AA$ pulping process, which seems not to be so affect by wood basic density. The pulp obtained from hybrid with higher basic density showed higher cell wall thickness, higher fiber coarseness and lower number of fibers per gram than the hybrid with lower basic 
density. The analysis of black liquor showed that the $\mathrm{pH}$, the effective residual alkali and the total dissolved solids materials increased when the alkali charge applied is higher too, however a uniform profile is noted for these variables, showing the homogeneity of Lo-Solids ${ }^{\circledR}$ pulping process. 


\section{INTRODUÇÃO}

O setor de celulose e papel no Brasil utiliza madeira de florestas plantadas e emprega técnicas de manejo florestal, seleção e melhoramento genético que são referências em todo o mundo, sendo o estágio atual de desenvolvimento da silvicultura brasileira resultado de intensos estudos realizados, principalmente com madeiras de eucalipto.

Introduzido no Brasil ainda no século XVIII, o eucalipto encontrou condições edáficas favoráveis ao seu rápido crescimento e elevados índices de produtividade. Seu plantio foi então intensificado no século seguinte, sendo utilizado inicialmente na construção de ferrovias. No final do século 20 as indústrias siderúrgicas mineiras passaram a utilizar esse gênero para a produção de carvão vegetal, matéria-prima utilizada no processo de fabricação de ferro-gusa. Mas foi no início da década 50 que o engenheiro Gunar Krogh com seus estudos preliminares encontrou no eucalipto um grande potencial para a produção de polpa celulósica, a qual era até então obtida exclusivamente de madeira de coníferas.

O setor celulósico mundial apresentou uma evolução tecnológica expressiva nas últimas décadas. Houve pressões ambientais visando reduzir os impactos causados pelo cozimento kraft convencional, o que levou a necessidade de aumentar o nível de deslignificação e adequar a polpa ao branqueamento ECF (Elemental Chlorine Free). Nos anos 80 foram desenvolvidas as tecnologias de cozimento MCC ("Modified Continuous Cooking") e cozimento XMCC ("Extended Modified Continuous Cooking"), denominados processos modificados de polpação. Havia ainda um aspecto relacionado ao rendimento relativamente baixo do processo de polpação. Nos anos 90 foram implantadas comercialmente as tecnologias de cozimento ITC "Iİso Thermal Cooking"), cozimento com baixo teor de sólidos dissolvidos (Lo-Solids) e o conceito de cozimento Compact Cooking, tecnologias de cozimento modificados que permitiram a 
manutenção do maior nível de deslignificação e incremento no rendimento de processo e da qualidade da polpa produzida.

O Brasil ocupa a primeira posição entre os países produtores de polpa celulósica branqueada de eucalipto e utiliza, em sua maior parte, os processos modificados de polpação kraft ou sulfato e emprega, em sua maioria, seqüências de branqueamento livre de cloro elementar, buscando através dessas tecnologias aumentar a eficiência de deslignificação da polpa, preservar o rendimento do processo de polpação kraft e também diminuir o impacto ambiental das unidades de produção.

Portanto, os estudos de polpação buscam, principalmente, compreender o efeito das propriedades da madeira e das condições do processo de polpação sobre a qualidade da polpa celulósica, visando fornecer subsídios aos programas de melhoramento florestal e também à indústria para a definição de estratégias de processamento ou ainda para a compreensão do comportamento das variáveis do processo produtivo sob condições específicas.

Dentro desse contexto o objetivo do presente estudo foi verificar a influência da carga alcalina no processo de polpação Lo-Solids ${ }^{\circledR}$ para híbridos de $E$. grandis $x E$. urophylla com diferentes densidades básicas, com enfoque nos parâmetros de qualidade da madeira, nas variáveis de processo e nas características da polpa celulósica. 


\section{REVISÃO DE LITERATURA}

\subsection{Densidade básica da madeira}

Segundo Foelkel (1992), a densidade básica da madeira é uma propriedade de fácil determinação, porém muito complexa, pois a mesma é resultado da interação entre propriedades físicas, químicas e anatômicas da madeira. $\mathrm{O}$ autor descreve que a densidade básica da madeira pode variar entre espécie, gênero, dentro da mesma espécie, com a idade da floresta, com o local de plantio, no sentido base-topo e também na direção medula casca.

Wehr (1991) observou que madeiras mais densas apresentam também maior teor de extrativos, maior teor de lignina e menor teor de hemiceluloses Já Shimoyama (1990) estudou E. grandis com 7 anos de idade e não constatou nenhuma relação entre densidade básica e composição química da madeira. Garcia (1995) descreve que a densidade é resultado do conjunto de características anatômicas e químicas da madeira, porém não está quantificado a influência individual desses parâmetros sobre a densidade da madeira, o que pode justificar os resultados obtidos em diferentes pesquisas.

Oliveira (1979) descreve que a densidade básica de madeiras de folhosas, por representarem um estágio mais evoluído no reino vegetal e possuírem tecidos mais especializados e complexos, não depende apenas da espessura de parede celular, mas também da proporção dos vários tecidos presentes. Porém, dentro de uma mesma espécie essa proporção é relativamente œnstante e a espessura de parede controla as variações de densidade.

Segundo Foelkel (1992), a densidade básica da madeira do gênero eucalipto pode variar de 0,300 a 0,800 $\mathrm{g} / \mathrm{cm}^{3}$. O autor descreve que a densidade básica da madeira é um parâmetro importante para o processo de produção da polpa celulósica tendo em vista a influência que a mesma exerce sobre a quantidade de polpa 
produzida por unidade de volume de madeira consumido e também sobre a eficiência do processo de deslignificação.

Wehr (1991) descreve que madeiras de maior densidade podem produzir cavacos com dimensões não uniforme e também dificultar a impregnação dos mesmos pelo licor de coziment, levando ao incremento do consumo de reagentes químicos durante a polpação, aumentando o teor de rejeitos e reduzindo o rendimento do processo.

Santos (2000) descreve que a densidade básica influencia diretamente o processo de polpação e os parâmetros de qualidade da polpa, observados através das propriedades de resistência mecânicas, superficiais e ópticas. A densidade básica da madeira se correlaciona de forma positiva com o coeficiente de flexibilidade das fibras, sendo o último parâmetro expresso por 100 vezes a relação diâmetro do lume/largura de fibra. A autora descreve que, por essas razões, a densidade básica da madeira é considerada um parâmetro importante no processo de produção de polpa celulósica e, por apresentar um elevado índice de herdabilidade, essa propriedade é tida como referência nos programas de melhoramento genético.

Estudo conduzido por Demuner et al. (1991) mostra que a densidade básica da madeira exerce influência sobre o coeficiente de flexibilidade da fibra, número de fibras por grama e coarseness de fibra, sendo que esse último parâmetro expressa a massa do material fibroso por unidade de comprimento. Os resultados obtidos indicam que madeiras de maior densidade básica apresentam fibras com maior coarseness devido, principalmente, a maior espessura de parede. Os resultados obtidos por esses autores não constatam correlação entre densidade básica e comprimento de fibra.

Silva Júnior (1995) descreve que madeira de maior densidade básica tende a apresentar fibras mais espessas, menor volume de tecido parenquimático e menor freqüência de vasos, os quais podem estar obstruídos por tilos e dificultar com isso a impregnação dos cavacos pelo licor de cozimento. O aumento da densidade básica se correlaciona de forma positiva com maior teor de lignina e proporciona redução no rendimento depurado. Os resultados mostram a existência de correlação positiva entre a densidade básica e o volume específico do papel para madeira de E. grandis, associado com fibras apresentando alta fração parede (200 vezes a relação espessura de parede/largura de fibra). O autor conclui que utilizando o parâmetro de densidade 
básica da madeira é possível estimar o volume específico do papel a ser fabricado com determinada polpa.

Ratnieks \& Foelkel (1996) comentam que fibras com paredes mais espessas associadas a madeiras mais densas facilitam a drenagem de água durante a fabricação do papel e dão origem a folhas mais volumosas e porosas, maior coarseness, menor população fibrosa por massa de polpa e, conseqüentemente, menor área específica para ligações interfibras.

Foelkel et al. (1992) estudou madeiras de E. saligna, E. grandis, E. tereticornis, E. camaldulensis e E. citriodora com densidade básica vaiando de 0,35 a $0,75 \mathrm{~g} / \mathrm{cm}^{3}$ conclui que quanto maior a densidade básica da madeira mais volumosa é a folha de papel resultante, menor é a resistência à passagem de ar e a capacidade de absorção de líquidos (capilaridade klemm) do papel. As características de absorção capilar klemm, volume específico e resistência à passagem de ar mostram ser mais dependente da densidade básica do que das espécies estudas. Os autores descrevem também que madeira de maior densidade apresenta fibras com maior comprimento médio ponderado, o qual pode estar associado às atividades das células da região do cambio.

Alencar (2002) estudou híbridos de E. grandis x E. urophylla com idade de 1 a 7 anos e constatou incremento da densidade básica e do comprimento de fibra a medida que a idade da floresta aumenta.

Foelkel (1998) comenta as características da madeira de eucalipto requisitadas pela polpa celulósica destinada a fabricação de papéis para imprimir e escrever e para fins sanitários. O autor cita os trabalhos de Ratnieks \& Foelkel (1996) e reforça que os papéis sanitários requerem fibras mais rígidas, pouco flexível, com baixa habilidade de ligação, baixo poder de colapsamento, propriedades associadas a fibras com maior espessura de parede e madeiras de maior densidade básica.

Assis (1996) descreve que polpa celulósica produzida com madeira de menor densidade apresenta fibras com menor espessura de parede é esse tipo de fibra é mais adequada para produção de papéis utilizados para impressão e escrita. Já a polpa celulósica obtida de madeiras mais densas é mais adequada para atender as industrias fabricantes dos papéis absorventes. 


\subsection{Propriedades químicas da madeira}

Trugilho et al. (1996) descreve que a madeira apresenta uma estrutura muito complexa, não por possuir um grande número de compostos químicos, mas devido às diferenças em relação as suas estruturas e composição química, resultado da interação anatômica e química de seus constituintes.

Alencar (2002) comenta que a madeira com maior teor de lignina pode exigir uma maior quantidade de álcali para que se possa manter o nível de deslignificação da polpa, o que implica numa maior degradação dos carboidratos e dissolução dos polissacarídeos de baixo peso molecular, causando redução no rendimento, queda de viscosidade da polpa e resistência física, além de gerar também maior quantidade de sólidos para queima na caldeira.

Santos (2000) descreve que a composição química da madeira desempenha um papel econômico no processo de produção da polpa celulósica. Uma madeira com maior teor de lignina pode exigir um maior consumo de álcali durante a polpação, gerando, conseqüentemente, um maior teor de sólidos para queima na caldeira.

Almeida et al. (2000) menciona que o teor de extrativos e de lignina presente na madeira influencia diretamente o consumo de álcali, o rendimento e a taxa de deslignificação, podendo os mesmos definir o potencial de uma matéria-prima para produção de polpa celulósica.

Smook (1997) descreve que os extrativos compõem uma extraordinária diversidade de compostos e suas proporções na madeira também variam amplamente, podendo ser encontrados, principalmente, em regiões como a casca, folhas, frutos, sementes, acículas, exudações. Segundo o autor os extrativos são representados, principalmente, por ácidos graxos e ácidos resinosos, sendo que diferentes solventes podem ser utilizados na quantificação dos mesmos, porém o mais comum na industria de celulose o tolueno e o diclorometano. O autor menciona que os extrativos são compostos indesejáveis no processo de polpação, uma vez que os mesmos podem consumir reagentes químicos e provocar incrustações (pitch) em tubulações e também causar problemas de absorção de lignina e de cargas durante o processo de fabricação do papel.

Segundo Jordão \& Mangolini (1988), os extrativos exercem efeito marcante sobre as propriedades de absorção da polpa celulósica, pois esses compostos formam 
rearranjo estrutural na superfície da fibra à medida que o tempo de estocagem aumenta, podendo dessa forma influenciar a taxa de absorção de água dos papéis para fins sanitários.

Com relação ao teor de holocelulose Almeida et al. (2000) descreve que o mesmo está relacionado com o rendimento do processo de polpação. O autor descreve que as hemiceluloses facilitam também a refinação das fibras, desempenhando papel fundamental no desenvolvimento das propriedades de resistência físico-mecânica da polpa e na interação química entre as fibras e produtos químicos adicionados no processo de fabricação do papel.

\subsection{Propriedades anatômicas da madeira}

Barrichelo \& Brito (1976) descrevem que as fibras, os elementos de vasos e os parênquimas são células presentes em madeiras de folhosas, as quais funcionam como tecido de suporte, armazenamento e auxiliam também no transporte de água e de nutrientes no tecido vegetal. Os elementos de vasos também favorecem a penetração do licor de cozimento no interior dos cavacos durante o processo de polpação. Segundo os autores, variações de densidade básica da madeira estão, geralmente, relacionadas com as alterações nas dimensões dos elementos anatômicos da madeira.

Amidon (1981) menciona que o comprimento de fibra e a espessura de parede são os parâmetros mais importantes da fibra, os quais exercem influência sobre o coeficiente de flexibilidade, sobre a fração parede e sobre o índice de Runkel, sendo o último parâmetro expresso por 2 vezes a relação espessura de parede/diâmetro do lume da fibra.

Watsom et al. (1961), Smook (1997) descrevem que fibras de maior comprimento exercem influência significativa e positiva sobre a resistência ao rasgo da folha de papel. Segundo os autores fibras com maior espessura de parede também contribui para o incremento da resistência ao rasgo e se correlaciona de forma negativa com o número de fibras por grama de polpa e de forma positiva com o coarseness de fibras e volume específico do papel.

Segundo Carpim et al. (1987), fibras com maior espessura de parede proporcionam maior volume específico e maior resistência à passagem de luz através 
da folha de papel ("opacidade"). Os autores descrevem também que a densidade básica da madeira exerce pouca influência sobre o comprimento.

Silva Júnior \& Mcdonough (2002) descrevem que o comprimento de fibra é um parâmetro importante e que se relaciona com propriedades da polpa celulósica. Com relação ao efeito do processo de polpação sobre as dimensões da fibras os autores descrevem que não é de se esperar um efeito negativo do cozimento sobre as dimensões das fibras.

Segundo Abitz \& Luner (1991), as propriedades de resistência da polpa são influenciadas pelo coeficiente de flexibilidade das fibras. Fibras com maior flexibilidade apresentam um maior poder de fazer ligações interfibras e como isso desenvolvem maior resistência à tração, porém reduz o volume específico do papel.

Smook (1997) menciona que, apesar do parâmetro coeficiente de flexibilidade das fibras ser utilizado pelos fabricantes de polpa na predição de propriedades de resistência da polpa, uma indicação mais específica do comportamento da fibra pode ser fornecido pelo parâmetro de coarseness de fibra.

Segundo Santos (2002), o coarseness de fibra influência parâmetros estruturais do papel como densidade, lisura, resistência à passagem de ar ("porosidade"), resistência física e propriedades ópticas do papel. Com relação aos índices a autora descreve que o índice de enfeltramento (1000 vezes a relação comprimento/largura de fibra) não é parâmetro indicativo de qualidade da polpa. Porém, índice de Runkel com valor próximo de 1 indica fibras com maior poder de ligação e, conseqüentemente, maior resistência física. $O$ índice de Runkel se correlaciona também com propriedades com rigidez da polpa e volume específico do papel.

Barrichelo \& Brito (1976) comentam que as dimensões de fibras isoladamente podem não mostrar correlações significativas com propriedades da madeira e da polpa, sendo comum agrupá-las na forma de índices e coeficientes, os quais combinam as propriedades morfológicas. Porém, os autores ressaltam que esses índices e outros coeficientes relacionados com as dimensões das fibras não devem ser utilizados de forma isolada para indicação de uma determinada propriedade do papel. 


\subsection{Carga alcalina}

Conforme descreve Gomide (1979), o licor normal de cozimento do processo de polpação kraft é constituído pelos reagentes químicos $\mathrm{NaOH}$ e $\mathrm{Na}_{2} \mathrm{~S}$, os quais são eletrólitos e, em solução aquosa, dissociam-se formando os íons de $\mathrm{Na}^{+}, \mathrm{OH}^{-}, \mathrm{HS}^{-}$e $\mathrm{S}^{=}$. Segundo o autor, a quantidade de $\mathrm{Na}_{2} \mathrm{~S}$ presente no licor de cozimento em relação à quantidade de $\mathrm{NaOH}$ é denominada de sulfidez, a qual também pode variar, de acordo com as premissas de cada unidade industrial. $O$ autor descreve que, apesar de outras substâncias químicas estarem presente no licor de cozimento kraft normal, os íons $\mathrm{OH}^{-} \mathrm{HS}^{-}$, e o $\mathrm{S}^{=}$são os únicos íons ativos nas reações de polpação.

Segundo Gomide (1979), as reações de dissociação do sulfeto podem ser resumidas conforme o seguinte equilíbrio químico:

$$
\begin{array}{llll} 
& \multicolumn{3}{c}{\text { pka1 }=7} \\
\mathrm{H}_{2} \mathrm{~S} & \multicolumn{2}{c}{\text { pka2 }=13,5} \\
\rightleftharpoons & \mathrm{H}^{+}+\mathrm{HS}^{-} & \mathrm{H}^{+}+\mathrm{S}^{=}
\end{array}
$$

O íon $\mathrm{S}^{\mathrm{E}}$ é uma base mais forte que a água e, por conseqüência, reage com a mesma, formando o íon bissulfeto (HS ${ }^{-}$). $\mathrm{O}$ íon $\mathrm{HS}^{-}$por sua vez, também reage com a água e forma o sulfeto de hidrogênio $\left(\mathrm{H}_{2} \mathrm{~S}\right)$, de acordo com as seguintes reações de hidrólise:

$$
\begin{array}{llll}
\mathrm{S}^{=}+\mathrm{H}_{2} \mathrm{O} & \mathrm{HS}^{-}+\mathrm{OH}^{-} & \text {(Reação 1) } \\
\mathrm{HS}^{-}+\mathrm{H}_{2} \mathrm{O} & \rightleftharpoons & \mathrm{H}_{2} \mathrm{~S}+\mathrm{OH}^{2} & \text { (Reação 2) }
\end{array}
$$

Segundo Gomide (1979), apesar das reações de hidrólise 1 e 2 alterarem a concentração dos íons $\mathrm{HS}^{-}$e $\mathrm{OH}^{-}$durante o processo de na polpação kraft , apenas a reação 1 ocorre de maneira completa, sendo que a reação 2 ocorre de maneira insignificante devido ao maior valor de $\mathrm{pH}$ do meio. Portanto, a quantidade real de 
álcali disponível para as reações durante o processo de polpação kraft pode ser expressa como álcali efetivo, representado pela concentração dos reagentes químicos $[\mathrm{NaOH}]+1 / 2\left[\mathrm{Na}_{2} \mathrm{~S}\right]$; concentração essa que pode ser expressa, dependendo do país, considerando-se como base os compostos químicos $\mathrm{NaOH}$ ou $\mathrm{Na}_{2} \mathrm{O}$.

Gomide (1979) comenta que apenas as estruturas de lignina reagem com o sulfeto durante o processo de polpação kraft formando tioligninas, as quais são solúveis no licor de cozimento. $\mathrm{O}$ autor descreve que a maior parte dos reagentes químicos empregados no processo de polpação kraft normal são consumidos durante as reações de neutralização de compostos de ácidos orgânicos formados durante as reações de degradação da hemiceluloses e da celulose. Essas reações de degradação iniciam-se em temperaturas em torno de $60^{\circ} \mathrm{C}$ e são completadas quando a temperatura do processo de polpação atinge $150^{\circ} \mathrm{C}$, quando a deslignificação passa a ser a reação dominante. Segundo o autor, a lignina é responsável pelo consumo de apenas de $1 / 4$ do álcali presente no licor de cozimento kraft e 2/3 do álcali é consumido durante a neutralização dos produtos das reações de degradação dos polissacarídeos (hemiceluloses e celulose). O restante do álcali é consumido durante as reações de solubilização de alguns carboidratos mais facilmente removíveis da madeira (amidos, pectinas e parte de glucomananas), nas reações com os extrativos e nas reações de neutralização do ácido acético, produto das reações com os grupos acetilas da madeira.

Segundo Bassa (2002), as reações de remoção das hemiceluloses facilitam a difusão dos reagentes químicos do licor para o interior da parede das células e o acesso desse licor até a lamela média, região onde apresenta maior concentração de lignina. Por outro lado, os polissacarídeos localizados, principalmente, na parede secundária das células, reagem com os compostos químicos do licor. Essas reações provocam alterações estruturais que diminuem a resistência intrínseca e a conformidade das fibras, além da redução acentuada do rendimento do processo, da viscosidade e das propriedades físicas da fibra.

Almeida et al. (2000) estudaram a dissolução dos constituintes químicos da madeira de eucalipto ao longo do processo de polpação kraft convencional e constataram que a carga alcalina aplicada exerce efeito considerável na taxa de deslignificação e sobre a degradação das hemiceluloses, principalmente nas etapas iniciais de cozimento. 
Ek et al. (2001) descrevem que o aumento da carga alcalina do cozimento proporciona redução significativa do rendimento total do processo de polpação. Segundo os autores a queda no rendimento acontece, no caso de madeira de folhosas, devido à degradação das xilanas, as quais são sensíveis ao aumento da carga alcalina, causando impactos negativos na seletividade do cozimento, a qual pode ser expressa pela relação viscosidade/número kappa ou rendimento/número kappa.

Gengo et al. (1990) estudaram a retenção das hemiceluloses durante a polpação kraft para madeira de spruce e álcali efetivo de $16 \%, 20 \%, 24 \%$, e $28 \%$. Os autores verificaram que quanto maior a carga de álcali aplicada menor é a retenção das hemiceluloses nas fibras e o rendimento do processo.

Alencar (2002) estou o híbrido de E. grandis x E. urophyllacom idades de 1 até 7 anos aplicando-se carga alcalina de 13\%, 14\%, 15\%, 16\% e 17\% de álcali ativo como $\mathrm{Na}_{2} \mathrm{O}$. A autora constatou que a media que aumenta o nível de álcali dos cozimentos tem-se um incremento do nível de deslignificação e, conseqüentemente, redução do número kappa, do rendimento depurado, do teor de rejeitos e aumento da relação rendimento/kappa.

Kubes et al. (1980) estudaram o efeito do álcali efetivo aplicado no cozimento kraft convencional e Kraft-AQ para madeira de spruce sobre a viscosidade da polpa não branqueada. Os pesquisadores constataram que o aumento do álcali efetivo influência de maneira expressiva a viscosidade da polpa, estando esse comportamento de acordo com estudos conduzidos anteriormente.

Chai et al. (2001) descreve que a carga alcalina e o fator $\mathrm{H}$ são as principais variáveis que influenciam na formação dos ácidos hexenurônicos durante a polpação kraft. Ek et al. (2001) estudaram a formação, dissolução e degradação dos ácidos hexenurônicos durante a polpação kraft convencional para madeira de E. glóbulos. Os autores descrevem que a carga alcalina é o principal fator que contribui para a formação e degradação dos ácidos hexenurônicos durante a polpação. O aumento da carga alcalina promove a dissolução e degradação das xilanas e, conseqüentemente, reduz a quantidade de ácidos hexenurônicos da polpa, uma vez que esses grupos de ácidos estão ligados as cadeias de xilanas. Os estudos conduzidos por esses autores mostram que a formação dos ácidos hexenurônicos aumenta para número kappa variando de 11 a 18 e acima desse valor de kappa tem-se uma redução desses compostos devido a degradação das hemiceluloses. 
Colodette et al. (2000) descrevem que o teor de ácidos hexenurônicos de polpa Kraft de eucalipto reduz em torno de $26 \%$ quando a carga alcalina é aumentada de $16 \%$ para $24 \%$ e a temperatura de $160^{\circ} \mathrm{C}$ para $170^{\circ} \mathrm{C}$, evidenciando a maior degradação desses grupos de ácidos sob condições de cozimento mais severas.

\subsection{Processo de polpação kraft modificado}

Ganqiang et al. (1998) descreve que o processo de polpação kraft convencional produz polpa celulósica com qualidade para número kappa variando de 18 a 22 para madeira de folhosas e de 28 a 32 para madeira de coníferas. Segundos os autores, a prática de menor número kappa pelo processo convencional proporciona redução significativa na resistência da polpa, no rendimento do processo, aumento de sólidos para queima na caldeira e consumo específico de madeira por tonelada de polpa produzida. Por outro lado, a manutenção de valores de kappa elevados dificulta o processo de branqueamento da polpa, levando a necessidade da adição de maiores dosagens de agentes químicos nesta fase do processo, podendo causar impactos negativos ao meio ambiente devido à formação de compostos organoclorados, uma vez que o cloro e o dióxido de cloro são compostos normalmente empregados nessa fase do processo.

Segundo Silva Junior (1997), o desenvolvimento dos processos de polpação conhecidos atualmente como cozimentos modificados surgiram inicialmente devido as pressões ambientais decorrente dos impactos causados pelo cozimento kraft convencional, o que levou a necessidade de aumentar o nível de deslignificação e adequar a polpa a branqueamento ECF (Elemental Chlorine Free). Numa segunda fase de desenvolvimento outras tecnologias de cozimento modificado contínuo foram desenvolvidas visando aumentar o rendimento do processo e a qualidade da polpa e, consequentemente, reduzir o teor de rejeitos gerados e o consumo específico de madeira por tonelada de polpa produzida, mantendo os maiores níveis de deslignificação obtidos inicialmente.

Ganqiang et al. (1998) descreve a evolução dos processos de cozimento e comentam que no final dos anos 70 e início dos anos 80 a tecnologia de cozimento modificado contínuo MCC ("Modified Continuous Cooking") foi aplicada no norte da Europa. O cozimento MCC possui como característica a aplicação da carga alcalina de forma fracionada ao longo das fases de cozimento, o que permitiu melhorar de forma 
significativa a seletividade quando comparado ao processo kraft convencional, resultando numa polpa com maior viscosidade e resistência física, além da redução teor de rejeitos. No final dos anos 80 pesquisadores da Kamyr desenvolveram, baseado no processo MCC, a tecnologia de cozimento modificado contínuo estendido XMCC ("Extended Modified Continuous Cooking"), a qual permitiu aumentar ainda mais o nível de deslignificação da polpa através do uso da zona de lavagem para cozimento e redução da temperatura na fase de cozimento. Em 1993 as tecnologias de cozimento isotérmico ITC ("İso Thermal Cooking") e cozimento com baixo teor de sólidos dissolvidos ("Lo-Solids") foram implantadas comercialmente. O cozimento ITC, desenvolvido por pesquisadores da Kvaerner, apresenta como característica a prática de temperatura homogênea ao longo das fases de cozimento. O processo Lo-Solids ${ }^{\circledR}$, desenvolvido por pesquisadores da Ahlstrom, possui como princípio básico a redução da concentração de sólidos da madeira dissolvidos nas fases de deslignificação principal e residual por meio de extrações de licor negro. Cada extração é seguida de uma injeção de licor de forma que haja remoção de material dissolvido no licor e ao mesmo tempo o perfil de carga alcalina e a relação licor madeira seja mantida. Em 1997 pesquisadores da Kvaerner desenvolveram o conceito de cozimento Compact Cooking o que possibilitou a operação do digestor com relação licor/madeira de até 6:1, favorecido pelo fato dessa tecnologia empregar um vaso exclusivo para impregnação dos cavacos, o que possibilitou trabalhar menor fator $\mathrm{H}$ mantê-lo uniforme durante o processo de polpação, resultando em polpas com elevadas propriedades físico-mecânicas e branqueabilidade.

Marcoccia et al. (1998) descrevem as modificações executadas a partir do processo de cozimento kraft convencional, para que o conceito de cozimento modificado pudesse ser atingido:

- Estabilidade do perfil de carga alcalina ao longo do cozimento e redução dos picos de concentrações, principalmente na fase inicial do cozimento;

- $\quad$ Adição de maior sulfidez na fase de deslignificação inicial e no começo da fase principal;

- Uniformidade de temperatura e manutenção de menores valores, especialmente na fase inicial e final do cozimento;

- Redução da concentração de lignina dissolvida e de íons de sódio, principalmente na fase final do cozimento. 
Turqueti (2001) menciona que as tecnologias de cozimento modificado contínuo têm como objetivo fornecer condições de cozimento brandas e uniformes, levando em consideração as principais variáveis do processo de polpação, que são: temperatura, fator $\mathrm{H}$, relação $\mathrm{HS}^{-} / \mathrm{OH}$, perfil alcalino, impregnação dos cavacos, teor de sólidos da madeira dissolvidos no licor, relação licor madeira. $O$ autor descreve que com o emprego da tecnologia de polpação kraft modificado é possível produzir polpas não branqueadas com baixos valores de número kappa o que possibilita o emprego de seqüências de branqueamento menos agressiva ao meio ambiente e a manutenção da seletividade do cozimento e das propriedades físico-mecânicas da polpa. 


\section{MATERIAL E MÉTODOS}

\subsection{Materiais}

Para realização do estudo foram utilizados clones de híbridos de $E$. grandis $\times$ E. urophylla de área experimental da Votorantim Celulose e Papel, situada na região de Luiz Antônio (SP), cujas características são descritas a seguir.

Tabela 1. Dados de silvicultura dos materiais

\begin{tabular}{|c|c|c|}
\hline Parâmetros|Materiais & $\begin{array}{c}\text { Híbrido E. grandis x E. } \\
\text { urophyllla P4299 }\end{array}$ & $\begin{array}{c}\text { Híbrido E. grandis x E. } \\
\text { urophylla C085 }\end{array}$ \\
\hline Idade & 07 anos & 07 anos \\
\hline IMA (6,5 anos), m³/ha/ano & 58.6 & 67.0 \\
\hline Espaçamento & $3.0 \mathrm{~m} \times 2.5 \mathrm{~m}$ & $3.0 \mathrm{~m} \times 2.5 \mathrm{~m}$ \\
\hline Tipo de solo & LVd2 & LVd2 \\
\hline Latitude & $21^{\circ} 32^{\prime} 45^{\prime \prime}$ & $21^{\circ} 32^{\prime} 45^{\prime \prime}$ \\
\hline Longitude & $47^{\circ} 42^{\prime} 21^{\prime \prime}$ & $47^{\circ} 42^{\prime} 21^{\prime \prime}$ \\
\hline Altitude & $630 \mathrm{~m}$ & $630 \mathrm{~m}$ \\
\hline Precipitação média anual* & $1338 \mathrm{~mm}$ & $1338 \mathrm{~mm}$ \\
\hline Temperatura média anual* ${ }^{*}$ & $23,1^{\circ}$ & $23,1^{\circ}$ \\
\hline
\end{tabular}

* Valores médio ao longo de 10 anos. Fonte: Posto Meteorológico Cara Preta, Luiz Antonio - SP

Os materiais serão referenciados no decorrer do estudo simplesmente como P4299 e C085, visando facilitar as discussões.

\subsubsection{Amostragem}

Para cada clone de híbridos de E. grandis x E. urophylla foram amostradas 10 árvores apresentando diâmetro médio do povoamento de $28 \pm 2 \mathrm{~cm}$ com base em inventário e de cada árvore foram retirados toretes de $50 \mathrm{~cm}$ de comprimento nas posições correspondentes à base, 25\%,50\%, 75\% e 100\% da altura comercial do 
tronco (diâmetro mínimo $8 \mathrm{~cm}$ ). Os toretes de madeira foram transformados em cavacos utilizando-se um picador modelo Demuth.

\subsection{Métodos}

\subsubsection{Madeira}

Para caracterização da madeira as 10 árvores de cada material foram avaliadas individualmente (2 repetições para cada árvore), buscando verificar a homogeneidade entre as árvores para os parâmetros de densidade básica, teor de lignina e teor de holocelulose.

Após constatar que havia homogeneidade, conforme mostra a análise estatística presente nos Apêndices 4 e 5, foi realizada uma amostra composta e os tratamentos foram realizados a partir dessa amostra composta.

As análises, incluindo composição química e densidade básica, realizada inicialmente nas árvores individuais, foram realizadas novamente a partir da amostra composta (3 repetições).

\subsubsection{Densidade básica}

A densidade básica foi determinada pelo método do máximo teor de umidade, conforme metodologia descrita por Foelkel et al. (1975), tomando-se 3 amostras de $100 \mathrm{~g}$ de cavacos para cada repetição do material a ser analisado.

\subsubsection{Composição química da madeira}

O teor de extrativos totais, o teor de lignina e o teor de holocelulose foi obtido utilizando-se a metodologia utilizada nos laboratórios de Química, Celulose e Energia (LQCE) do Departamento de Ciências Florestais da ESALQ/USP, conforme Apêndice 1. A serragem dos cavacos de madeira foi obtida em moinho de laboratório, após a classificação da mesma em um conjunto de peneira de 40 e 60 mesh. Para cada repetição foram tomadas 3 amostras. 


\subsubsection{Pentosanas}

O teor de pentosanas na madeira foi determinado pela norma TAPPI T223 cm 84, tomando-se 3 amostras para cada repetição.

\subsubsection{Carboidratos da madeira}

O teor de carboidratos presentes na madeira foi determinado através de cromatografia líquida de alto desempenho, conforme descrito seguir.

Alíquotas de 0,3 $\mathrm{g}$ de serragem livre de extrativos foram hidrolisadas em $3 \mathrm{ml}$ de $\mathrm{H}_{2} \mathrm{SO}_{4} 4 \mathrm{~N}$ por uma hora, a $30^{\circ} \mathrm{C}$. Após esse período, adicionaram-se $79 \mathrm{ml}$ de água e as amostras foram colocadas em uma autoclave a $120{ }^{\circ} \mathrm{C}$ - 1atm, onde permaneceram por uma hora. Após o resfriamento filtrou-se a mistura e o filtrado foi coletado em um balão de $100 \mathrm{ml}$.

O filtrado foi analisado por cromatografia líquida de alto desempenho, utilizando-se uma coluna Bio Rard Aminex HPX $87 \mathrm{H}(4.8 \times 300 \mathrm{~mm})$ aquecida a $60^{\circ} \mathrm{C}$. A amostra foi diluída com água destilada, mantendo-se o fluxo de água e filtrado de 0.6 $\mathrm{ml} / \mathrm{min}$. As concentrações dos açúcares (glucanas, xilanas, arabinanas, ácido glucorônico e grupos acetilas) foram determinadas pelo método do padrão externo, utilizando-se padrões analíticos comerciais. Para detecção dos monossacarídeos utilizou-se um detector de refração diferencial e a integração dos picos foi determinada por um programa de computador (LC 10 -SHIMADZU).

\subsubsection{Dimensões das fibras}

As medições foram executadas após a maceração da amostra dos materiais em estudo pelo processo nítrico-acético, conforme metodologia utilizada pelo laboratório de Química, Celulose e Energia (LQCE) do Departamento de Ciências Florestais da ESALQ/USP. Cerca de 50 fragmentos de cavacos de madeira foram cortados nas dimensões de $5,0 \times 0,1 \times 0,2 \mathrm{~cm}$ em comprimento, largura e espessura, respectivamente. Os fragmentos foram colocados em tubo de ensaio e submetidos a um tratamento com solução de ácido acético glacial, ácido nítrico concentrado e água destilada (5:1:2), permanecendo em banho-maria a $100^{\circ} \mathrm{C}$ por um período de tempo suficiente para que as fibras fossem individualizadas. Após a completa individualização do material o mesmo foi lavado com água destilada, utilizando-se um cadinho de vidro 
de placa porosa. Uma pequena porção do material individualizado foi coletada e 5 lâminas histológicas foram montadas adicionando-se $0,5 \mathrm{~mL}$ de safranina e $0,5 \mathrm{~mL}$ de glicerina. Utilizado-se microscopia ótica comum com ocular micrométrica acoplada 20 fibras de cada lâmina foram medidas com relação ao comprimento $(C)$, largura $(\mathrm{L})$, espessura de parede (E) e diâmetro do lume (DL). Para comprimento de fibra utilizouse fator de conversão igual a 0,217, para largura de fibra e diâmetro do lume fator igual a 2,5 e a partir das dimensões de fibras obteve-se as seguintes relações:

Índice de Runkel $=(2 \times E / D)$.

Fração parede $=(200 \times \mathrm{E} / \mathrm{L})$

Coeficiente de Flexibilidade $=(100 \mathrm{DL} / \mathrm{L})$

Índice de Enfeltramento $=(1000 \times \mathrm{C} / \mathrm{L})$

\subsubsection{Classificação granulométrica}

A amostra de cavacos composta pelas 10 árvores de cada material foi classificada quanto ao tamanho e espessura. Para cada análise (3 repetições) tomouse $5 \mathrm{~kg}$ de cavacos.

Um classificador elétrico com peneiras nas dimensões de furos de 5, 10, 16, 22 e $29 \mathrm{~mm}$ foi utilizado para a classificação quanto ao tamanho (largura e comprimento).

Utilizando-se do mesmo classificador elétrico os cavacos foram também classificados quanto à espessura em peneiras com as seguintes dimensões: 2, 4, 6, 8, $10 \mathrm{~mm}$. Os resultados para classificação por tamanho e espessura foram expressos em porcentagem (base peso) considerando-se peso de cavacos total que foi de $5 \mathrm{~kg} \mathrm{e}$ massa dos cavacos retidos em cada peneira.

Para realização dos cozimentos foram descartados os cavacos retidos na peneira de $29 \mathrm{~mm}$ e os que ultrapassaram a peneira de 5 , respectivamente os "oversizes" e finos, sendo denominado as demais frações como os cavacos aceitos da classificação por tamanho.

\subsubsection{Cozimentos}

O sistema utilizado para os cozimentos consiste basicamente de um conjunto de vasos acumuladores de licores, ligados por um conjunto de válvulas e bombas dosadoras a um digestor modelo MK com circulação forçada e capacidade para 6,7L. 
Os cozimentos foram realizados a partir de uma amostra de cavacos composta pelas 10 árvores e após classificação dos mesmos, sendo que os tratamentos foram realizados em triplicatas, conforme condições expressas nas Tabelas 2 e 3.

Tabela 2. Condições dos cozimentos: quantidade de cavacos, relação licor madeira, carga alcalina, sulfidez e fator $\mathrm{H}$

\begin{tabular}{cc}
\hline Parâmetro & Condição \\
\hline Quantidade de cavacos & $800 \mathrm{~g}$ \\
Relação licor madeira & $4: 1$ \\
Álcali ativo $\left(\mathrm{Na}_{2} \mathrm{O}\right)$ & $13,15,17,19,21,23,25$ e 27 \\
Sulfidez & $30,0 \%$ \\
Fator $\mathrm{H}$ & 2045 \\
\hline
\end{tabular}

Tabela 3. Tempo, temperatura e distribuição da carga alcalina nas fases do cozimento

\begin{tabular}{cccc}
\hline Fases & $\begin{array}{c}\text { Tempo } \\
\text { (min.) }\end{array}$ & $\begin{array}{c}\text { Temperatura } \\
\left({ }^{\circ} \mathbf{C}\right)\end{array}$ & $\begin{array}{c}\text { Distribuição Carga } \\
\text { Alcalina (\%) }\end{array}$ \\
\hline Pré-vaporização & 15 & 100 & - \\
Impregnação & 40 & 120 & 50 \\
Substituição & 90 & 158 & 35 \\
Cozimento & 70 & 158 & - \\
Lavagem & 200 & 158 & 15 \\
\hline
\end{tabular}

Foram feitas 6 injeções de licor branco $(50 \mathrm{~g} / \mathrm{L})$ na fase de substituição, sendo 1 injeção de $160 \mathrm{~mL}$ a cada $15 \mathrm{~min}$. Já durante a lavagem foram feitas 5 injeções de licor branco (30g/L), sendo 1 injeção de $135 \mathrm{~mL}$ a cada $40 \mathrm{~min}$. A freqüência das injeções de licor foi previamente definida de forma que o perfil de alcali residual e teor de sólidos do licor fosse mantido estável ao longo das fases de cozimento. Antes de cada injeção foi feita a remoção de um volume equivalente para que a relação licor madeira pudesse ser mantida. 


\subsubsection{Polpa não branqueada}

Após cada cozimento a polpa obtida foi desagregada e lavada até todo o licor existente ser removido. Esta etapa foi conduzida utilizando-se sacos de microfibras e água corrente desmineralizada. Em seguida a amostra de polpa foi centrifugada para que os ensaios possam ser realizados.

\subsubsection{Rendimento bruto, depurado e teor de rejeitos}

Para cada cozimento foi determinada a quantidade de celulose absolutamente seca produzida. A relação percentual entre o peso de celulose absolutamente seca produzida e o peso de madeira absolutamente seca utilizado forneceu o rendimento bruto. Em seguida, por meio de depuração em depurador Noriam com fenda de 0.2 $\mathrm{mm}$, os rejeitos foram separados da polpa celulósica produzida. Estes rejeitos foram então secos em estufas a $105 \pm 3{ }^{\circ} \mathrm{C}$ e a relação percentual entre o peso seco de rejeitos e o peso seco de madeira também utilizada no cozimento forneceu o teor de rejeitos. O rendimento depurado foi obtido pela diferença entre o rendimento bruto e o teor de rejeitos.

Com os valores de rendimento depurado e número kappa foi determinada a relação rendimento/número kappa para cada tratamento.

\subsubsection{Número kappa}

O número kappa foi determinado pela norma TAPPPI T236 cm-85. O número kappa corrigido foi obtido após a quantificação dos ácidos hexenurônicos e utilizandose do fator de conversão proposto por Li \& Gellerstedt (1997), no qual 11,9 mmol de Ahexs/kg de polpa corresponde a uma unidade de número kappa.

\subsubsection{Viscosidade}

A viscosidade da polpa foi determinada de acordo coma norma TAPPI T230 om-94. Com os valores de viscosidade e número kappa foi determinada a relação viscosidade/número kappa, a qual é denominada de seletividade.

\subsubsection{Pentosanas}

O teor de pentosanas da polpa foi determinado pela norma TAPPI T223 cm 84 . 


\subsubsection{5 Ácidos hexenurônicos}

Os ácidos hexenurônicos foram determinados de acordo com metodologia desenvolvida por Chai et al. (2001).

\subsubsection{Dimensões de fibras}

As dimensões das fibras da polpa obtidas nos cozimentos foram determinadas conforme metodologia descrita pela norma TAPPI T721 utilizando-se o equipamento Kajaani - Fiber Lab Versão 1.1.

\subsubsection{Solubilidade em NaOH 5\% - S5}

Uma amostra de aproximadamente $1,5 \mathrm{~g}$ seca de polpa foi desintegrada e uma folha foi formada. Essa folha foi cortada em pequenos pedaços é colocada num béquer de $600 \mathrm{ml}$ onde se adicionou $100 \mathrm{ml}$ de hidróxido de sódio a $5 \%$. O béquer foi agitado e permaneceu em repouso por 5 minutos. Em seguida a amostra foi desintegrada num agitador de hélice e permaneceu em seguida num banho-maria por 1 hora numa temperatura de $20^{\circ} \mathrm{C}$. A solução foi então filtrada desprezando-se os primeiros $20 \mathrm{ml}$. Pipetaram-se $10 \mathrm{ml}$ desse filtrado e o mesmo foi transferido para um erlenmeyer de $100 \mathrm{ml}$, no qual foi adicionado em seguida $10 \mathrm{ml}$ de dicromato de potássio $0,4 \mathrm{~N}$ e $45 \mathrm{ml}$ de ácido sulfúrico PA. Aguardou-se10 minutos e adicionou-se então lentamente 500ml de água destilada, levando em seguida o erlenmeyer novamente ao banho-maria a $20^{\circ} \mathrm{C}$, onde permaneceu por 5 minutos. Após o resfriamento adicionou-se $10 \mathrm{ml}$ de iodeto de potássio e tampou-se o erlenmeyer com uma rolha de borracha, mantendo-o em repouso por mais 5 minutos. Filtrou-se e titulou-se o filtrado com tiossulfeto de sódio $0,1 \mathrm{~N}$ até o aparecimento da coloração amarelo claro. Adicionaram-se $4 \mathrm{ml}$ de solução indicadora de amido $0,4 \%$ e continuou a titulação com tiossulfeto de sódio $0,1 \mathrm{~N}$ até o ponto de viragem (verde claro). A porcentagem de polpa solúvel em álcali a frio e é dado pela seguinte expressão:

$\mathrm{X}=((\mathrm{Pb}-\mathrm{Vt}) \times \mathrm{N} \times 68,5) /(\mathrm{PR} \times 10)$.

Onde:

$X=$ porcentagem de polpa solúvel em álcali na concentração de $5 \% \mathrm{~A}$;

$\mathrm{Pb}=$ Volume de tiossulfato de sódio gasto na prova em branco em $\mathrm{ml}$; 
$\mathrm{Vt}=$ Volume de tiossulfato de sódio gasto na titulação em $\mathrm{mL}$;

$\mathrm{N}$ = Normalidade da solução de tiossulfato de sódio;

$\mathrm{PR}=$ Peso da amostra seca em gramas;

Vol. = volume de filtrado alcalino (amostra) utilizado na titulação $(10 \mathrm{ml})$.

\subsubsection{Carboidratos}

O teor de carboidratos presentes na polpa não branqueada foi determinado através da cromatografia líquida de alto desempenho, conforme metodologia descrita anteriormente (item 3.2.1.4). Porém, onde se lê serragem de madeira naquela descrição, a mesma deve ser substituída por polpa celulósica.

Para o cálculo da remoção de xilanas, glucanas e glucoronil considerou-se a composição química inicial da madeira (amostra composta), a quantidade de cavacos secos utilizadas para cozimento, o rendimento do processo de polpação e a composição química da polpa obtida.

\subsubsection{Licor negro}

\subsubsection{1 Álcali residual, pH e consumo de álcali}

Amostras de licor negro foi coletado no final da fase de impregnação, nas extrações de licor da fase de substituição, no final da fase de cozimento, nas extrações de licor da fase de lavagem e no final do cozimento e os valores de $\mathrm{pH}$, álcali ativo residual, álcali efetivo residual e álcali total residual foram determinados conforme metodologia descrita pela norma TAPPI T625 cm-85.

Paca cada tratamento foi calculado o consumo de álcali por tonelada de polpa produzida. Os valores foram obtidos considerando-se a diferença entre a carga alcalina aplicada e a quantidade de álcali removida ao longo das fases de cozimento levando em consideração o volume e a concentração dos licores extraídos.

\subsubsection{Teor de sólidos}

Para determinação dos sólidos do licor utilizou-se a norma TAPPI T650. 


\subsubsection{Teor de sólidos secos}

O teor de sólidos secos por tonelada de polpa produzida foi obtido pela seguinte expressão: tss $=((100-R b)+A A) / R d$.

Onde:

tss = teor de sólidos secos - tss/odt;

$\mathrm{Rb}=$ rendimento bruto $-\%$;

$\mathrm{AA}=$ álcali ativo aplicado $\left(\right.$ como $\left.\mathrm{Na}_{2} \mathrm{O}\right)-\%$;

$\mathrm{Rd}=$ rendimento depurado $-\%$.

\subsubsection{Delineamento experimental e análise estatística}

Adotourse o delineamento experimental inteiramente casualisado e para alguns parâmetros foram realizadas análise da variância e de regressão polinomial utilizandose o programa SAS (Statistical Analysis System).

Foi feita uma análise de grupo de experimentos, uma vez que os quadrados médios não diferiam muito entre si e, para isto, adotou-se o critério de que as razões entre variâncias não deveriam superar a 4, conforme descreve Pimentel \& Garcia (2002). 


\section{RESULTADOS E DISCUSSÃO}

\subsection{Madeira}

\subsubsection{Densidade básica da madeira}

A densidade básica é uma propriedade física da madeira e é definida como a relação entre o peso absolutamente seco de madeira e o volume verde de madeira, sendo a mesma de fundamental importância para o processo de polpação, tendo em vista o aspecto econômico relacionado ao consumo específico de madeira, influência sobre variáveis do processo de polpação e carac terísticas da polpa celulósica.

$\mathrm{Na}$ Tabela 4 são apresentados a média, desvio padrão e coeficiente de variação da densidade básica dos materiais avaliados.

Tabela 4. Densidade básica da madeira

\begin{tabular}{lcccccc}
\hline & Híbrido E. grandis x E. urophylla & \multicolumn{2}{c}{ Híbrido E. grandis x E. urophylla } \\
P4299 & & & \multicolumn{3}{c}{ C085 } & \\
\hline & Média & $\begin{array}{c}\text { Desvio } \\
\text { Padrão }\end{array}$ & C.V & Média & $\begin{array}{c}\text { Desvio } \\
\text { Padrão }\end{array}$ & C.V \\
& 0,499 & 0,0121 & 2,43 & 0,559 & 0,0123 & 2,20 \\
$\begin{array}{l}\text { Densidade } \\
\text { Básica }\left(\mathrm{g} / \mathrm{cm}^{3}\right)\end{array}$ & 0,499 & & & \\
\hline
\end{tabular}

c.v = coeficiente de variação

A Tabela 4 mostra que os materiais estudados apresentam diferentes densidade básica, conforme indica também a análise estatística (Apêndice 6), sendo que o híbrido C085 apresenta o maior valor. O valor de densidade básica obtido para o material C085 está consoante com os valores obtidos por Alencar (2002) e também por Bassa (2002), quando estudaram híbridos E. grandis x E. urophylla também com idade 
de 7 anos. Já o híbrido P4299 apresentou valor de densidade básico inferior aos valores obtidos pelos autores citados anteriormente.

Segundo Panshin (1962) floresta com maior taxa de crescimento produz madeira com menor densidade básica, em função do próprio ritmo de crescimento da floresta, porém esse comportamento não se confirma para os materiais estudados, uma vez que o material C085 apresentou maior incremento médio anual (Tabela 1) e também densidade básica. Vale ressaltar que, apesar de estarem num mesmo ambiente, os materiais são diferentes geneticamente, podendo a densidade básica ter sido resultado do metabolismo desses materiais.

É importante ressaltar que, o fato dos materiais estudados serem híbridos de $E$. grandis x E. urophylla não significa que os mesmos devam apresentar propriedades de densidade básica e composição química semelhantes. No item a seguir encontram-se as propriedades químicas dos materiais estudados.

\subsubsection{Composição química da madeira}

$\mathrm{Na}$ Tabela 5 são apresentados a média, desvio padrão e coeficiente de variação dos constituintes químicos da madeira.

Tabela 5. Teor de lignina total, solúvel e insolúvel, teor de holocelulose, teor de extrativos e teor de pentosanas

\begin{tabular}{lcccccc}
\hline & \multicolumn{3}{c}{$\begin{array}{c}\text { Híbrido E. grandis x E. } \\
\text { urophyllla P4299 }\end{array}$} & \multicolumn{3}{c}{$\begin{array}{c}\text { Híbrido E. grandis x E. } \\
\text { urophylla C085 }\end{array}$} \\
& Média & $\begin{array}{c}\text { Desvio } \\
\text { Padrão }\end{array}$ & C.V & Média & $\begin{array}{c}\text { Desvio } \\
\text { Padrão }\end{array}$ & C. V \\
Lignina Total (\%) & 28,81 & 0,97 & 3,36 & 29,33 & 1,08 & 3,67 \\
Lignina Solúvel (\%) & 2,37 & 0,27 & 11,29 & 2,56 & 0,48 & 18,54 \\
Lignina Insolúvel (\%) & 26,44 & 1,10 & 4,15 & 26,77 & 0,94 & 3,50 \\
Holocelulose (\%) & 68,81 & 1,20 & 1,75 & 68,15 & 1,23 & 1,80 \\
Extrativos (\%) & 2,30 & 0,44 & 18,94 & 3,02 & 0,75 & 24,78 \\
Pentosanas (\%) & 17,94 & 0,69 & 3,85 & 16,26 & 0,83 & 5,11 \\
\hline C.V = coeficiente de variação & & & & &
\end{tabular}

c.v = coeficiente de variação 
Os materiais estudados apresentam teores de lignina semelhantes, comprovado também estatisticamente (Apêndice 6). Os teores de lignina observados para os materiais estão de acordo com os obtidos por Bassa (2002) também para híbrido E. grandis x E. urophylla e superiores aos obtidos por Almeida \& Silva (2001), Alencar (2002) e Queiroz \& Gomide (2003), principalmente o teor de lignina insolúvel.

$O$ teor de holocelulose da madeira dos materiais avaliados não mostra diferenças significativas, conforme mostra também a análise estatística (Apêndice 6), porém os resultados obtidos encontram-se inferiores aos obtidos por Bassa (2002).

$O$ ter de extrativos encontrados nos materiais estudados ficaram superiores aos resultados obtidos por Almeida \& Silva (2001) e Queiroz \& Gomide (2003) quando também estudaram híbridos de E. grandis x E. urophylla, sendo que dos materiais avaliados o híbrido C085 apresenta maior teor de extrativos, porém a análise estatística (Apêndice 6) não mostra diferença significativa entre os materiais estudados.

\subsubsection{Carboidratos da madeira}

As serragens de madeira dos materiais foram hidrolisadas, conforme metodologia já descrita, e os carboidratos foram determinados via cromatografia líquida de alto desempenho. Os resultados encontram-se na Tabela 6 a seguir. 
Tabela 6. Grupos acetis, ácidos glicurônicos, glucanas, xilanas e arabinanas

\begin{tabular}{|c|c|c|c|c|c|c|}
\hline & \multicolumn{3}{|c|}{$\begin{array}{c}\text { Híbrido E. grandis x E. } \\
\text { urophyllla P4299 }\end{array}$} & \multicolumn{3}{|c|}{$\begin{array}{l}\text { Híbrido E. grandis x E. } \\
\text { urophylla C085 }\end{array}$} \\
\hline & Média & $\begin{array}{l}\text { Desvio } \\
\text { Padrão }\end{array}$ & C.V & Média & $\begin{array}{l}\text { Desvio } \\
\text { Padrão }\end{array}$ & C.V \\
\hline Grupos Acetis (\%) & 3,29 & 0,14 & 4,33 & 3,39 & 0,17 & 5,13 \\
\hline Ácidos glicurônicos (\%) & 1,48 & 0,07 & 4,84 & 1,55 & 0,08 & 5,41 \\
\hline Carboidratos* $\left.^{*} \%\right)$ & 58,23 & 1,90 & 3,26 & 59,05 & 1,22 & 2,06 \\
\hline Glucanas (\%) & 45,10 & 1,67 & 3,71 & 45,83 & 0,92 & 2,01 \\
\hline Xilanas (\%) & 12,94 & 0,38 & 2,95 & 13,02 & 0,31 & 2,41 \\
\hline Arabinanas (\%) & 0,19 & 0,04 & 23,11 & 0,21 & 0,07 & 34,17 \\
\hline Balanço HPLC ${ }^{\star *}$ & 91,81 & 1,78 & 1,94 & 93,33 & 1,41 & 1,51 \\
\hline
\end{tabular}

A análise dos carboidratos por cromatografia de alto desempenho indica que os materiais apresentam valores semelhantes, porém os resultados obtidos são inferiores aos resultados obtidos por Bassa (2002) e superiores aos encontrados por Queiroz \& Gomide (2003), quando também estudaram híbridos de E. grandis X E. urophylla.

Os resultados de pentosanas da madeira mostram que o híbrido P4299 apresenta um maior teor de pentosanas que o híbrido C085 (Tabela 5), porém o resultado de xilanas não indica que os materiais apresentam diferentes teores de hemiceluloses.

Os valores de ácidos glicurônicos, os quais são precursores dos ácidos hexenurônicos formados no processo de polpação, está inferior aos resultados obtidos por Bassa (2002), enquanto os valores dos grupos acetis estão semelhantes. Já os somatórios dos compostos químicos dos materiais ficaram semelhantes e, mesmo não considerando os elementos voláteis e as "cinzas", pode-se considerar níveis aceitáveis para balanço. 


\subsubsection{Dimensões das fibras}

A Tabela 7 apresenta os resultados de dimensões de fibras para os materiais.

Tabela 7. Comprimento, largura, espessura da parede, diâmetro do lume, fração parede, coeficiente de flexibilidade, índice de Runkel e índice de enfeltramento

\begin{tabular}{|c|c|c|c|c|c|c|}
\hline & \multicolumn{3}{|c|}{$\begin{array}{c}\text { Híbrido E. grandis x E. } \\
\text { urophyllla P4299 }\end{array}$} & \multicolumn{3}{|c|}{$\begin{array}{c}\text { Híbrido E. grandis x E. } \\
\text { urophylla C085 }\end{array}$} \\
\hline & Média & $\begin{array}{l}\text { Desvio } \\
\text { Padrão }\end{array}$ & C.V & Média & $\begin{array}{l}\text { Desvio } \\
\text { Padrão }\end{array}$ & C.V \\
\hline $\begin{array}{l}\text { Comprimento de fibra } \\
(\mathrm{mm})\end{array}$ & 0,96 & 0,16 & 16,67 & 0,97 & 0,14 & 14,43 \\
\hline Largura de fibra $(\mu \mathrm{m})$ & 18,85 & 1,86 & 9,87 & 18,50 & 2,02 & 10,92 \\
\hline $\begin{array}{l}\text { Espessura da parede } \\
(\mu \mathrm{m})\end{array}$ & 4,78 & 0,45 & 9,41 & 4,84 & 0,62 & 12,81 \\
\hline $\begin{array}{l}\text { Diâmetro do Lume } \\
(\mu \mathrm{m})\end{array}$ & 9,30 & 1,33 & 14,30 & 8,83 & 1,04 & 11,78 \\
\hline Fração Parede (\%) & 51 & 2,90 & 5,68 & 52 & 3,99 & 7,67 \\
\hline $\begin{array}{l}\text { Coeficiente de } \\
\text { Flexibilidade }(\%)\end{array}$ & 49 & 2,7 & 5,51 & 48 & 4,28 & 8,92 \\
\hline Índice de Runkel & 1,03 & 0,13 & 12,62 & 1,10 & 0,17 & 15,45 \\
\hline $\begin{array}{l}\text { Índice Enfeltramento } \\
(\%)\end{array}$ & 51 & 3,09 & 6,06 & 52 & 4,08 & 7,85 \\
\hline
\end{tabular}

Os valores de comprimento e largura de fibra estão consoantes com os resultados obtidos por Queiroz \& Gomide (2003) e inferiores aos observados por Alencar (2002), principalmente o comprimento de fibra. Já os parâmetros de diâmetro do lume e espessura de parede ficaram inferiores aos obtidos por Queiroz \& Gomide (2003).

Os materiais estudados apresentam fibras com valores semelhantes de dimensões, não indicando que os valores de densidade básica apresentado pelos os mesmos possam ser resultado dessas características, como o constatado por Queiroz \& Gomide (2003). 
Vale ressaltar que as diferenças de densidade básicas apresentadas pelos materiais podem também estar relacionado com parâmetros como diâmetro dos elementos de vasos e área ocupada pelos mesmos, assim como características das células de parênquima, variáveis não estudada devido ao foco do estudo.

Com relação aos índices, os quais combinam as propriedades morfológicas se associam com propriedades de resistência da polpa, os valores obtidos estão dentro da faixa recomendável para a produção de papel, conforme descreve Pacini (1978).

\subsubsection{Classificação granulométrica dos cavacos da madeira}

Os cavacos obtidos após picagem foram classificados quanto tamanho e espessura e os resultados encontram-se na Tabela 8 . Vale lembrar que para os cozimentos foram descartados os "overs sizes" e finos (cavacos maiores que $29 \mathrm{~mm}$ e menores que $5 \mathrm{~mm}$, respectivamente), conforme mencionado anteriormente.

Tabela 8. Distribuição granulométrica do tamanho dos cavacos

\begin{tabular}{ccccc}
\hline $\begin{array}{c}\text { Diâmetro do } \\
\text { Furo (mm) }\end{array}$ & \multicolumn{2}{c}{$\begin{array}{c}\text { Híbrido E. grandis x E. urophyllla } \\
\text { P4299 }\end{array}$} & \multicolumn{2}{c}{$\begin{array}{c}\text { Híbrido E. grandis } \\
\text { C085 E. urophylla }\end{array}$} \\
\cline { 2 - 5 } & Distribuição (\%) & Acumulado (\%) Distribuição (\%) Acumulado (\%) \\
\hline$<5$ & 1,5 & 1,5 & 1,7 & 1,7 \\
5 & 7,0 & 8,5 & 6,7 & 8,4 \\
10 & 29,7 & 38,2 & 31,0 & 39,4 \\
16 & 47,0 & 85,2 & 44,0 & 83,4 \\
22 & 12,0 & 97,2 & 14,2 & 97,6 \\
29 & 2,75 & 100,0 & 2,4 & 100,0 \\
\hline
\end{tabular}


A Figura 1 a seguir apresenta a distribuição do tamanho dos cavacos para os híbridos E. grandis x E. urophylla P4299 e C085.

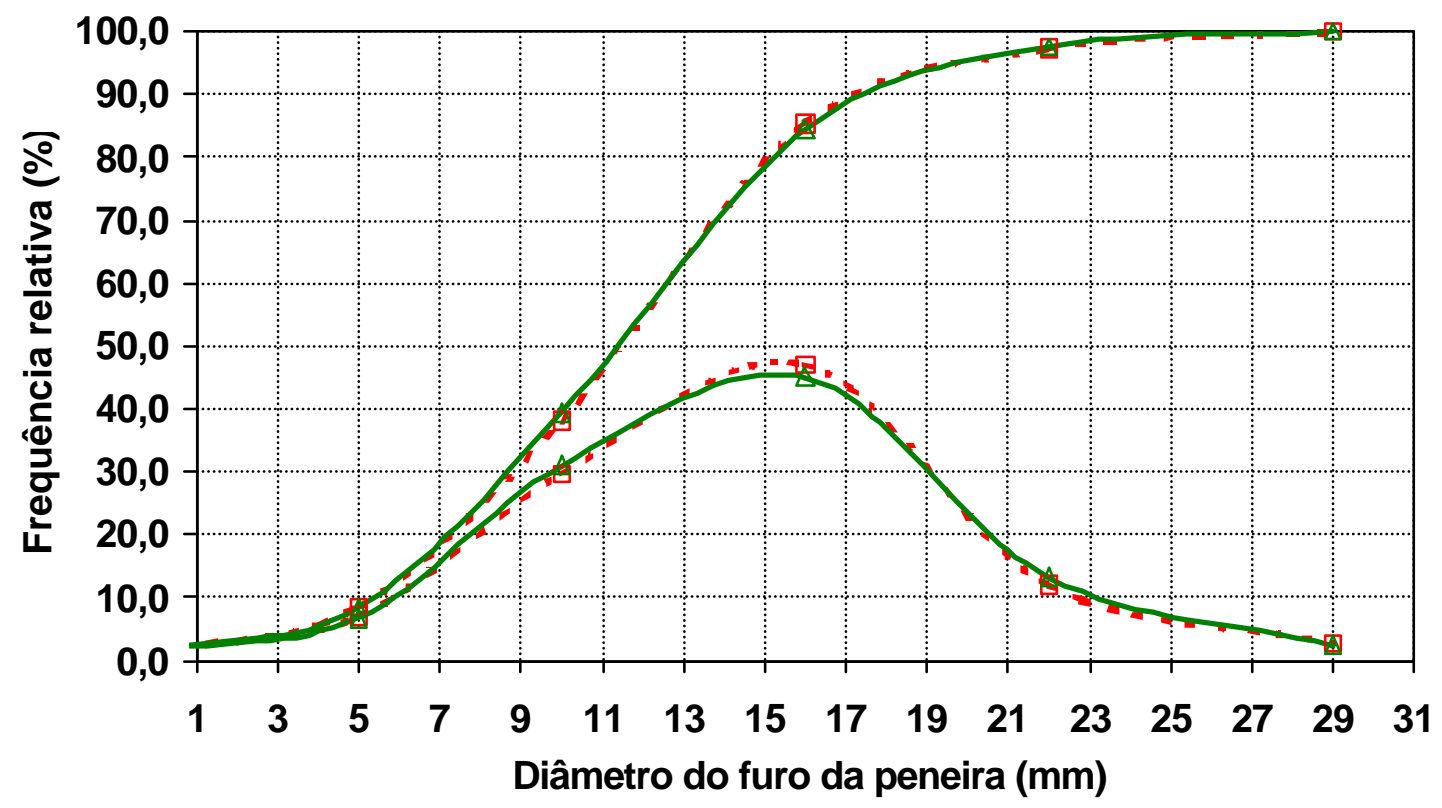

- ६ 'E. grandis x E. urophylla P4299 Distribuição - — 'E. grandis x E. urophylla P4299 Acumulado

$\triangle$ E. grandis x E. urophylla C085 Distribuição $\triangle$ E. grandis x E. urophylla C085 Acumulado

Figura 1 - Tamanho dos cavacos

Nota-se uma distribuição do tamanho de cavacos semelhantes para os dois materiais estudados, sendo que aproximadamente $80 \%$ dos cavacos obtidos em laboratório apresentam tamanhos menores que $16 \mathrm{~mm}$. Não se observou também nenhuma diferença significativa com relação à distribuição do tamanho de cavacos para os materiais estudados.

Os cavacos foram também classificados por espessura e os resultados encontram-se na Tabela 9. 
Tabela 9. Distribuição em espessura dos cavacos

\begin{tabular}{ccccc}
\hline \multirow{2}{*}{$\begin{array}{c}\text { Classe de } \\
\text { Espessura (mm) }\end{array}$} & \multicolumn{3}{c}{ Híbrido E. grandis $\begin{array}{c}\text { P4299 urophylla Híbrido E. grandisx E. urophylla } \\
\text { C085 }\end{array}$} \\
\cline { 2 - 5 } & Distribuição (\%) & $\begin{array}{c}\text { Acumulado } \\
\text { (\%) }\end{array}$ & Distribuição (\%) & $\begin{array}{c}\text { Acumulado } \\
\text { (\%) }\end{array}$ \\
\hline$<2$ & 7,5 & 7,5 & 8,8 & 8,8 \\
2 & 50,2 & 57,8 & 51,4 & 60,2 \\
4 & 38,9 & 96,7 & 34,0 & 94,2 \\
6 & 2,3 & 99,0 & 4,1 & 98,3 \\
8 & 0,8 & 99,8 & 1,0 & 99,3 \\
10 & 0,2 & 100,0 & 0,7 & 100,0 \\
\hline
\end{tabular}

A Figura 2 apresenta a distribuição da espessura dos cavacos para os materiais P4299 e C085.

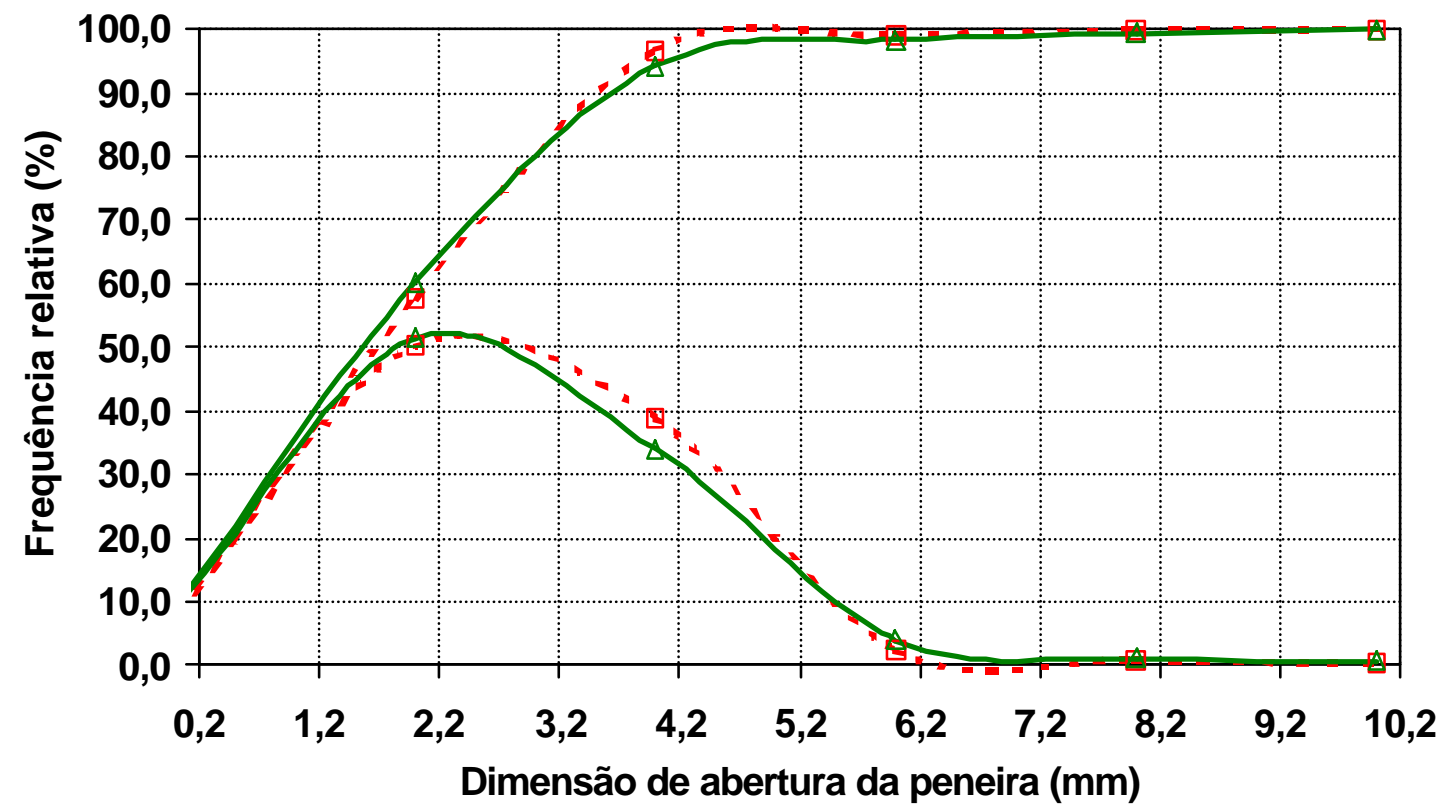

\footnotetext{
- $\square$ 'E. grandis x E. urophylla P4299 Distribuição - - $\quad$ 'E. grandis x E. urophylla P4299 Acumulado

$\triangle$ E. grandis x E. urophylla C085 Distribuição $\triangle$ E. grandis x E. urophylla C085 Acumulado
}

Figura 2 - Espessura dos cavacos 
O tamanho do cavaco foi considerado no passado a dimensão mais importante, porém estudos mais recentes constatam que a espessura do cavaco exerce também influência marcante sobre o processo de impregnação dos cavacos e, conseqüentemente, sobre a homogeneidade do processo de polpação kraft e qualidade da polpa celulósica obtida. O processo de impregnação dos cavacos pelo álcali do cozimento ocorre por difusão e por penetração. Quando por meio da difusão, o processo de impregnação ocorre na direção transversal e, por essa razão, a espessura dos cavacos é o parâmetro que pode restringir a penetração do licor de cozimento na superfície do cavaco, levando a maior geração de rejeitos e queda do rendimento do processo.

Os resultados de espessura de cavacos obtidos para os materiais estudados estão semelhantes, não podendo justificar variações no processo cozimento. A seguir são apresentados os resultados obtidos nos cozimentos.

\subsection{Cozimentos}

Nos Quadros 1 e 2 são apresentados os resultados médios (3 repetições), desvio padrão e coeficiente de variação dos cozimentos para os materiais P4299 e C085, respectivamente. 


\begin{tabular}{|c|c|c|c|c|c|c|c|c|c|}
\hline \multirow{2}{*}{\multicolumn{2}{|c|}{$\begin{array}{c}\text { Parâmetros - \% AA } \\
\left(\mathrm{Na}_{2} \mathrm{O}\right)\end{array}$}} & \multicolumn{8}{|c|}{ Hibrido E. grandis x E. urophylla P4299 } \\
\hline & & \multirow{2}{*}{$\frac{13}{31,77}$} & \multirow{2}{*}{$\frac{15}{17,07}$} & \multirow{2}{*}{$\frac{17}{13,80}$} & \multirow{2}{*}{$\frac{19}{13,18}$} & \multirow{2}{*}{$\frac{\mathbf{2 1}}{12,13}$} & \multirow{2}{*}{$\begin{array}{c}23 \\
9,90\end{array}$} & \multirow{2}{*}{$\begin{array}{c}25 \\
9,43\end{array}$} & \multirow{2}{*}{$\frac{27}{8,40}$} \\
\hline & édia & & & & & & & & \\
\hline & , & 1,14 & 0,32 & 0,23 & 0,16 & 0,23 & 0,26 & 0,38 & 0,20 \\
\hline & & 3,58 & 1,88 & 1,67 & 1,22 & 1,90 & 2,67 & 4,01 & ,38 \\
\hline \multirow{3}{*}{$\begin{array}{l}\text { Número kappa } \\
\text { corrigido }\end{array}$} & dia &, 10 & 12,94 & 8,08 & 7,90 & 7,20 & 6,05 & 7,03 & 7,31 \\
\hline & 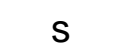 & 1,16 & 0,50 & 0,45 & 0,16 & 0,15 & 0,13 & 0,44 & 0,20 \\
\hline & 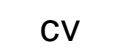 & 4,00 & 3,84 & 5,59 & 2,04 & 2,15 & 2,19 & 6,19 & 2,71 \\
\hline \multirow{3}{*}{$\begin{array}{l}\text { Rendimento } \\
\text { depurado (\%) }\end{array}$} & édia & 53,06 & 51,89 & 50,32 & 49,19 & 48,94 & 48,00 & 47,93 & 47,60 \\
\hline & S & 0,20 & 0,32 & 0,36 & 0,19 & 0,01 & 0,27 & 0,20 & 0,20 \\
\hline & $v_{v}$ & 0,37 & 0,61 & 0,72 & 0,39 & 0,01 & 0,55 & 0,43 & 0,42 \\
\hline \multirow{3}{*}{$\begin{array}{c}\text { Rendimento bruto } \\
(\%)\end{array}$} & & \begin{tabular}{|l}
54,69 \\
\end{tabular} & 51 & 50,34 & 49,21 & 48,95 & 48,01 & 47,94 & 47,60 \\
\hline & $\mathrm{s}$ & 0,34 & 0,32 & 0,36 & 0,19 & 0,01 & 0,27 & 0,20 & 0,20 \\
\hline & (2) & 0,62 & 0,61 & 0,72 & 0,39 & 0,01 & 0,55 & 0,43 & 0,42 \\
\hline \multirow{3}{*}{$\begin{array}{c}\text { Teor de rejeitos } \\
(\%)\end{array}$} & édia & 1,43 & 0,02 & 0,02 & 0,02 & 0,01 & 0,01 & 0,01 & 0,00 \\
\hline & . & 0,15 & 0,00 & 0,01 & 0,0 & 0,00 & 0,00 & 0,00 & 0,00 \\
\hline & v & 10,30 & 0,00 & 54,71 & 34,64 & 0,00 & 0,00 & 0,00 & 0,00 \\
\hline \multirow{3}{*}{$\begin{array}{c}\text { Teor sólidos secos } \\
\text { (tss/odt) }\end{array}$} & média & 1,10 & 1,22 & 1,32 & 1,42 & 1,47 & 1,56 & 1,61 & 1,67 \\
\hline & 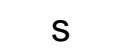 & 0,00 & 0,01 & 0,02 & 0,01 & 0,00 & 0,01 & 0,01 & 0,01 \\
\hline & & 42 &, 12 & 1,26 & 0,66 & 0,02 & 0,91 & 0,69 & 0,67 \\
\hline \multirow{3}{*}{$\begin{array}{l}\text { Viscosidade } \\
\text { (cP) }\end{array}$} & média & 74,10 & 66,97 & 41,65 & 34,80 & 38,83 & 27,93 & 20,63 & 12,03 \\
\hline & $\mathrm{s}$ & 3,76 & 7,64 & 5,69 & 2,55 & 1,18 & 2,60 & 1,19 & 0,65 \\
\hline & & & 11,41 & 13,66 & 7,33 & 3,05 & 9,30 & 570 & 5,41 \\
\hline \multirow{3}{*}{$\begin{array}{c}\text { Relação } \\
\text { Rendimento/kappa }\end{array}$} & édia & / & 3,04 & 3 & 3,73 & 4,03 & 4,85 & 5,09 & 5,67 \\
\hline & $\mathrm{s}$ & 0.07 & 0,04 & 0,04 & 0,05 & 0,08 & 0,12 & 0,19 & 0,11 \\
\hline & 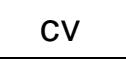 & 3,99 & 1,40 & 1,14 & 1,35 & 1,87 & 2,48 & 3,71 & 1,96 \\
\hline \multirow{3}{*}{$\begin{array}{c}\text { Relação } \\
\text { Viscosidade/kappa }\end{array}$} & éd & 0,95 & 3,93 & 3,02 & 2,64 & 3,20 & 2,82 & 2,19 & 1,43 \\
\hline & S & 0,08 & 0,51 & 0,38 & 0,16 & 0,14 & 0,20 & 0,09 & 0,11 \\
\hline & 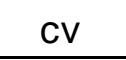 & 8,73 & 12,89 & 12,75 & 6,24 & 4,36 & 7,17 & 4,02 & 7,79 \\
\hline
\end{tabular}

Quadro 1 - Resultados dos cozimentos para E. grandis x E. urophylla P4299

$\mathrm{S}=$ desvio padrão; c.v = coeficiente de variação 


\begin{tabular}{|c|c|c|c|c|c|c|c|c|c|}
\hline \multirow{2}{*}{\multicolumn{2}{|c|}{$\begin{array}{c}\text { Parâmetros - \% AA } \\
\left(\mathrm{Na}_{2} \mathrm{O}\right)\end{array}$}} & \multicolumn{8}{|c|}{ Híbrido E. grandis x E. urophylla C085 } \\
\hline & & \multirow{2}{*}{$\frac{13}{33,00}$} & \multirow{2}{*}{$\frac{15}{17,98}$} & \multirow{2}{*}{$\frac{17}{15,09}$} & \multirow{2}{*}{$\frac{19}{13,43}$} & \multirow{2}{*}{$\frac{\mathbf{2 1}}{12,30}$} & \multirow{2}{*}{$\frac{23}{10,37}$} & \multirow{2}{*}{$\begin{array}{c}25 \\
8,73\end{array}$} & \multirow{2}{*}{$\frac{27}{8,80}$} \\
\hline & 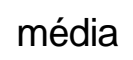 & & & & & & & & \\
\hline & & 100 & 0,31 & 0,42 & 0,12 & 0,53 & 0,45 & 0,40 & 0,20 \\
\hline & & & & & & , & & & \\
\hline \multirow{3}{*}{$\begin{array}{l}\text { Número kappa } \\
\text { corrigido }\end{array}$} & Tédia & 30,36 & 13,80 & 9,33 & & 7,38 & 41 & 50 & 7,88 \\
\hline & $s$ & & 0,58 & 0,33 & & 0,37 & & 0,13 & \\
\hline & & & 4,17 & & & 4,98 & & 2,08 & \\
\hline \multirow{3}{*}{$\begin{array}{c}\text { Rendimento } \\
\text { depurado } \\
(\%)\end{array}$} & édia & 52,62 & 51,60 & 50,39 & 49,36 & 48,75 & 48,02 & 47,00 & 46,80 \\
\hline & 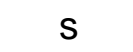 & 0 & 0,36 & 0,16 & & 0,33 & 0,19 & 0,33 & 10 \\
\hline & $\mathrm{cV}$ & 0,4 & 0,70 & 0,33 & & 0,68 & & 0,70 & 0,21 \\
\hline \multirow{3}{*}{$\begin{array}{c}\text { Rendimento bruto } \\
(\%)\end{array}$} & édia & 53,87 & 51,65 & 50,51 & 49,37 & 48,76 & 48,03 & 47,21 & 46,80 \\
\hline & 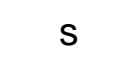 & 0,25 & 0,37 & 0,16 & 4 & 0,33 & 0,19 & 0,61 & 0,10 \\
\hline & 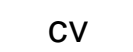 & 0,46 & 0,72 & 0,32 & & 8 & $y$ & ,29 & 21 \\
\hline \multirow{3}{*}{$\begin{array}{c}\text { Teor de rejeitos } \\
(\%)\end{array}$} & dia & 25 & 0,06 & 0,05 & &, 01 & 01 & 0,01 & \\
\hline & & 0 & 0,03 & 0,01 & & 0,00 & 0 & 0,00 & \\
\hline & & 00 & 45,74 & 18,24 & 0 &, 00 & 0 & 0,00 & 0,00 \\
\hline \multirow{3}{*}{$\begin{array}{c}\text { Teor de sólidos } \\
\text { secos } \\
\text { (tss/odt) }\end{array}$} & média & 2 & 1,23 & 1,32 & 1,41 & 48 & 6 & ,66 & 71 \\
\hline & $\mathrm{S}$ & 0 & 0,02 & 0,01 & &, 02 & 01 & 0,02 & 01 \\
\hline & 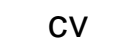 & 0,84 & 1,28 & 0,57 & & 1,14 & 63 & 1,45 & 0,34 \\
\hline \multirow{3}{*}{$\begin{array}{l}\text { Viscosidade } \\
\text { (cP) }\end{array}$} & édia & 79,33 & 75,90 & 46,28 & 36,57 & 42,17 & 30,10 & 19,20 & 16,50 \\
\hline & & 2,3 & 10,64 & 3,78 & & 5,56 & 2,44 & 2,46 & 0,66 \\
\hline & & $2, \mathrm{~S}$ & 14,02 & 8,17 & 4,06 & 13,18 & 12 & 80 & 3,97 \\
\hline \multirow{3}{*}{$\begin{array}{c}\text { Relação } \\
\text { Rendimento/kappa }\end{array}$} & & & & & & & & & \\
\hline & $\mathrm{s}$ & 0,05 & 0,03 & 0,10 & 03 & 0,16 & 0,19 & ,23 & 13 \\
\hline & $\mathrm{cV}$ & 2,8 & 1,22 & 2,96 & 1 & 4,00 & 4,16 & 33 & ,38 \\
\hline \multirow{3}{*}{$\begin{array}{c}\text { Relação } \\
\text { Viscosidade/kappa }\end{array}$} & IEUI & & 4 & 3, & & 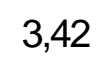 & $2, \cup 0$ & 2,17 & $1, \infty 0$ \\
\hline & $\mathrm{s}$ & 0,09 & 0,64 & 0,19 & 0,13 & 0,32 & 0,13 & 0,17 & 0,11 \\
\hline & $\mathrm{CV}$ & 9,31 & 15,20 & 6,21 & 4,91 & 9,36 & 4,38 & 8,11 & 6,25 \\
\hline
\end{tabular}

Quadro 2 - Resultados dos cozimentos para E. grandis x E. urophylla C085 $S=$ Desvio padrão; c.v = coeficiente de variação

Nos Quadros 3 e 4 são apresentados os resultados médios (3 repetições), desvio padrão e coeficiente de variação da composição química das para os materiais P4299 e C085, respectivamente. 


\begin{tabular}{|c|c|c|c|c|c|c|c|c|c|}
\hline \multirow{2}{*}{\multicolumn{2}{|c|}{$\begin{array}{c}\text { Parâmetros - } \% \text { AA } \\
\left(\mathrm{Na}_{2} \mathrm{O}\right)\end{array}$}} & \multicolumn{8}{|c|}{ Hibrido E. grandis x E. urophylla P4299 } \\
\hline & & \multirow{2}{*}{$\begin{array}{c}13 \\
0,77\end{array}$} & \multirow{2}{*}{$\begin{array}{r}15 \\
0,57\end{array}$} & \multirow{2}{*}{$\begin{array}{c}17 \\
0,57\end{array}$} & \multirow{2}{*}{$\begin{array}{c}19 \\
0,52\end{array}$} & \multirow{2}{*}{$\frac{\mathbf{2 1}}{0,36}$} & \multirow{2}{*}{$\begin{array}{r}23 \\
0,35\end{array}$} & \multirow{2}{*}{$\begin{array}{c}25 \\
0,29\end{array}$} & \multirow{2}{*}{$\begin{array}{r}27 \\
0,25\end{array}$} \\
\hline Lignina solúvel & média & & & & & & & & \\
\hline & S & 0,06 & 0,03 & 0,03 & 0,03 & 0,02 & 0,03 & 0,03 & 0,00 \\
\hline & $\mathrm{cv}$ & 7,53 & 4,44 & 4,39 & 6,66 & 4,81 & 8,17 & 10,34 & 0,00 \\
\hline Lignina & média & 4,40 & 1,87 & 0,90 & 0,67 & 0,90 & 0,78 & 0,72 & 0,69 \\
\hline 101 & s & 0,40 & 0,08 & 0,05 & 0,09 & 0,27 & 0,13 & 0,19 & 0,06 \\
\hline & cV & 9,09 & 4,15 & 4,99 & 13,80 & 29,34 & 16,61 & 26,19 & 8,36 \\
\hline Lignina total & média & 5,17 & 2,44 & 1,48 & 1,19 & 1,26 & 1,14 & 1,01 & 0,96 \\
\hline & S & 0,45 & 0,10 & 0,04 & 0,06 & 0,27 & 0,13 & 0,19 & 0,06 \\
\hline & $\mathrm{cV}$ & 8,73 & 3,91 & 2,56 & 5,05 & 21,01 & 11,62 & 18,80 & 6,01 \\
\hline & média & 91,04 & 95,82 & 97,53 & 98,07 & 97,97 & 98,22 & 98,43 & 98,94 \\
\hline & $\mathrm{s}$ & 0,78 & 0,20 & 0,00 & 0,16 & 0,40 & 0,24 & 0,27 & 0,78 \\
\hline Rem & $\mathrm{cV}$ & 0,86 & 0,20 & 0,00 & 0,16 & 0,41 & 0,24 & 0,28 & 0,79 \\
\hline Ác. $\mathrm{H}$ & média & 31,73 & 49,17 & 67,27 & 62,88 & 58,66 & 45,81 & 28,55 & 14,19 \\
\hline & s & 0,38 & 2,11 & 4,58 & 2,11 & 1,73 & 2,96 & 1,78 & 0,42 \\
\hline & $\mathrm{cV}$ & 1,19 & 4,30 & 6,81 & 3,36 & 2,96 & 6,47 & 6,24 & 2,99 \\
\hline Pentosanas & média & 15,68 & 14,54 & 14,04 & 13,80 & 13,85 & 13,84 & 13,87 & 13,70 \\
\hline & s & 0,16 & 0,10 & 0,10 & 0,28 & 0,30 & 0,04 & 0,36 & 0,09 \\
\hline & $c V$ & 0,99 & 0,66 & 0,70 & 2,06 & 2,15 & 0,28 & 2,60 & 0,68 \\
\hline Solubilidade em $\mathrm{NaOH}$ & média & 13,57 & 12,17 & 10,67 & 10,53 & 9,97 & 8,60 & 8,07 & 7,00 \\
\hline & s & 0,15 & 1,01 & 0,47 & 0,25 & 0,42 & 0,82 & 1,01 & 0,00 \\
\hline & $\mathrm{cV}$ & 1,13 & 8,31 & 4,43 & 2,39 & 4,18 & 9,52 & 12,54 & 0,00 \\
\hline & média & 14,17 & 14,30 & 14,4 & 14,47 & 14,77 & 14,60 & 14,20 & 11,60 \\
\hline Teor de Xilanas (\%) & s & 0,39 & 0,17 & 0,26 & 0,25 & 0,25 & 0,17 & 0,40 & 0,46 \\
\hline & $\mathrm{cV}$ & 2,67 & 1,21 & 1,84 & 1,70 & 1,70 & 1,19 & 2,82 & 3,95 \\
\hline$\overline{\text { Xila }}$ & média & 41,91 & 42,66 & 44,00 & 45,01 & 44,15 & 45,84 & 47,40 & 57,33 \\
\hline & S & 1,55 & 0,69 & 1,03 & 1,16 & 0,95 & 0,64 & 1,48 & 1,69 \\
\hline & cV & 3,70 & 1,63 & 2,34 & 2,58 & 2,16 & 1,40 & 3,13 & 2,94 \\
\hline Glucanas - Remoção & média & 10,82 & 14,05 & 14,09 & 15,33 & 16,52 & 18,23 & 19,41 & 19,51 \\
\hline & S & 0,24 & 0,12 & 0,89 & 1,27 & 1,89 & 0,27 & 0,22 & 0,06 \\
\hline & CV & 2,17 & 0,82 & 6,29 & 8,31 & 11,42 & 1,47 & 1,14 & 0,31 \\
\hline iil - Rem & média & 43,83 & 62,60 & 75,07 & 80,06 & 82,36 & 88,11 & 90,28 & 100,00 \\
\hline & $S$ & 2,07 & 7,30 & 5,19 & 3,32 & 1,91 & 1,87 & 0,00 & 0,00 \\
\hline & $c V$ & 4,72 & 11,66 & 6,92 & 4,15 & 2,32 & 2,13 & 0,00 & 0,00 \\
\hline
\end{tabular}

Quadro 3 - Composição química da polpa não branqueada para E. grandis $\times$ E. urophylla P4299

* somatório dos seguintes compostos: lignina total + ácido glicourônico + glucana + xilanas; $s$ = desvio padrão; c.v = coeficiente de variação 


\begin{tabular}{|c|c|c|c|c|c|c|c|c|c|}
\hline \multirow{2}{*}{\multicolumn{2}{|c|}{$\begin{array}{c}\text { Parâmetros - \% AA } \\
\left(\mathrm{Na}_{2} \mathrm{O}\right)\end{array}$}} & \multicolumn{8}{|c|}{ Hibrido E. grandis x E. urophyllaC085 } \\
\hline & & \multirow{2}{*}{$\begin{array}{c}\mathbf{1 3} \\
0,83\end{array}$} & \multirow{2}{*}{$\begin{array}{c}15 \\
0,26\end{array}$} & \multirow{2}{*}{$\begin{array}{c}\mathbf{1 7} \\
0,28\end{array}$} & \multirow{2}{*}{$\begin{array}{r}\mathbf{1 9} \\
0,25\end{array}$} & \multirow{2}{*}{$\begin{array}{c}\mathbf{2 1} \\
0,25\end{array}$} & \multirow{2}{*}{$\begin{array}{c}23 \\
0,16\end{array}$} & \multirow{2}{*}{$\begin{array}{c}\mathbf{2 5} \\
0,24\end{array}$} & \multirow{2}{*}{$\frac{27}{0,23}$} \\
\hline \multirow{3}{*}{$\begin{array}{l}\text { Lignina solúvel } \\
(\%)\end{array}$} & média & & & & & & & & \\
\hline & 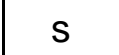 & 0,06 & 0,01 & 0,14 & 0,01 & 0,02 & 0,02 & 0,05 & 0,00 \\
\hline & $\mathrm{cV}$ & 6,93 & 3,53 & 51,14 & 2,47 & 9,30 & 12,12 & 21,17 & 0,00 \\
\hline \multirow{3}{*}{$\begin{array}{l}\text { Lignina insolúvel } \\
(\%)\end{array}$} & média & 5,57 & 1,81 & 1,02 & 0,90 & 0,77 & 0,49 & 0,48 & 0,47 \\
\hline & $c$ & 0,06 & 0,02 & 0,12 & 0,08 & 0,05 & 0,14 & 0,17 & 0,06 \\
\hline & $\mathrm{cV}$ & 1,04 & 0,96 & 11,74 & 8,45 & 6,43 & 29,06 & 34,27 & 12,28 \\
\hline \multirow{3}{*}{$\begin{array}{l}\text { Lignina total } \\
(\%)\end{array}$} & média & 6,40 & 2,07 & 1,30 & 1,15 & 1,01 & 0,65 & 0,73 & 0,69 \\
\hline & $s$ & 0,00 & 0,03 & 0,26 & 0,08 & 0,06 & 0,57 & 0,15 & 0,06 \\
\hline & $\mathrm{CV}$ & 0,00 & 1,26 & 19,74 & 7,17 & 5,59 & 87,61 & 20,12 & 8,36 \\
\hline \multirow{3}{*}{$\begin{array}{l}\text { Lignina Total - } \\
\text { Remoção (\%) }\end{array}$} & média & 88,52 & 96,31 & 97,71 & 98,20 & 98,28 & 98,36 & 98,82 & 98,90 \\
\hline & $s$ & 0,00 & 0,00 & 0,43 & 0,39 & 0,10 & 0,16 & 0,19 & 0,03 \\
\hline & $\mathrm{cV}$ & 0,00 & 0,00 & 0,44 & 0,40 & 0,10 & 0,17 & 0,19 & 0,03 \\
\hline \multirow{3}{*}{$\begin{array}{l}\text { Ác. Hexenurônicos } \\
(\mu \mathrm{mol} / \mathrm{g})\end{array}$} & média & 31,43 & 50,43 & 66,84 & 63,54 & 58,56 & 47,04 & 26,62 & 13,23 \\
\hline & $s$ & 0,74 & 2,66 & 1,59 & 2,45 & 2,04 & 3,71 & 5,68 & 0,63 \\
\hline & $\mathrm{cv}$ & 2,35 & 5,28 & 2,38 & 3,85 & 3,48 & 7,88 & 21,33 & 4,73 \\
\hline \multirow{3}{*}{$\begin{array}{c}\text { Pentosanas } \\
(\%)\end{array}$} & média & 14,68 & 14,23 & 13,70 & 13,57 & 13,60 & 13,55 & 13,65 & 13,56 \\
\hline & $s$ & 0,63 & 0,28 & 0,20 & 0,37 & 0,20 & 0,13 & 0,31 & 0,37 \\
\hline & $\mathrm{cV}$ & 4,32 & 1,96 & 1,46 & 2,74 & 1,47 & 0,97 & 2,25 & 2,73 \\
\hline \multirow{3}{*}{$\begin{array}{c}\text { Solubilidade em } \\
\mathrm{NaOH} 5 \%-\mathrm{S} 5(\%)\end{array}$} & média & 13,40 & 11,87 & 10,67 & 9,73 & 9,77 & 9,23 & 8,27 & 8,30 \\
\hline & $\mathrm{s}$ & 0,20 & 0,29 & 0,25 & 0,67 & 0,12 & 0,06 & 0,25 & 0,10 \\
\hline & $\mathrm{cV}$ & 1,49 & 2,43 & 2,36 & 6,84 & 1,18 & 0,63 & 3,04 & 1,20 \\
\hline \multirow{3}{*}{ Teor de Xilanas (\%) } & média & 13,83 & 13,50 & 13,47 & 13,50 & 13,60 & 13,80 & 13,47 & 12,02 \\
\hline & 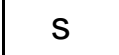 & 0,42 & 0,35 & 0,32 & 0,30 & 0,26 & 0,10 & 0,12 & 0,55 \\
\hline & $\mathrm{cv}$ & 3,01 & 2,57 & 2,39 & 2,22 & 1,95 & 0,72 & 0,86 & 4,56 \\
\hline \multirow{3}{*}{$\begin{array}{c}\text { Xilanas - Remoção } \\
\text { (\%) }\end{array}$} & média & 44,09 & 46,50 & 47,88 & 48,82 & 49,09 & 49,10 & 51,39 & 56,63 \\
\hline & $\mathrm{c}$ & 1,68 & 1,37 & 1,24 & 1,14 & 0,99 & 0,37 & 0,42 & 1,98 \\
\hline & $\mathrm{cv}$ & 3,81 & 2,95 & 2,60 & 2,33 & 2,02 & 0,75 & 0,81 & 3,50 \\
\hline \multirow{3}{*}{$\begin{array}{c}\text { Glucanas - Remoção } \\
(\%)\end{array}$} & nédia & 14,69 & 16,08 & 17,98 & 19,51 & 20,65 & 21,10 & 21,99 & 21,40 \\
\hline & $\mathrm{s}$ & 0,30 & 0,62 & 0,50 & 0,16 & 0,11 & 0,42 & 0,60 & 2,53 \\
\hline & $\mathrm{cv}$ & 2,06 & 3,86 & 2,80 & 0,84 & 0,52 & 1,99 & 2,73 & 11,82 \\
\hline \multirow{3}{*}{$\begin{array}{c}\text { Glucoronil - Remoção } \\
(\%)\end{array}$} & Tédia & 42,29 & 55,61 & 72,91 & 73,46 & 79,03 & 78,31 & 85,85 & 100,00 \\
\hline & $\mathrm{s}$ & 3,39 & 3,84 & 1,88 & 7,35 & 1,82 & 6,20 & 3,50 & 0,00 \\
\hline & $\mathrm{cv}$ & 8,03 & 6,91 & 2,57 & 10,01 & 2,30 & 7,91 & 4,08 & 0,00 \\
\hline
\end{tabular}

Quadro 4 - Composição química da polpa celulósica não branqueada para $E$. grandisx E. urophylla $\mathrm{C} 085$

* somatório dos seguintes compostos: lignina total + ácido glicourônico + glucana + xilanas; $\mathrm{S}=$ desvio padrão; cv = coeficiente de variação 
A Tabela 10 apresenta a análise de variância e teste $\mathrm{F}$ para número kappa em função das cargas alcalinas aplicadas para os materiais estudados, bem como suas interações.

Tabela 10. Análise de variância e teste F para o parâmetro número kappa

\begin{tabular}{lrrrrr}
\hline & GL & SQ & QM & \multicolumn{1}{c}{ F } & Prob>F \\
\hline Dosagem de Álcali & 7 & 2512,00 & 358,86 & 578,69 & 0,0001 \\
Material & 1 & 3,00 & 3,00 & 4,84 & 0,0638 \\
Dosagem de Álcali X Material & 7 & 4,34 & 0,62 & 2,64 & 0,0284 \\
Resíduo & 32 & 7,52 & 0,23 & & \\
\hline Total & 47 & 2526,85 & & & \\
\hline
\end{tabular}

$\mathrm{GL}=$ grau de liberdade $\mathrm{SQ}=$ soma de quadrados $\mathrm{QM}=$ quadrado médio Prob = probabilidade

Os resultados da Tabela 10 indicam que a dosagem de álcali apresenta efeito significativo sobre o número kappa da polpa, como já esperado. Nota-se também que não há efeito significativo do fator material genético sobre o número kappa, o que possivelmente está associado a semelhança de composição química entre os materiais. Observa-se que há efeito significativo da interação entre os fatores material e dosagem de álcali, ou seja, os mesmos apresentam um padrão de variação diferente para o parâmetro kappa quando submetidos às dosagens de álcali.

A Figura 3 apresenta os valores de numero kappa obtido para os materiais estudados quando submetidos as diferentes dosagens álcali ativo 


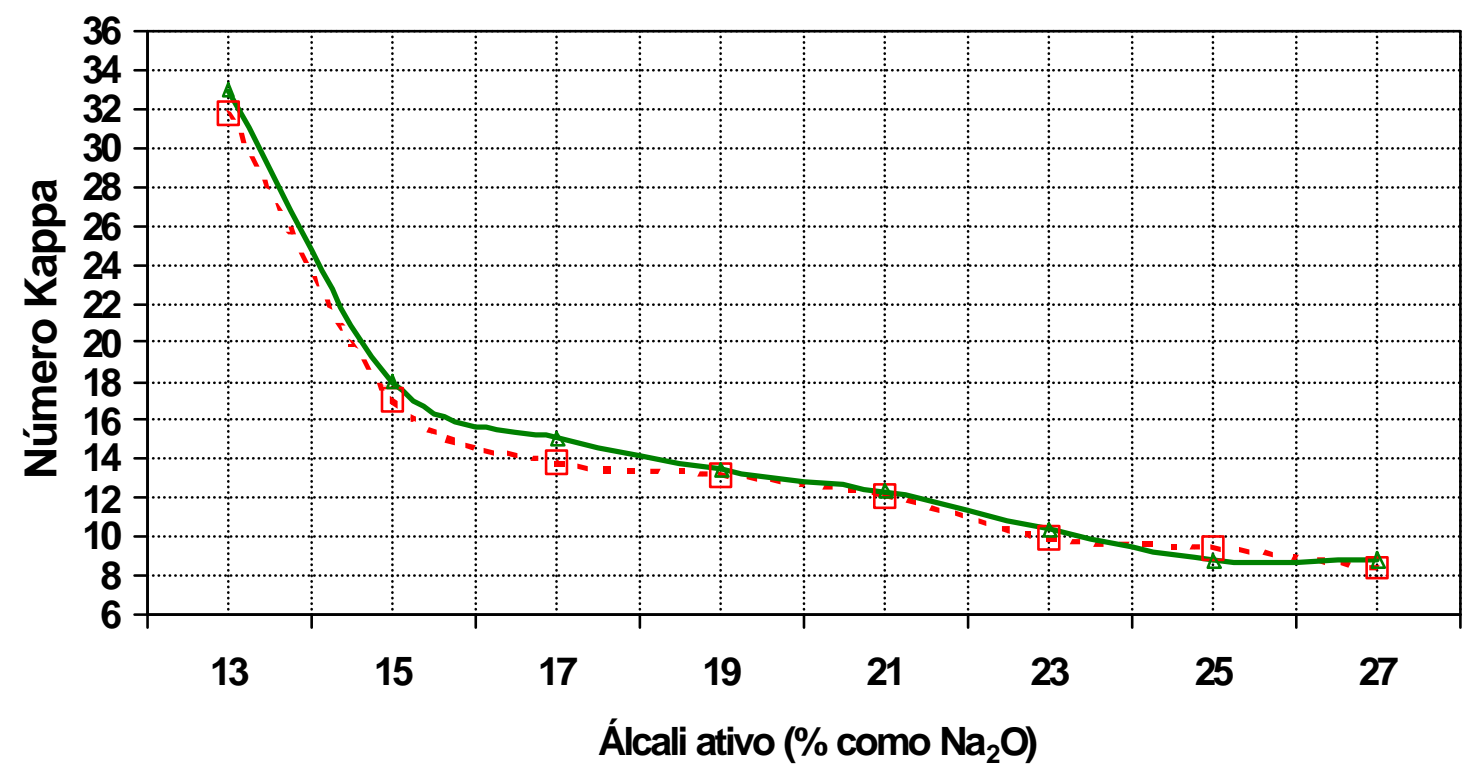

- ๒- E. grandis x E. urophylla P4299

$\leftarrow$ E. grandis x E. urophylla C085

Figura 3 - Número kappa x álcali ativo

O número kappa é um parâmetro extremamente importante para o processo de produção da polpa celulósica branqueada, uma vez que o mesmo é um indicativo da quantidade de lignina presente na polpa, determinando dessa forma a estratégia envolvida na fase de branqueamento, quando do desenvolvimento de sequencias.

O número kappa é uma variável pré-estabelecida pelo processo industrial, a qual exerce influência sobre rendimento do processo e propriedades da polpa celulósica. Entretanto, as características da matéria-prima madeira como teor de lignina, teor de extrativos, densidade básica e a espessura dos cavacos influenciam diretamente o parâmetro de kappa da polpa. A carga alcalina aplicada e o fator $\mathrm{H}$ passam a ser os principais parâmetros do processo de polpação kraft utilizado para controle das oscilações devido a matéria-prima, visando manter relativamente constante o nível de deslignificação da polpa.

Apesar de não se verificar efeito significativo do material sobre o nível de deslignificação da polpa, nota-se valores de kappa ligeiramente superiores para o híbrido C085, principalmente para as dosagens de álcali inferior a 19\% de álcali ativo e número kappa maior que 14. Tal comportamento desse material deve-se, possivelmente, ao maior valor de densidade básica do mesmo, o que ofereceu maior 
resistência à impregnação dos cavacos pelo licor de cozimento e diminuiu o nível de deslignificação, conforme descreve Wehr (1991).

Os níveis de deslignificação semelhantes apresentados pelos materiais quando submetidos às diferentes cargas alcalinas pode estar associado ao fato do processo de polpacão Lo-Solids ${ }^{\circledR}$ ser menos sensível ao parâmetro de densidade básica da madeira devido, principalmente, a boa eficiência da fase de impegnação.

Gidnert et al. (1998) verificou que o número kappa é influenciado pelo teor de ácidos hexenurônico da polpa, compostos químicos formados durante a fase polpação a partir da conversão dos ácidos 4-O-metil-glicurônicos presentes na madeira. Os ácidos hexenurônicos consomem o permanganato de potássio, reagente utilizado na determinação do número kappa da polpa, contribuindo dessa forma para um incremento no valor do número kappa. Estudos conduzidos sugeriram alguns fatores de conversão para o cálculo do número kappa corrigido, sendo comum utilizar o fator proposto por Li et al. (1997), no qual uma unidade de número kappa corresponde a $11,9 \mathrm{mmol}$ de Ahexs/kg de polpa.

A Figura 4 apresenta os valores de kappa corrigido e sem correção obtidos para as polpas. 


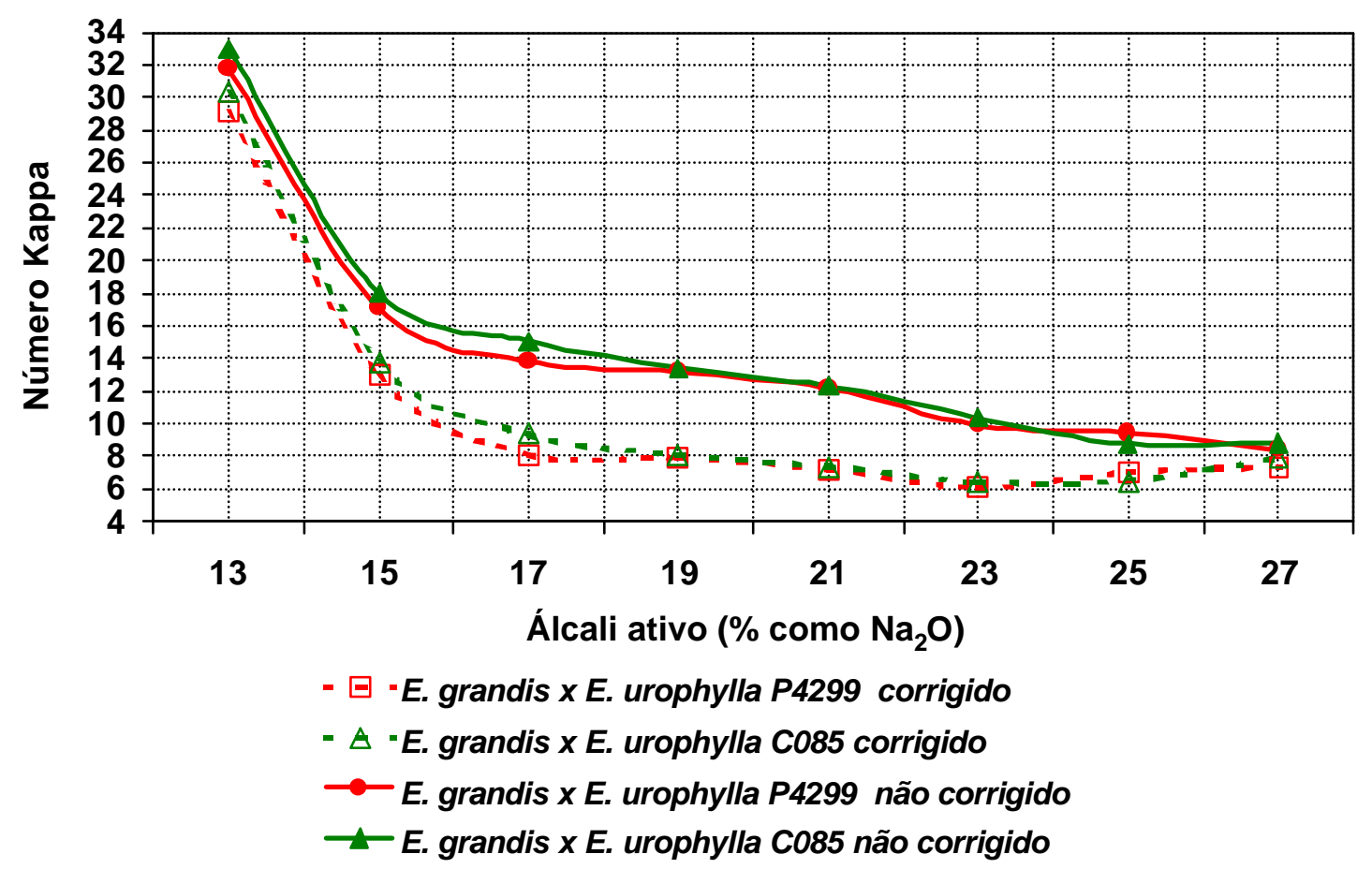

Figura 4 - Número kappa corrigido x álcali ativo

Os resultados da Figura 4 mostram diferenças significativas entre os valores de kappa da polpa sem e após a correção, evidenciando a importância da quantificação dos ácidos hexenurônicos na definição de estratégias na fase de branqueamento, tendo em vista a influência desses compostos na fase de branqueamento, consumindo os reagentes químicos como o cloro, dióxido de cloro, ozônio, ligando a íons metálicos e causando reversão de alvura de polpas branqueadas.

A Figura 5 apresenta o percentual de lignina removido da madeira para as diferentes cargas alcalinas aplicadas. Para cálculo tomo-se como base o teor de lignina presente inicialmente na madeira (amostra composta da 10 árvores), o rendimento do processo de polpação e a quantidade de lignina total presente na polpa. 


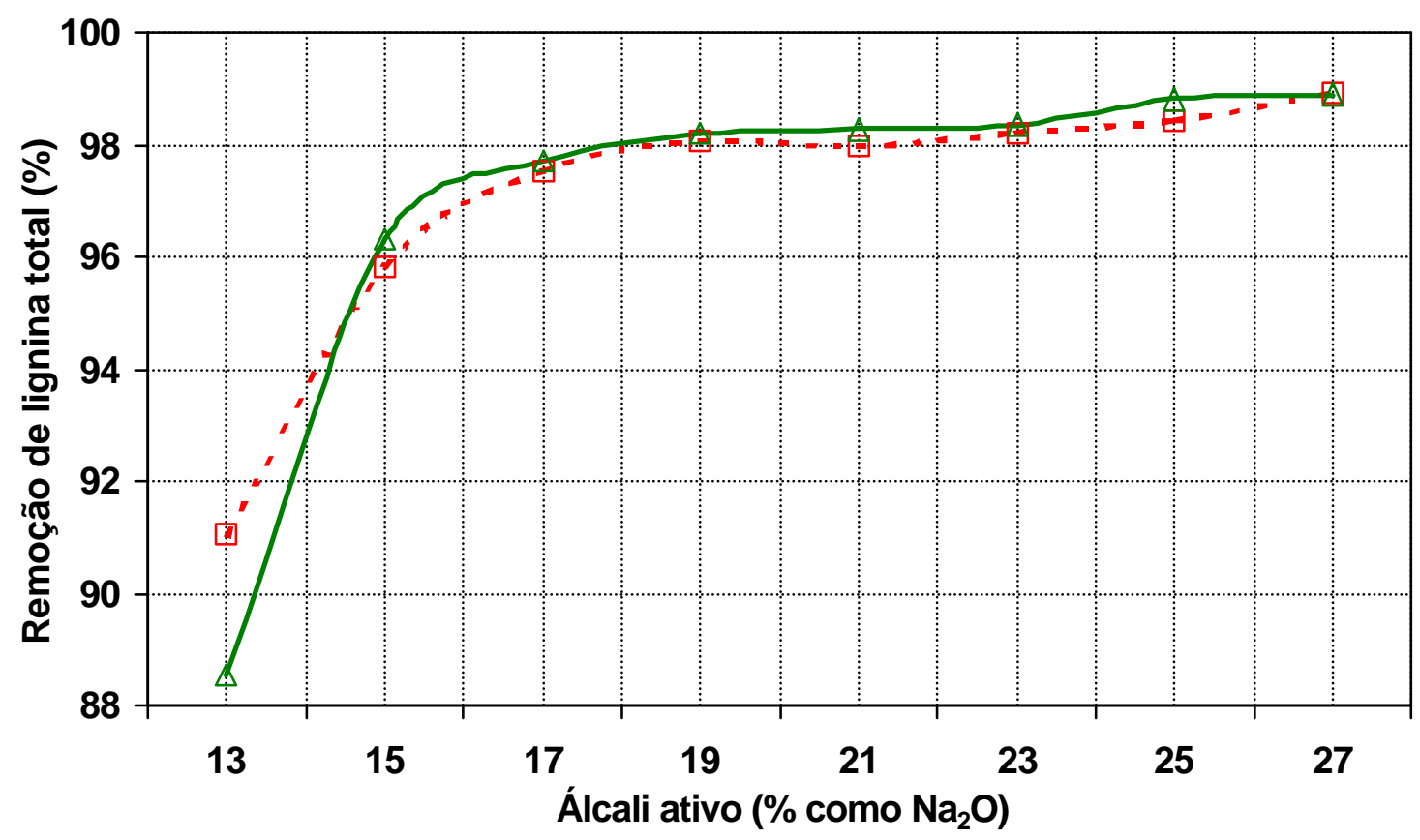

- $\square$ - E. grandis x E. urophylla P4299 $\triangle$ E. grandis x E. urophylla C085

Figura 5 - Percentual de lignina total removido x álcali ativo

Os resultados da Figura 5 indicam que cerca de $97 \%$ da lignina total da madeira é removida para uma carga alcalina aplicada de $17 \%$ de álcali ativo. Não se observa também ganho significativo na remoção de lignina da madeira para kappa menor que 17, o qual possa justificar a prática de menores valores de kappa visando exclusivamente aumentar o nível de deslignificação.

A Tabela 11 apresenta a análise de variância e teste $F$ para rendimento depurado em função da carga alcalina aplicada para os materiais estudados, bem como suas interações. 
Tabela 11. Análise de variância e teste $\mathrm{F}$ para o parâmetro rendimento depurado

\begin{tabular}{lrrrrr}
\hline & GL & \multicolumn{1}{c}{ SQ } & \multicolumn{1}{c}{ QM } & \multicolumn{1}{c}{ F } & Prob>F \\
\hline Dosagens de Álcali & 7 & 175,78 & 25,11 & 87,30 & 0,0001 \\
Material & 1 & 0,78 & 0,78 & 2,69 & 0,1447 \\
Dosagens de Álcali X Material & 7 & 2,01 & 0,29 & 5,80 & 0,0002 \\
Resíduo & 32 & 1,59 & 0,05 & & \\
\hline Total & 47 & 180,16 & & & \\
\hline
\end{tabular}

$\mathrm{GL}=$ grau de liberdade $\mathrm{SQ}=$ soma de quadrados $\mathrm{QM}=$ quadrado médio $\mathrm{Prob}=$ probabilidade

Os resultados da Tabela 11 indicam que a dosagem de álcali apresenta efeito significativo sobre o rendimento depurado, o que está relacionado a remoção dos carboidratos, principalmente as hemiceluloses. Nota-se também que, embora os materiais apresentem diferentes valores de densidade básica, não há efeito significativo dos materiais sobre parâmetro de rendimento, o que pode ser atribuído a semelhança de composição química entre os materiais e, principalmente, a boa impregnação do sistema Lo-Solids ${ }^{\circledR}$. Observa-se também que ocorre uma interação entre os fatores dosagem de álcali e material, ou seja, os mesmos apresentam padrão de variação diferente para o parâmetro rendimento depurado.

A Figura 6 mostra o efeito da carga alcalina aplicada sobre o rendimento depurado do processo de polpação para os materiais P4299 e C085. 


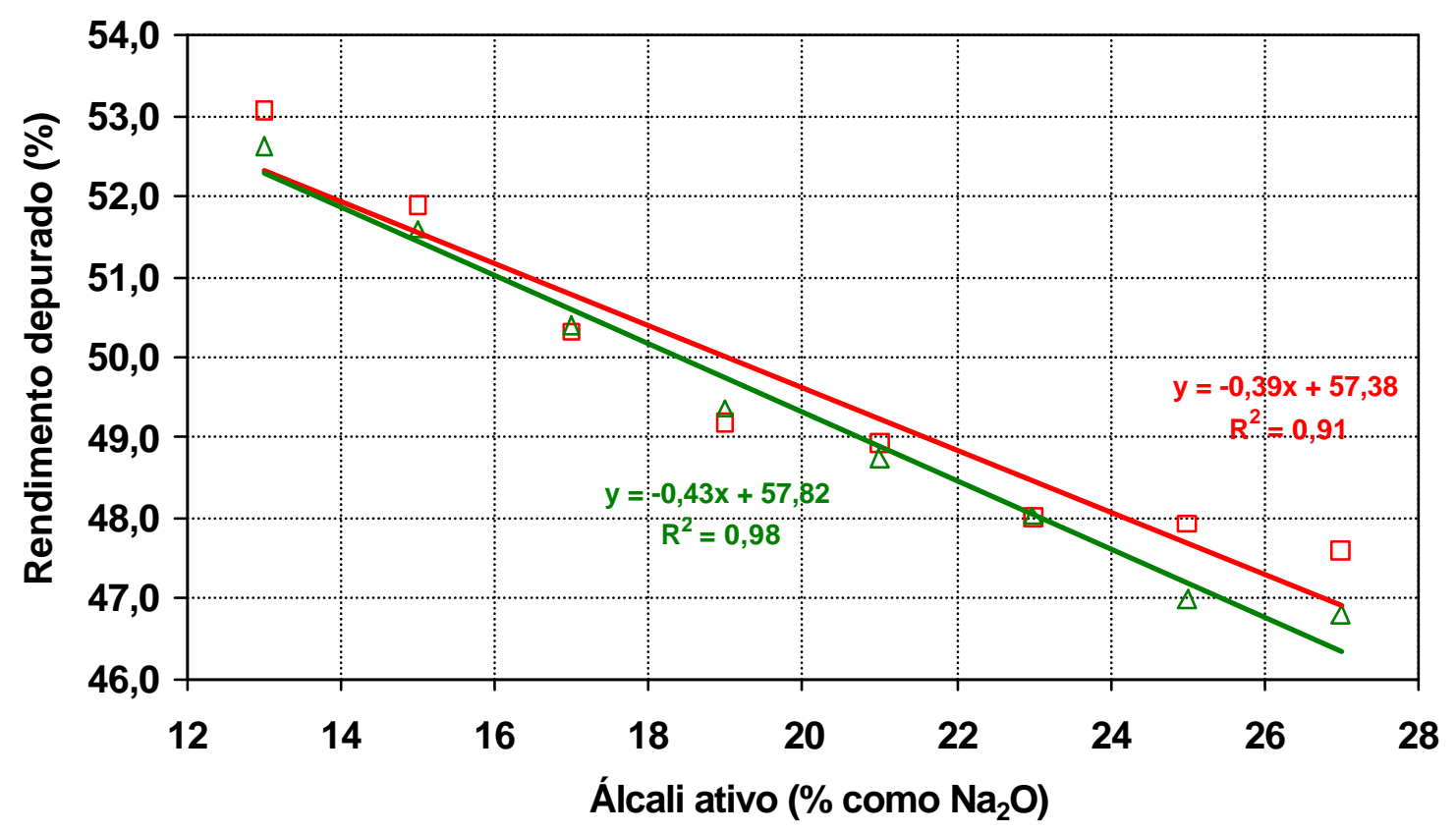

$\square$ E. grandis X E. urophylla P4299

$\triangle$ E. grandis $x$ E. urophylla C085

Figura 6 - Rendimento depurado x álcali ativo

Nota-se pelos resultados obtidos uma redução significativa do rendimento depurado à medida que se aumenta a dosagem de álcali ativo do processo de polpação. Tal comportamento está associado à perda de carboidratos, principalmente os polissacarídeos de baixo pelo molecular, ocasionado pelas reações de degradação e dissolução dos mesmos.

O rendimento depurado é um parâmetro extremamente importante para a fabricante de polpa celulósica tendo em vista os aspectos econômicos relacionados ao consumo de madeira, uma vez que a matéria-prima é responsável pela maior parte do custo de produção da polpa.

Além do aspecto negativo relacionado ao maior consumo específico de madeira devido ao menor rendimento, baixo rendimento gera também maior teor de sólidos no licor, podendo resultar numa menor taxa de produção, caso a caldeira de recuperação esteja trabalhando em seu limite de projeto. 
A Figura 7 mostra o efeito do nível de deslignificação (número kappa) sobre o rendimento depurado do processo de polpação para os materiais P4299 e C085.

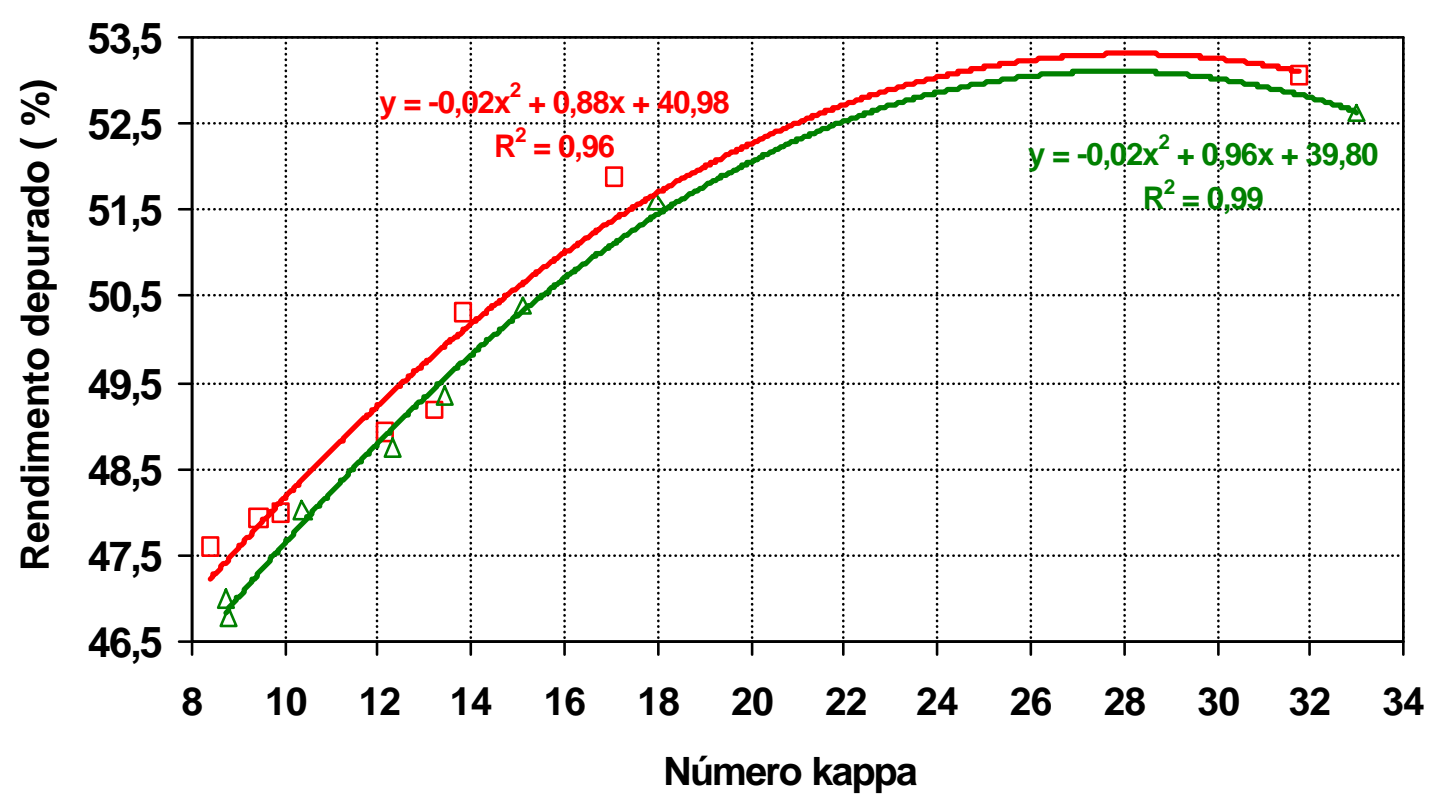

$\square$ E. grandis $x$ E. urophylla P4299

$\triangle$ E. grandis $x$ E. urophylla C085

Figura 7 - Rendimento depurado x número kappa

Nota-se que para valores de kappa menor igual a 18 tem -se praticamente um efeito linear do número kappa sobre o rendimento depurado do processo de polpação, evidenciando a importância da não avaliação isolada de parâmetros como rendimento, carga alcalina aplicada e, conseqüentemente, nível de deslignificação. Já para valores de kappa em torno de 30 tem-se também uma redução do rendimento depurado devido a maior geração de rejeitos, os quais estão associados à baixa carga de álcali aplicada no cozimento. Verificam-se também valores semelhantes para os materiais P4299 e C085, os quais possivelmente estão associados a semelhança de composição química entre os materiais e a boa impregnação do sistema de coziemnto Lo-Solids ${ }^{\circledR}$.

A Figura 8 mostra a relação rendimento depurado/número kappa obtido para os dois materiais estudados quando submetidos às diferentes dosagens de álcali ativo. 


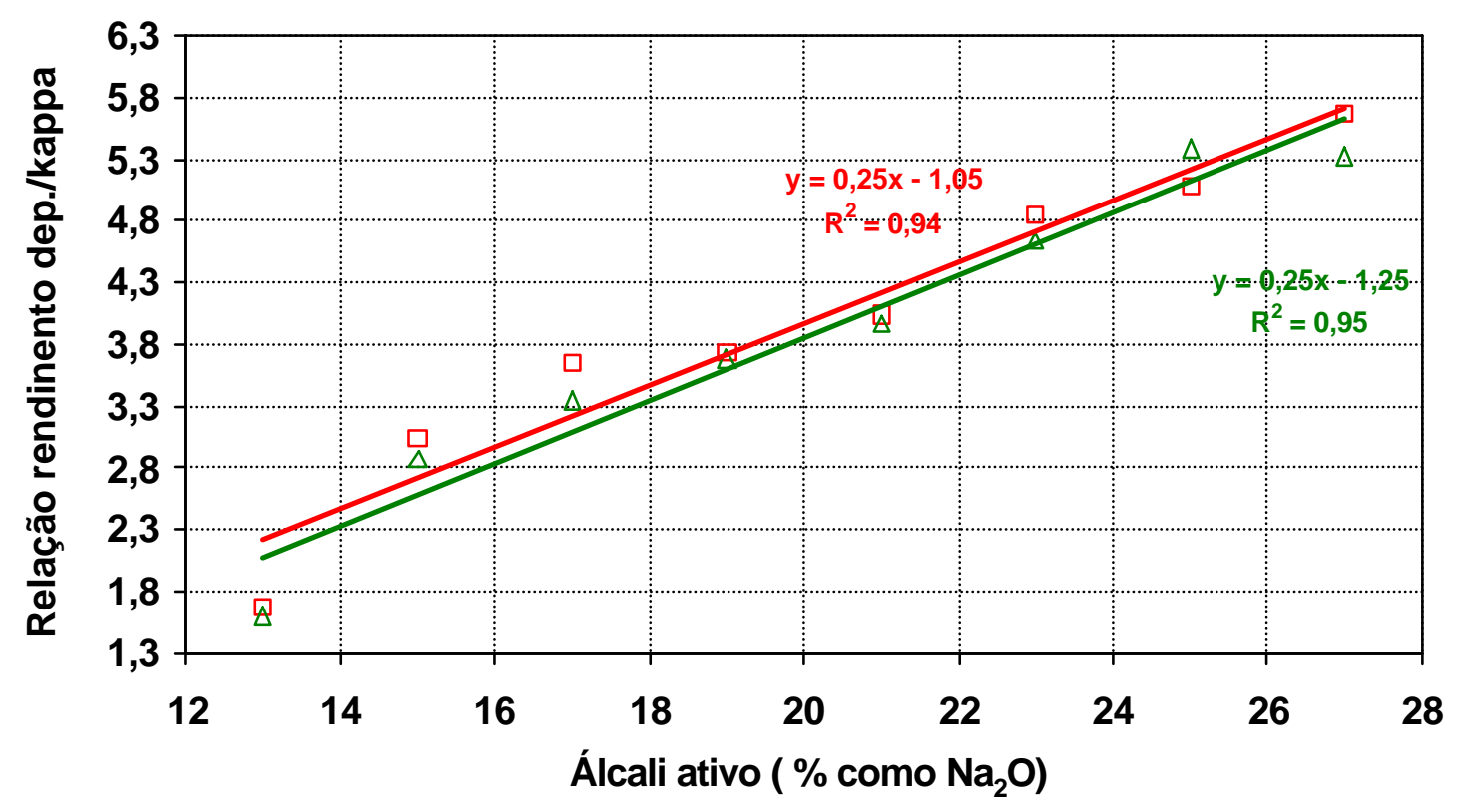

$\square$ E. grandis x E. urophylla P4299

$\triangle$ E. grandis $x$ E. urophylla C085

Figura 8 - Relação rendimento depurado/número kappa x álcali ativo

Conforme descrito anteriormente, existe uma interdependência entre variável rendimento depurado e número kappa. Como a polpa de eucalipto destina-se, principalmente, a produção de papéis com elevados valores de alvura, a avaliação da relação rendimento depurado/número kappa é uma prática comum.

Nota-se pela Figura 8 um aumento significativo da relação rendimento/kappa à medida que se aumenta o álcali ativo no processo de polpação, o que está associado a redução do número kappa da polpa. Vale ressaltar que a viabilidade na prática de valores elevados dessa relação deve levar em conta também os impactos com relação à perda de rendimento. O material P4299, de maneira geral, apresenta valores ligeiramente superiores quando comparado ao material C085, o que pode estar associado ao menor valor densidade básica apresentado pelo material P4299 e, conseqüentemente, aos valores de número kappa ligeiramente inferiores obtidos nos tratamentos. 
A Tabela 12 apresenta a análise de variância e teste $F$ para teor de rejeitos em função da carga alcalina aplicada para os materiais estudados, bem como suas interações.

Tabela 12. Análise de variância e teste $\mathrm{F}$ para o parâmetro teor de rejeitos

\begin{tabular}{lrlrrr}
\hline & GL & SQ & QM & \multicolumn{1}{c}{ F } & Prob>F \\
\hline Dosagem de Álcali & 7 & 9,200 & 1,314 & 177,08 & 0,0001 \\
Material & 1 & 0,002 & 0,002 & 0,27 & 0,6195 \\
Dosagem de Álcali X Material & 7 & 0,052 & 0,007 & 4,77 & 0,0009 \\
Resíduo & 32 & 0,050 & 0,002 & & \\
\hline Total & 47 & 9,300 & & & \\
\hline
\end{tabular}

$\mathrm{GL}=$ grau de liberdade $\mathrm{SQ}=$ soma de quadrados $\mathrm{QM}=$ quadrado médio Prob = probabilidade

Os resultados da Tabela 12 mostram que a dosagem de álcali apresenta efeito significativo sobre o teor de rejeitos, uma vez que a presença de material não totalmente cozido (rejeitos) está relacionado com a carga de álcali aplicada no cozimento. Nota-se também que não há efeito significativo do material sobre esse parâmetro, porém observa-se que há efeito significativo da interação entre os fatores dosagem de álcali e material, ou seja, o padrão de variação para o parâmetro teor de rejeitos não é o mesmo para os materiais.

Na Figura 9 são apresentados os valores de rejeitos obtidos após depuração da polpa dos tratamentos realizados para os materiais estudados. 


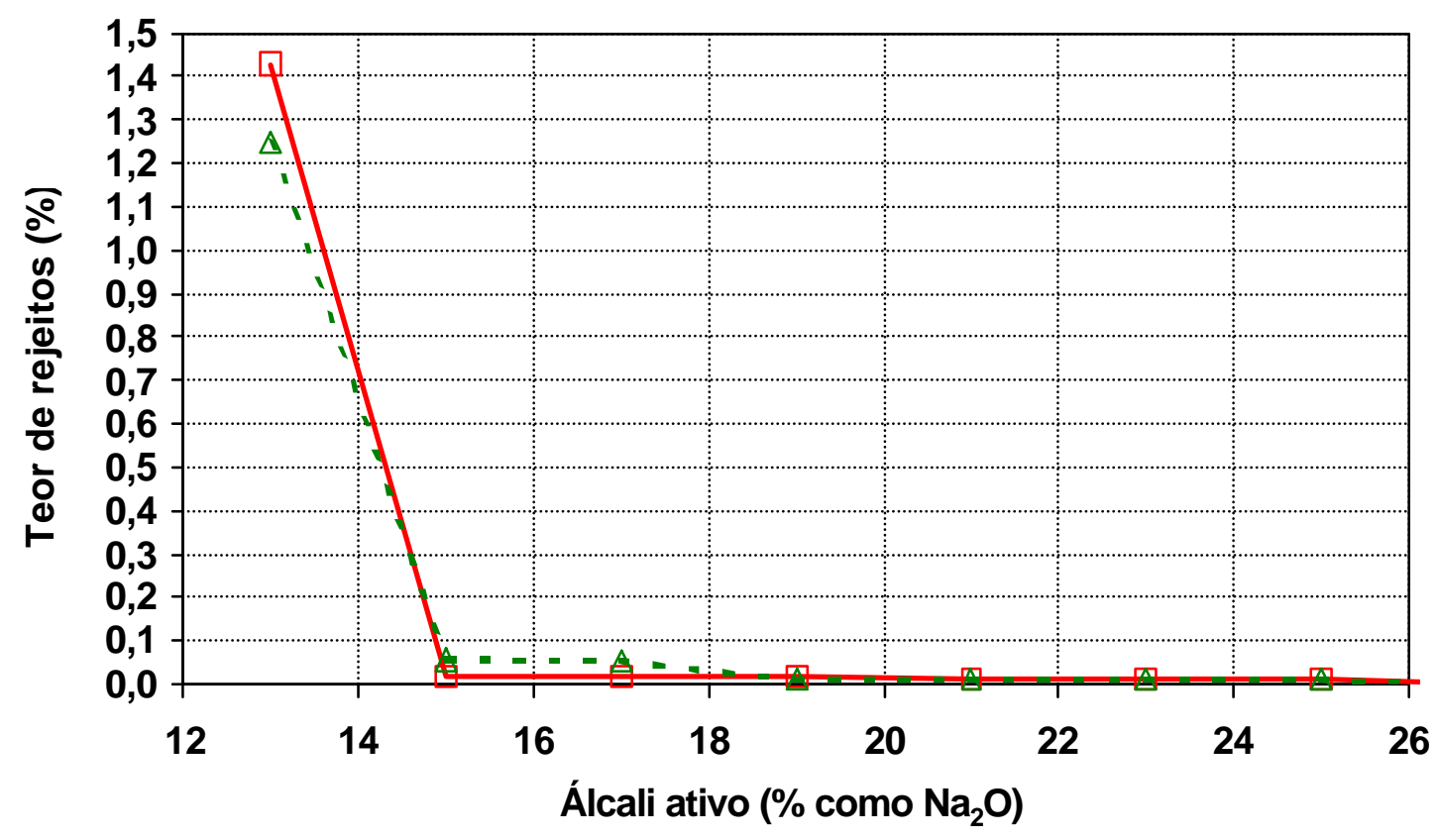

$\square$ E. grandis x E. urophylla P4299

- A - E. grandis x E. urophylla C085

Figura 9 - Teor de rejeitos $\mathrm{x}$ álcali ativo

O teor de rejeitos do processo de polpação está relacionado às características da matéria-prima madeira e os parâmetros do processo de polpação, principalmente, tempo e temperatura de impregnação, fator $\mathrm{H}$ e carga alcalina também exercem influência sobre o teor de rejeitos. Valores elevados de densidade básica da madeira, maior teor de lignina e de extrativos podem diminuir a eficiência das reações de deslignificação, dando origem a materiais parcialmente cozidos e que são classificados como rejeitos do processo de polpação. A etapa de impregnação dos cavacos e, portanto, a uniformidade no tamanho e espessura dos cavacos é também muito importante, uma vez que no momento em que se atinge a temperatura máxima de cozimento requer-se que o álcali esteja no interior dos cavacos para que as reações de deslignificação possam acontecer de maneira uniforme.

Os teores de rejeitos obtidos nos diferentes tratamentos para os dois materiais estudados podem ser considerados baixos, apenas o tratamento com 13\% de álcali ativo apresentou maior valor, o qual pode ser atribuído à falta de álcali ativo desse tratamento, evidenciando a importância da carga alcalina para o processo de polpação. 
O baixo teor de rejeito obtido nos tratamentos pode ser atribuído a qualidade dos cavacos de laboratório, a composição química dos materiais estudados e, principalmente, pelo fato do sistema de cozimento Lo-Solids ${ }^{\circledR}$ apresentar um longo período de impregnação. Os resultados semelhantes obtidos para os materiais indicam também que o cozimento Lo-Solids ${ }^{\circledR}$ apresenta menor sensibilidade ao parâmetro de densidade básica da madeira.

A Figura 10 apresenta os teores de sólidos secos (tss) por toneladas de polpa produzida obtidos nos tratamentos realizados para os materiais P4299 e C085.

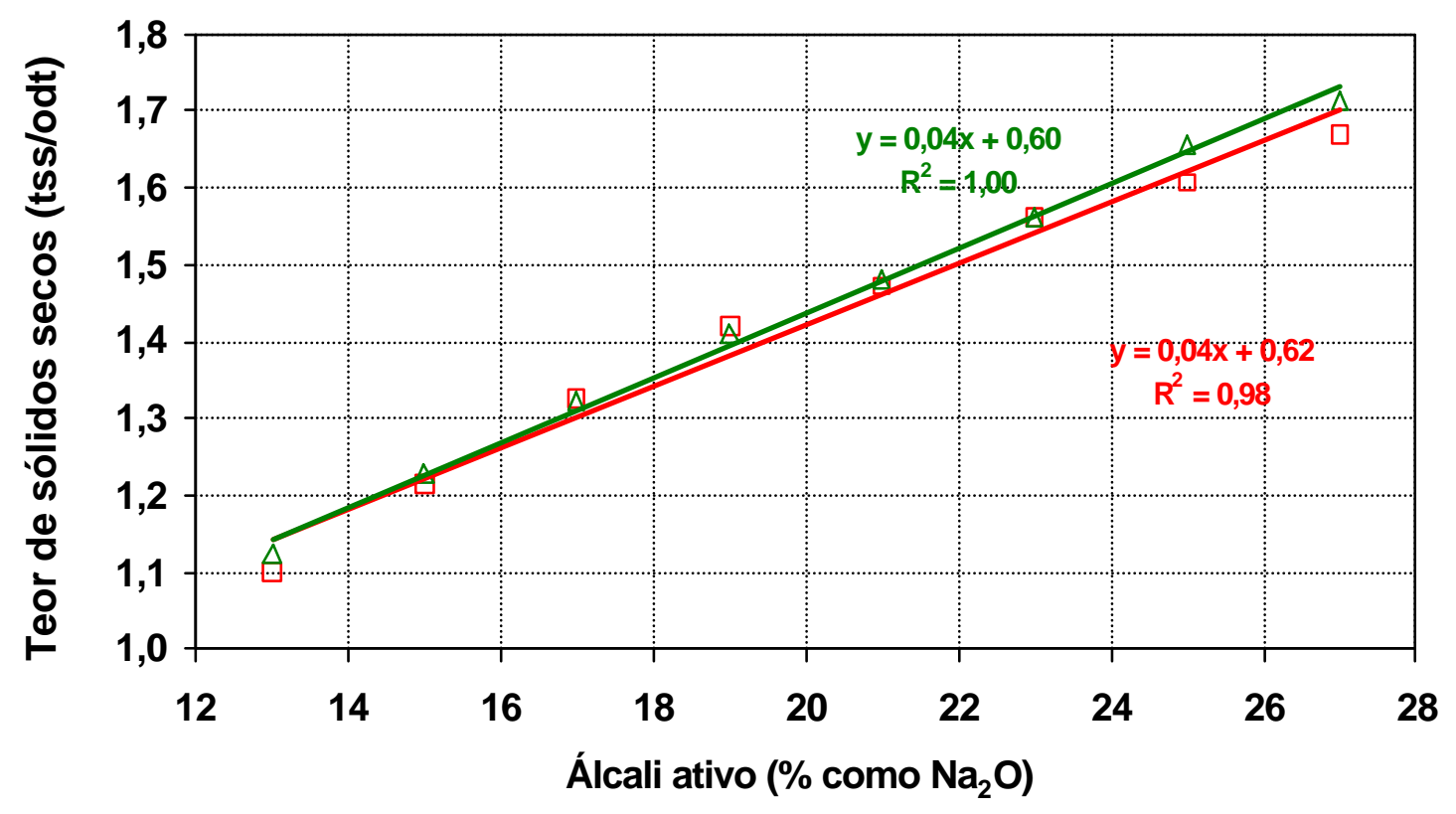

$\square$ E. grandis $x$ E. urophylla $P 4299$

$\triangle$ E. grandis $x$ E. urophylla C085

Figura 10 - Teor de sólidos secos (tss) x álcali ativo

O teor de sólidos secos é um parâmetro importante e expressa a quantidade de material destinado à queima na caldeira de recuperação. Como existe um limite de projeto para queima, a caldeira pode representar um gargalo à produção caso os valores de tss estejam incompatíveis com o dimensionamento da mesma.

Nota-se pela Figura 10 maiores teores de sólidos secos para os tratamentos com maior carga alcalina, justificável devido a maior quantidade de constituintes 
químicos do próprio licor de cozimento (material inorgânico) e também materiais orgânicos dissolvidos no licor negro (lignina e carboidratos) oriundos das reações de deslignificação e da queda do rendimento depurado, conforme observado anteriormente.

A Figura 11 apresenta o efeito do nível de deslignificação medido através do número kappa sobre o teor de sólidos secos gerados.

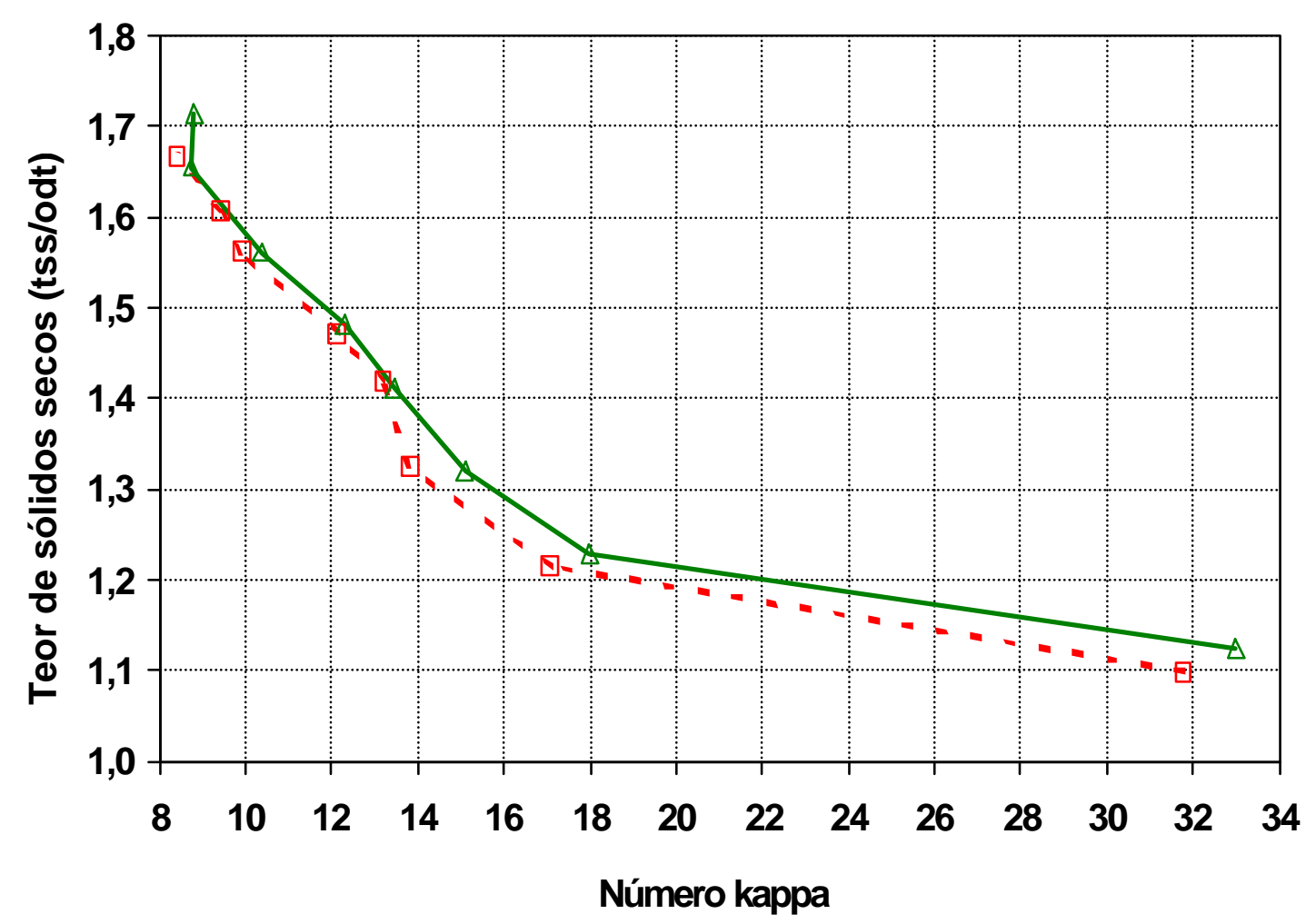

- . E. grandis x E. urophylla P4299 $\triangle$ E. grandis x E. urophylla C085

Figura 11 - Teor de sólidos secos (tss) x número kappa

Nota-se a influência do número kappa sobre o teor de sólidos gerados, o que pode se atribuído à remoção de materiais orgânicos (lignina e carboidratos) da madeira e também devido o próprio aumento na dosagem de álcali (material inorgânico). Observam-se também os materiais estudados apresentam resultados semelhantes para o teor de sólidos secos quando comparado num mesmo número kappa. 
A viscosidade da polpa celulósica é um parâmetro amplamente utilizado para controle da qualidade da polpa nas diferentes fases do processo de produção. $O$ parâmetro viscosidade da polpa está associado com o grau médio de polimerização e do correspondente peso molecular dos polímeros de celulose e hemiceluloses, sendo essa medida utilizada para estimar indiretamente o grau de polimerização e o nível de degradação dos carboidratos durante as fases do processo de obtenção da polpa celulósica.

A viscosidade de uma amostra de polpa isolada não permite inferir sobre as propriedades de resistência da mesma, pois a correlação entre viscosidade e resistência é diferente para matérias-primas, processos de polpação e seqüências de branqueamentos. Mas, de maneira geral, maior valor de viscosidade indica maior preservação dos carboidratos e, consequentemente, melhores propriedades de resistência físicas, principalmente aquelas que dependem da ligação entre fibras.

Para as polpas obtidas nos cozimentos com $13 \%$ de álcali ativo foi realizado antes da análise de viscosidade um tratamento com dióxido de cloro $\left(5 \mathrm{~kg} \mathrm{ClO}_{2}, 70^{\circ} \mathrm{C}\right.$, pH3,5 e 60min.), uma vez que o teor de lignina presente na polpa era superior a 4\%; valor limite para análise, conforme descreve a norma TAPPI T230 om-94

A Tabela 13 apresenta a análise de variância e teste $F$ para 0 parâmetro viscosidade em função da carga alcalina aplicada para os materiais estudados, bem como suas interações.

Tabela 13. Análise de variância e teste $\mathrm{F}$ para o parâmetro viscosidade

\begin{tabular}{lrrrrr}
\hline & GL & \multicolumn{1}{c}{ SQ } & \multicolumn{1}{c}{ QM } & \multicolumn{1}{c}{ F } & Prob>F \\
\hline Dosagem de Álcali & 7 & 21278,49 & 3039,78 & 194,53 & 0,0001 \\
Material & 1 & 180,19 & 180,19 & 11,53 & 0,0115 \\
Dosagem de Álcali X Material & 7 & 109,39 & 15,63 & 0,74 & 0,6369 \\
Resíduo & 32 & 672,14 & 21,00 & & \\
\hline Total & 47 & 22240,20 & & & \\
\hline
\end{tabular}

$\mathrm{GL}=$ grau de liberdade $\mathrm{SQ}=$ soma de quadrados $\mathrm{QM}=$ quadrado médio $\mathrm{Prob}=$ probabilidade 
Os resultados da Tabela 13 indicam que a dosagem de álcali apresenta efeito significativo sobre a viscosidade da polpa, o que está relacionado ao nível de degradação dos carboidratos da polpa devido ao aumento da dosagem de álcali. A análise de variância indica que há efeito significativo dos materiais sobre a viscosidade, porém nota-se pela Figura 12 que as diferenças mais significativa ocorrem para as dosagens de álcali inferior a 17\%. Observa também pela Tabela 13 que não há efeito significativo da interação entre os fatores dosagem de álcali e material, ou seja, o padrão de variação para os materiais quando submetido às dosagens de álcali é semelhante.

A Figura 12 apresenta os valores de viscosidade obtidos para os dois materiais estudados quando submetidos às diferentes dosagens de álcali ativo.

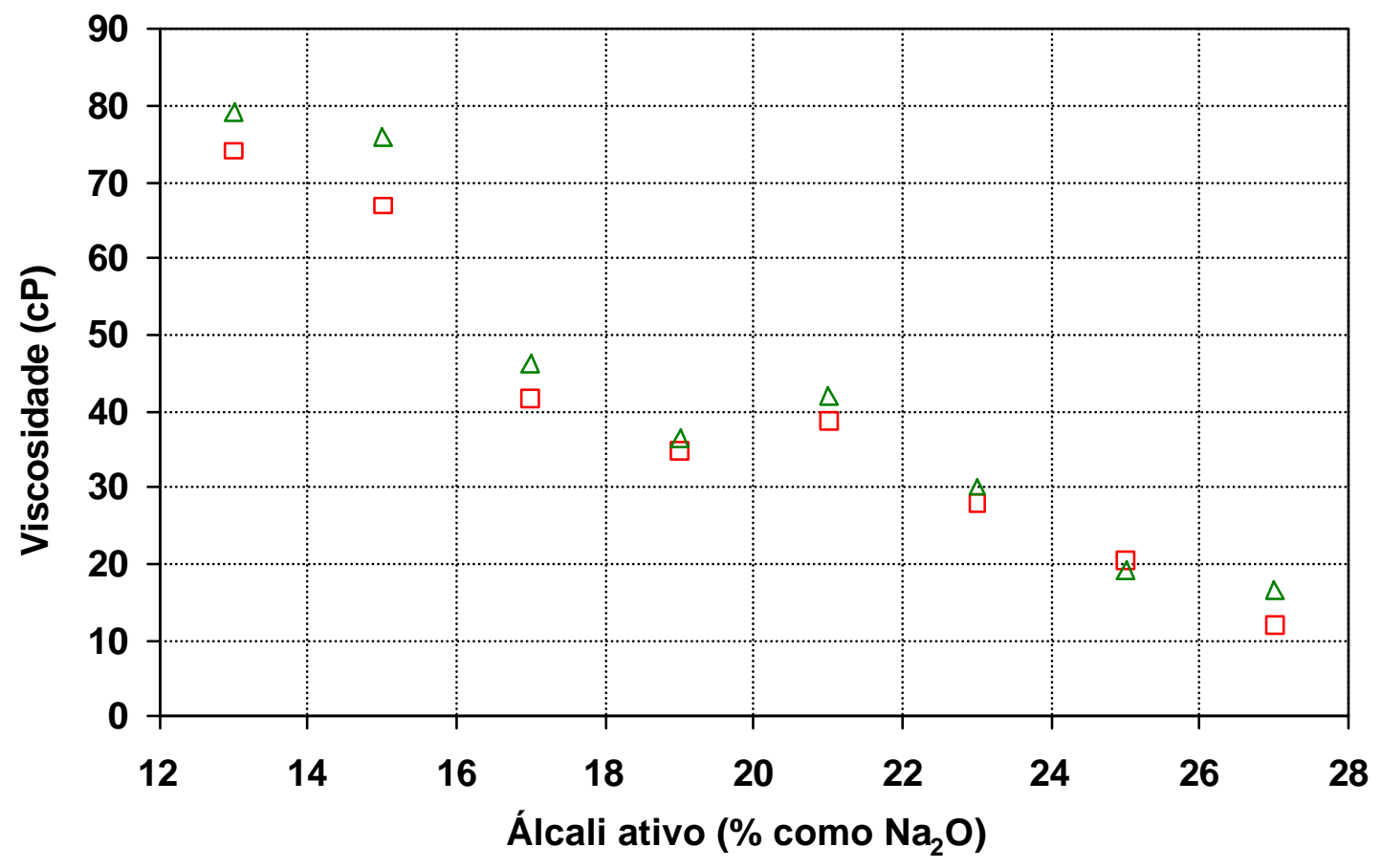

$\square$ E. grandis x E. urophylla P4299

$\triangle E$. grandis $x$ E. urophylla C085

Figura 12 - Viscosidade da polpa x álcali ativo

Observa-se pela Figura 12 que para a carga alcalina entre 17\% e 21\% não se verifica redução no valor de viscosidade da polpa, podendo essa ser uma região de transição. Uma hipótese seria que, embora para essa range de álcali haja remoção de 
polímeros de baixo peso molecular, tem-se a preservação dos polissacarídeos de alto peso molecular (celulose), o que permite manter o grau de polimerização médio dos carboidratos e a viscosidade da polpa. Esses resultados, se confirmados num estudo mais detalhado, podem ser interessantes na produção de polpa para fins higiênicos, pois indica um limite de carga alcalina e nível de deslignificação para o qual é possível remover as hemiceluloses da polpa sem comprometer a viscosidade da mesma.

Nota-se pela Figura 12 uma redução significativa do valor de viscosidade da polpa para dosagens de álcali ativo superior a $21 \%$, indicando degradação dos polissacarídeos, podendo com isso produzir polpas com menores propriedades de resistência física.

A Figura 13 mostra a correlação entre viscosidade e rendimento depurado obtidos para os materiais estudados.

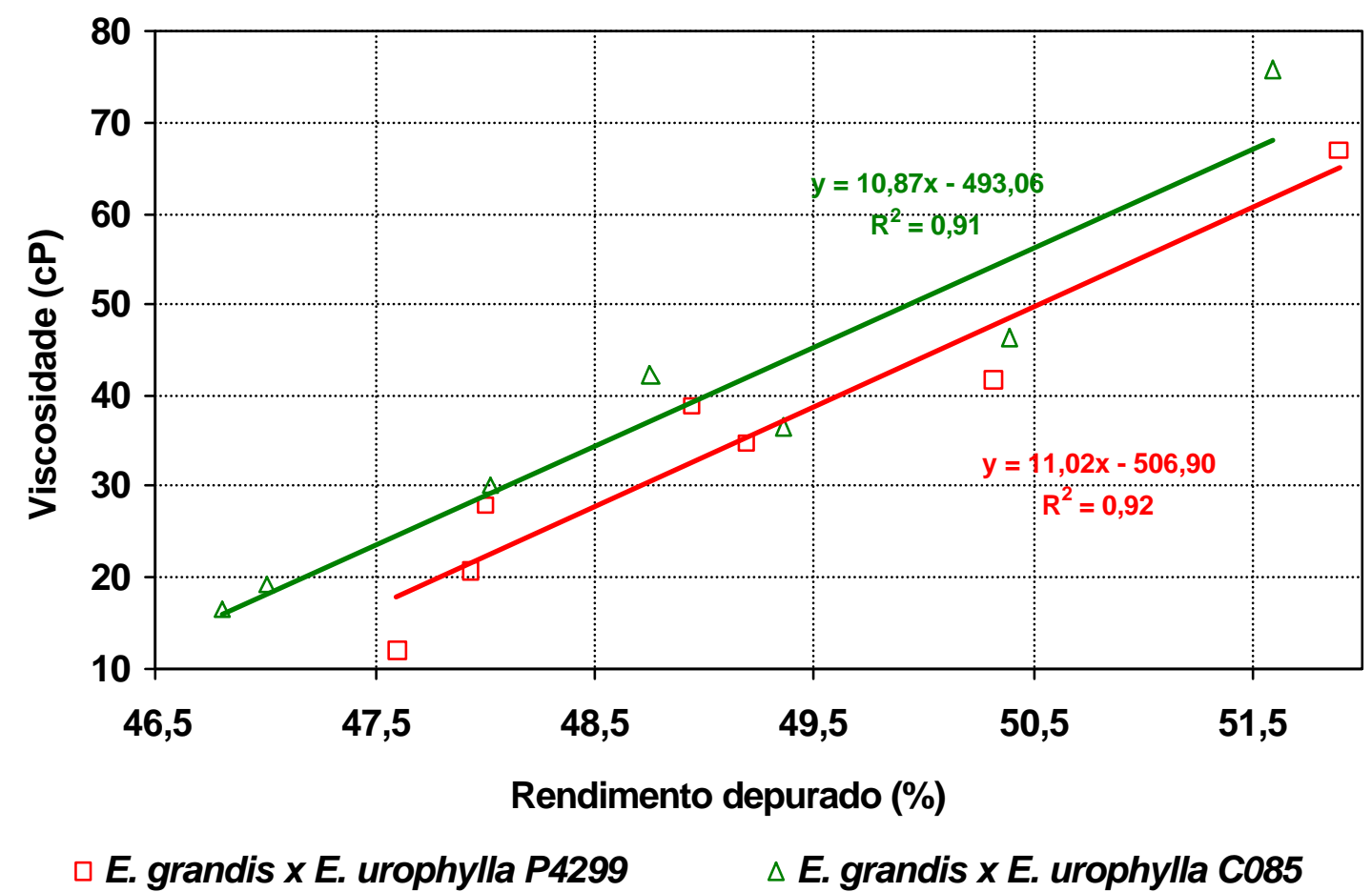

Figura 13 - Viscosidade da polpa x rendimento depurado 
Nota-se pela Figura 13 que os materiais P4299 e C085 apresentam comportamento semelhantes. Os Resultados obtidos estão de acordo com o descrito por Sansígolo (1988), quando o autor menciona que a viscosidade de polpas celulósicas kraft não-branqueada de folhosas correlaciona-se com rendimento.

A Figura 14 apresenta a correlação entre viscosidade e número kappa para os materiais P4299 e C085.

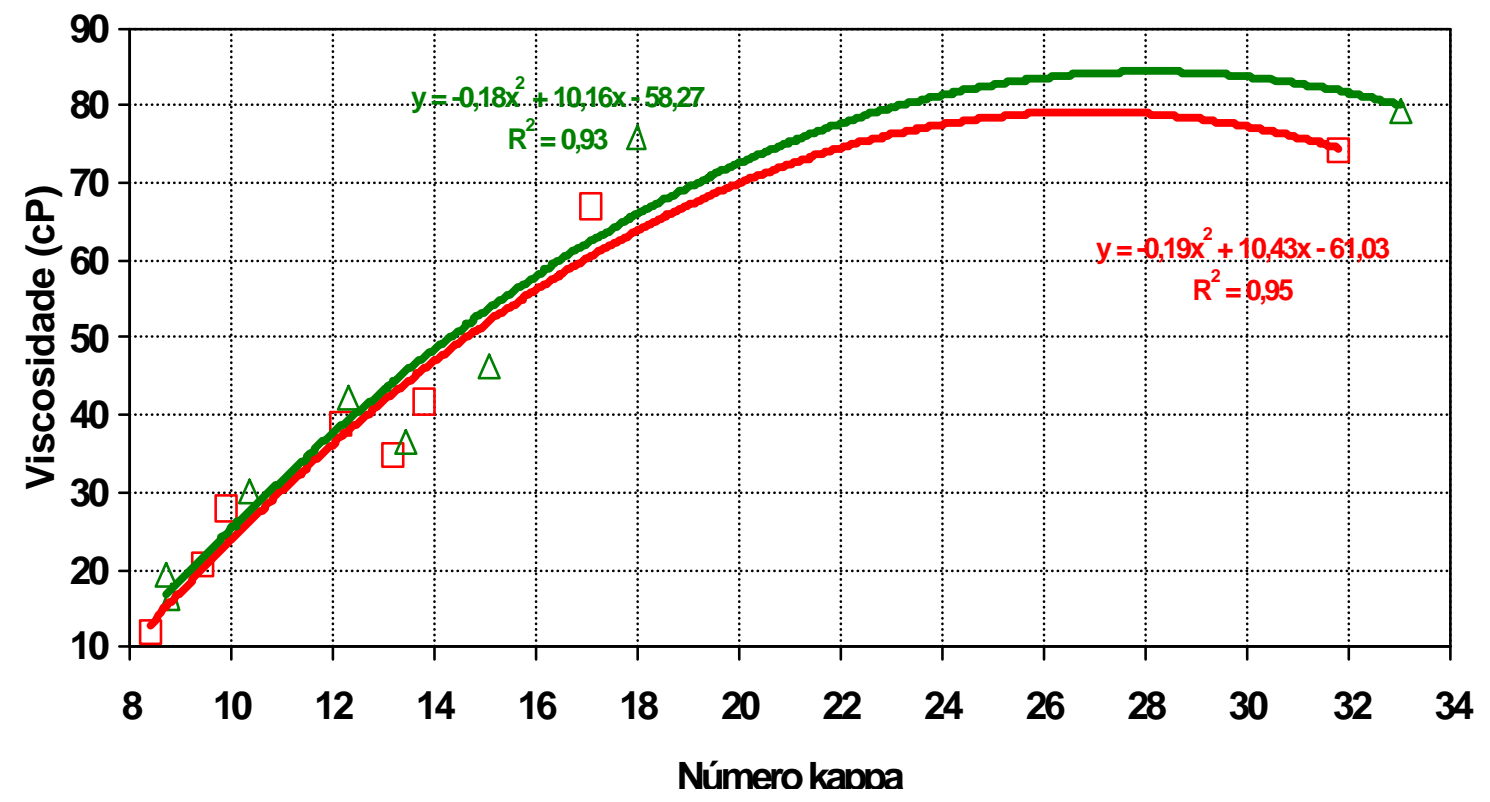

\section{$\square$ E grandis x E urophylla P4299 $\triangle E$ grandis x E. urophylla C085}

Figura 14 - Viscosidade da polpa x número kappa

Os resultados obtidos mostram também que a viscosidade da polpa obtida se relaciona com o número kappa, tendo em vista a própria associação desse último parâmetro com variáveis como consumo de álcali ativo e degradação dos carboidratos.

Verificase também que os valores de viscosidade obtidos para os dois materiais estudados são semelhantes quando comparados num mesmo nível de deslignificação, podendo estar associados a semelhança de composição química entre os materiais e também menor sensibilidade do cozimento Lo-Solids® ao parâmetro de densidade básica. 
A análise isolada da viscosidade e do número kappa é fundamental, porém é comum analisar a relação viscosidade/kappa, a qual é utilizada para verificar a seletividade do processo de polpação.

A Figura 15 apresenta a relação viscosidade/kappa para os materiais estudados.

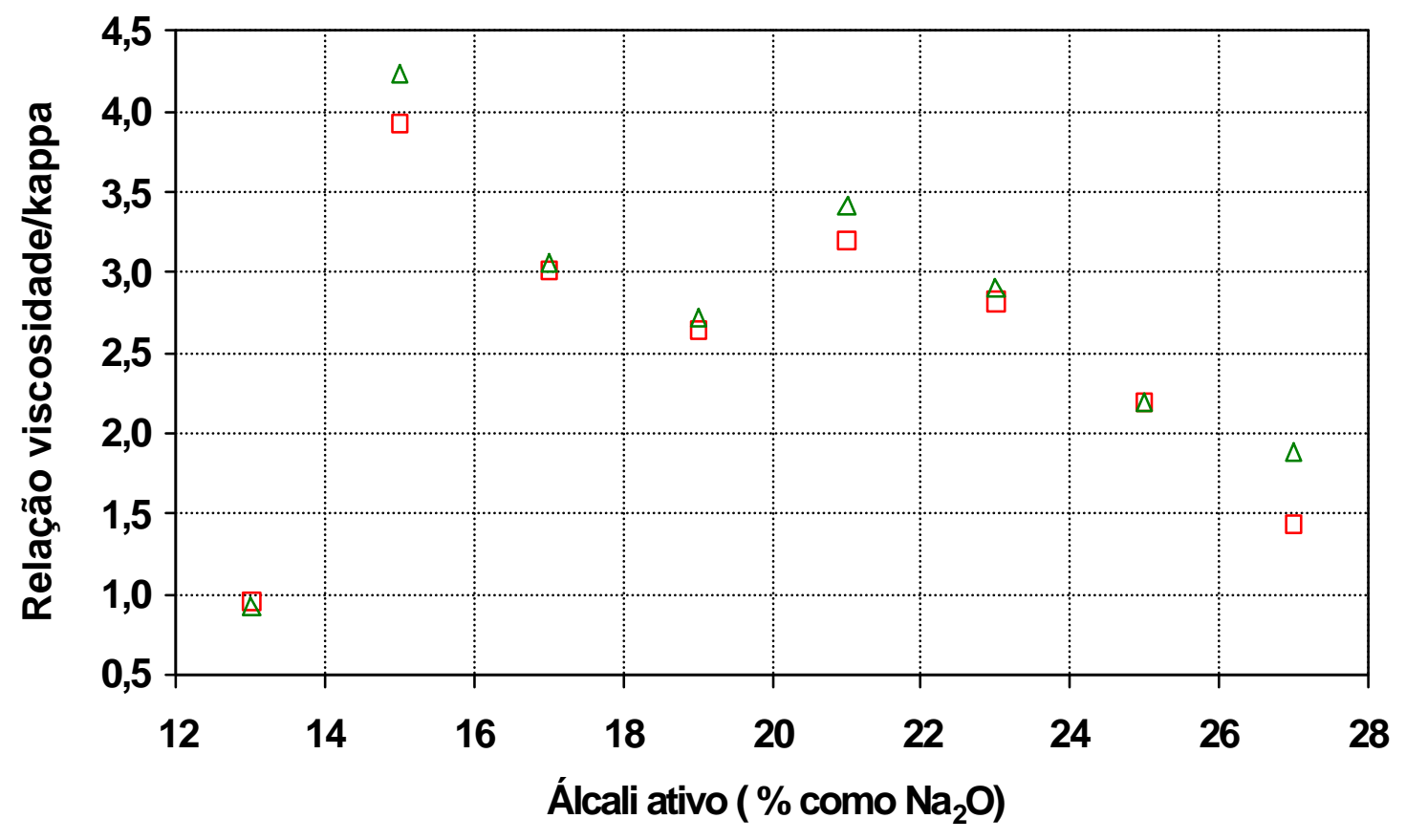

$\square$ E. grandis x E. urophylla P4299

$\triangle$ E. grandis x E. urophylla C085

Figura 15 - Relação viscosidade/número kappa x álcali ativo

Nota-se pela Figura 15 que a relação viscosidade/kappa é inferior para o tratamento com $13 \%$ de álcali ativo, o que possivelmente está associado ao elevado valor de número kappa apresentado pela polpa desse tratamento, uma vez que quantidade de álcali foi insuficiente para efetuar o cozimento por completo.

Verificase também que a partir de $21 \%$ de álcali a polpa apresenta menor relação viscosidade/kappa, provavelmente devido à degradação dos polissacarídeos e conseqüente redução da viscosidade da polpa, conforme observado anteriormente.

Observa-se também que quando a carga alcalina passa de 19 para 21\% há um incremento na relação viscosidade/kappa devido ao aumento também da viscosidade 
polpa, conforme discutido anteriormente. A relação viscosidade/kappa não dever ser analisada de forma isolada, mas a composição química da polpa obtida de também ser considerada. A relação entre os polímeros de celulose e hemiceluloses, por exemplo, deve ser avaliada, uma vez que as hemiceluloses apresentam polímeros com menor grau de polimerização e, conseqüentemente, também menor viscosidade.

A seguir serão discutidas as características químicas das polpas obtidas para os materiais quando submetidos aos tratamentos, iniciando-se pelos ácidos hexenurônicos, compostos que tem sido alvo freqüentes estudos.

Os ácidos hexenurônicos (Ahexs) são formados durante o processo de polpação kraft, a partir da conversão dos ácidos 4-O-metil-glicurônicos presentes nas xilanas, principais hemiceluloses presentes em madeiras de folhosas. Segundo Costa et al. (2001), essa conversão ocorre pelo mecanismo de b-eliminação do grupo metoxila. Os ácidos hexenurônicos, além de influenciarem na leitura do número kappa, conforme já discutido, os mesmos exercem influência sobre o processo de branqueamento. Esses compostos formam ligações covalentes com a lignina, consomem reagentes químicos eletrofílicos (cloro, dióxido de cloro, ozônio e perácidos), ligam a íons metálicos e causam reversão de alvura de polpas branqueadas.

A Tabela 14 apresenta a análise de variância e teste $F$ para ácidos hexenurônicos em função da carga alcalina aplicada para os materiais estudados, bem como suas interações.

Tabela 14. Análise de variância e teste $\mathrm{F}$ para o parâmetro ácido hexenurônico

\begin{tabular}{lrrrrr}
\hline & GL & \multicolumn{1}{c}{ SQ } & \multicolumn{1}{c}{ QM } & \multicolumn{1}{c}{ F } & Prob>F \\
\hline Dosagem de Álcali & 7 & 14940,44 & 2134,35 & 1176,39 & 0,0001 \\
Material & 1 & 0,06 & 0,06 & 0,03 & 0,8574 \\
Dosagem de Álcali X Material & 7 & 12,70 & 1,81 & 0,26 & 0,9651 \\
Resíduo & 32 & 223,75 & 6,99 & & \\
\hline Total & 47 & 15176,95 & & & \\
\hline
\end{tabular}

$\mathrm{GL}=$ grau de liberdade $\mathrm{SQ}=$ soma de quadrados $\mathrm{QM}=$ quadrado médio Prob = probabilidade 
Os resultados da Tabela 14 indicam que a dosagem de álcali apresenta efeito significativo sobre o teor de ácidos hexenurônicos da polpa, o que está de acordo com o descrito por Chai et al. (2001). Nota-se também que não há efeito significativo dos materiais sobre esse parâmetro, possivelmente devido à similaridade entre a composição química dos mesmos. Não se observa também efeito significativo da interação entre os fatores dosagem de álcali e material.

A Figura 16 apresenta os teores de ácidos hexenurônicos da polpa obtidos para os materiais P4299 e C085 quando submetidos as diferentes dosagens de álcali ativo.

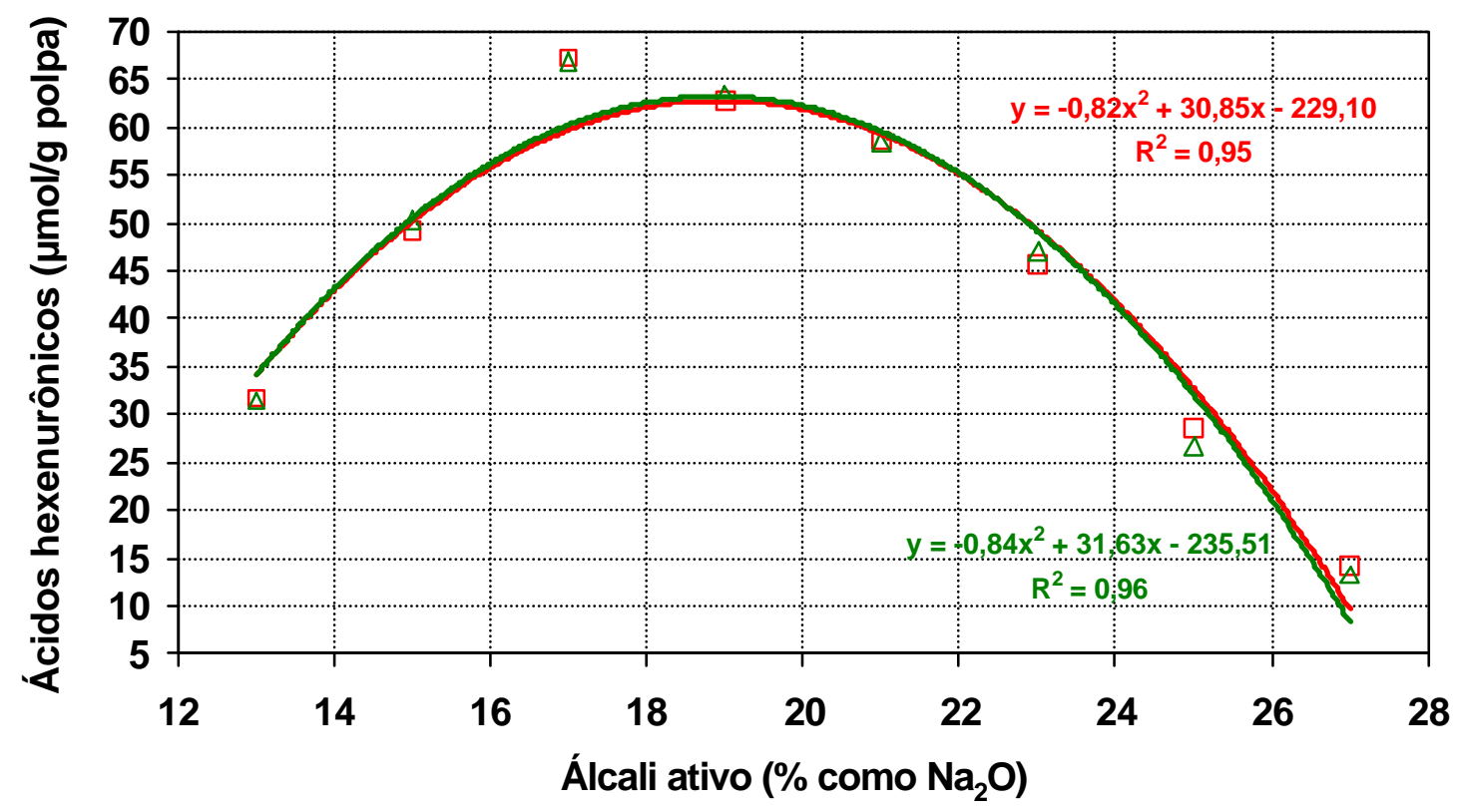

$\square$ E. grandis x E. urophylla P4299 $\triangle$ E. grandis x E. urophylla C085

Figura 16 - Teor de ácidos hexenurônicos da polpa x álcali ativo

Os resultados da Figura 16 mostram que a formação dos ácidos hexenurônicos é influenciada pelo nível de álcali utilizado no cozimento, confirmando os resultados obtidos por Chai et al. (2001), quando descrevem que a carga alcalina e o fator $\mathrm{H}$ são as principais variáveis que influenciam na formação dos ácidos hexenurônicos durante a polpação kraft. 
Nota-se pela Figura 16 um aumento de mais de 100\% no teor de ácidos hexenurônicos da polpa quando a carga alcalina aumenta de 13\% para 17\%. Já para carga alcalina superior a $17 \%$ de álcali ativo observa-se uma redução significativa dos ácidos hexenurônicos da polpa, possivelmente devido às dissoluções das hemiceluloses e degradação dos ácidos hexenurônicos.

Os resultados obtidos mostram redução em torno de $30 \%$ quando a carga alcalina aumenta de $17 \%$ para $23 \%$, confirmando os resultados obtidos por Colodette et al. (2000), quando verificaram que o teor de ácidos hexenurônicos de polpa kraft de eucalipto reduz em torno de $26 \%$ quando a carga alcalina é aumentada de $16 \%$ para $24 \%$.

O número kappa da polpa, conforme já mencionado, é um parâmetro que define estratégias envolvidas na fase de branqueamento como carga de químicos, número de estágios, seqüência a ser empregada. Por essa razão é importante analisar a relação existente entre número kappa e teor de ácidos hexenurônicos da polpa, tendo em vista a influência desses ácidos sobre a fase de branqueamento, conforme já discutido.

A Figura 17 mostra a correlação número kappa e teor de ácidos hexenurônicos da polpa para os dois materiais estudados quando submetidos às diferentes dosagens de álcali ativo. 


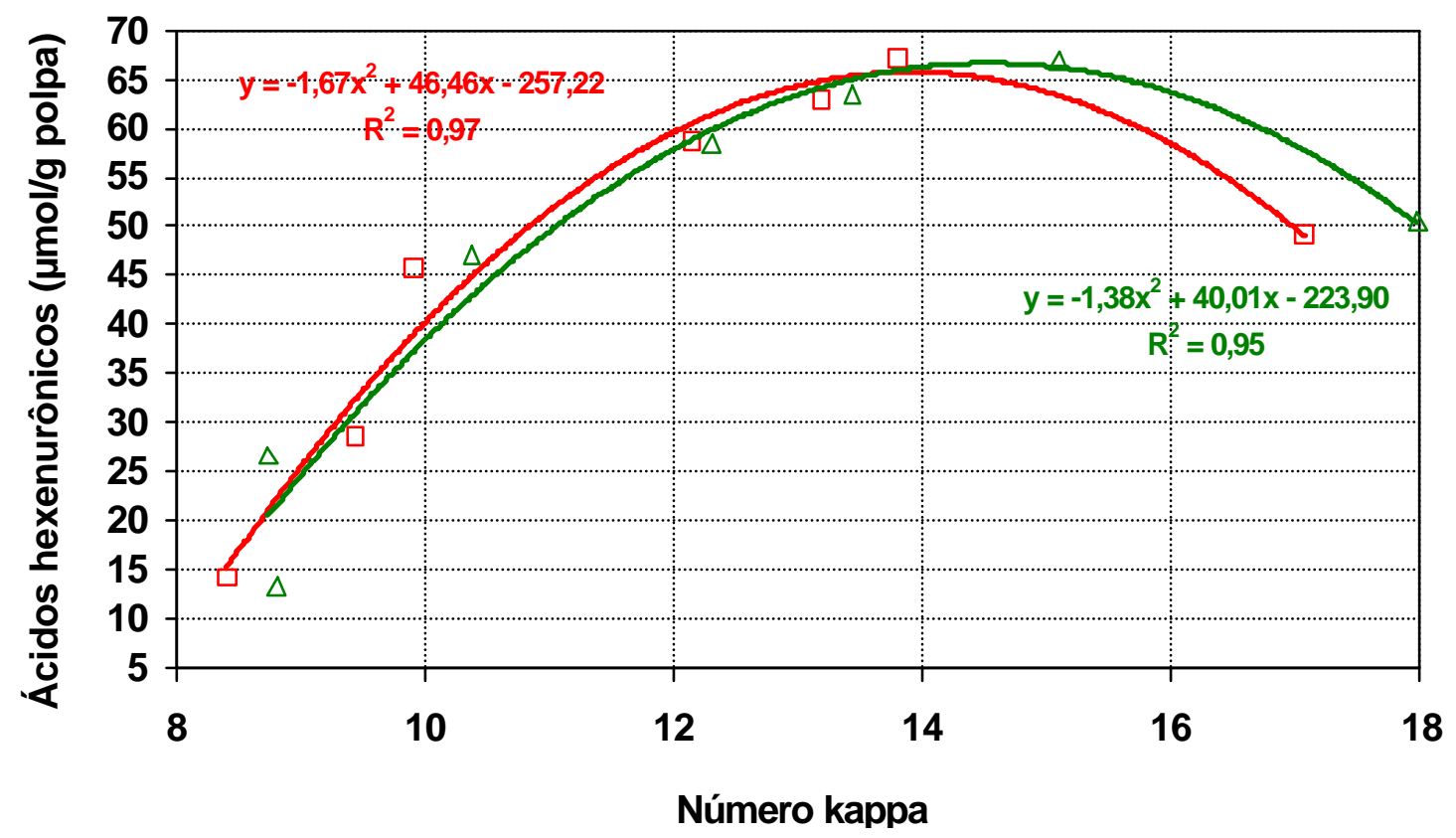

$\square$ E. grandis X E. urophylla P4299

$\triangle$ E. grandis $x$ E. urophylla C085

Figura 17 - Teor de ácidos hexenurônicos da polpa x número kappa

Nota-se pela Figura 17 que a quantidade de ácidos hexenurônicos dá-se também em função do número kappa da polpa, tendo em vista a própria associação deste último parâmetro com a carga alcalina aplicada no processo de polpação e, consequentemente, o nível de deslignificação da polpa.

Os resultados mostram que o teor de ácidos hexenurônicos da polpa celulósica reduz significativamente para valores de número kappa inferiores a 13, o que está relacionado à degradação dos mesmos pela dosagem de álcali, conforme já discutido. Observa-se que o teor de ácidos hexenurônicos aumenta quando o número kappa da polpa varia entre 12 e 15, alcançando um ponto de máximo para valor de kappa de aproximadamente 15. Para valores de kappa acima de 16 tem-se uma redução do teor de ácidos hexenurônicos da polpa, o que está relacionado ao menor nível de álcali aplicado no cozimento. Os resultados obtidos são semelhantes aos obtidos por Ek et al. (2001), quando estudaram a polpação kraft convencional para E. glóbulos. 
Os resultados obtidos por Chakar et al. (2000) mostram que o teor de ácidos hexenurônicos em polpa kraft de fibra curta (Liquidambar Styraciflua) obtida a partir de diferentes níveis de deslignificação decresce rapidamente quando a deslignificação é conduzida até número kappa inferior a 14 e, embora não se trate de madeira de eucalipto, o comportamento é também semelhante aos resultados obtidos nesse estudo.

As hemiceluloses são importantes compostos químicos presentes na polpa final. A presença das mesmas, dentro de certos limites, aumenta a facilidade de refinação das fibras e melhoram também as propriedades físicas do papel. No processo de refino a fibra recebe um tratamento mecânico, o qual causa a remoção da parede primária das fibras e permiti a hidratação das mesmas, aumentando com isso a flexibilidade e o poder de ligação das fibras e, conseqüentemente, as propriedades de resistência física do papel.

Uma maneira de expressar o teor de hemiceluloses presentes na polpa, representada em polpas de eucalipto principalmente pelas xilanas, é através das análises de solubilidade em $\mathrm{NaOH} 5 \%$ (S5) e de pentosanas.

A Tabela 15 apresenta a análise de variância e teste $F$ para o parâmetro solubilidade em álcali 5\% em função da carga alcalina aplicada para os materiais estudados, bem como suas interações.

Tabela 15. Análise de variância e teste $\mathrm{F}$ para solubilidade em $\mathrm{NaOH} 5 \%$ - S5

\begin{tabular}{lrrrrr} 
& GL & SQ & QM & \multicolumn{1}{c}{ F } & \multicolumn{1}{c}{$\boldsymbol{\propto}$} \\
\hline Dosagem de Álcali & 7 & 155,11 & 22,16 & $30,69^{* *}$ & 0,0001 \\
Material & 1 & 0,01 & 0,01 & $0,01 n . s$. & 0,9087 \\
Dosagem de Álcali X Material & 7 & 5,05 & 0,72 & $2,85^{\star}$ & 0,0198 \\
Resíduo & 32 & 8,10 & 0,25 & & \\
\hline Total & 47 & 168,28 & & & \\
\hline
\end{tabular}

Os valores do teste $\mathrm{F}$ seguidos de ${ }^{* *}$ demonstram efeito significativo ao nível de $\alpha<1 \%$ de significância, os valores do teste $\mathrm{F}$ seguidos de * demonstram efeito significativo ao nível de $\alpha<$ $5 \%$ de significância e os valores de $F$ seguidos de n.s. não demonstram efeito significativo 
Os resultados da Tabela 15 mostram que a dosagem de álcali apresenta efeito significativo sobre a solubilidade da polpa em álcali, o que possivelmente está relacionado ao nível de degradação dos carboidratos. Nota-se que não há efeito significativo dos materiais sobre esse parâmetro, porém verifica-se efeito significativo da interação entre os fatores cbsagem de álcali e material, ou seja, o padrão de variação não é o mesmo para os materiais.

A Figura 18 apresenta a solubilidade em álcali para os materiais P4299 e C085.

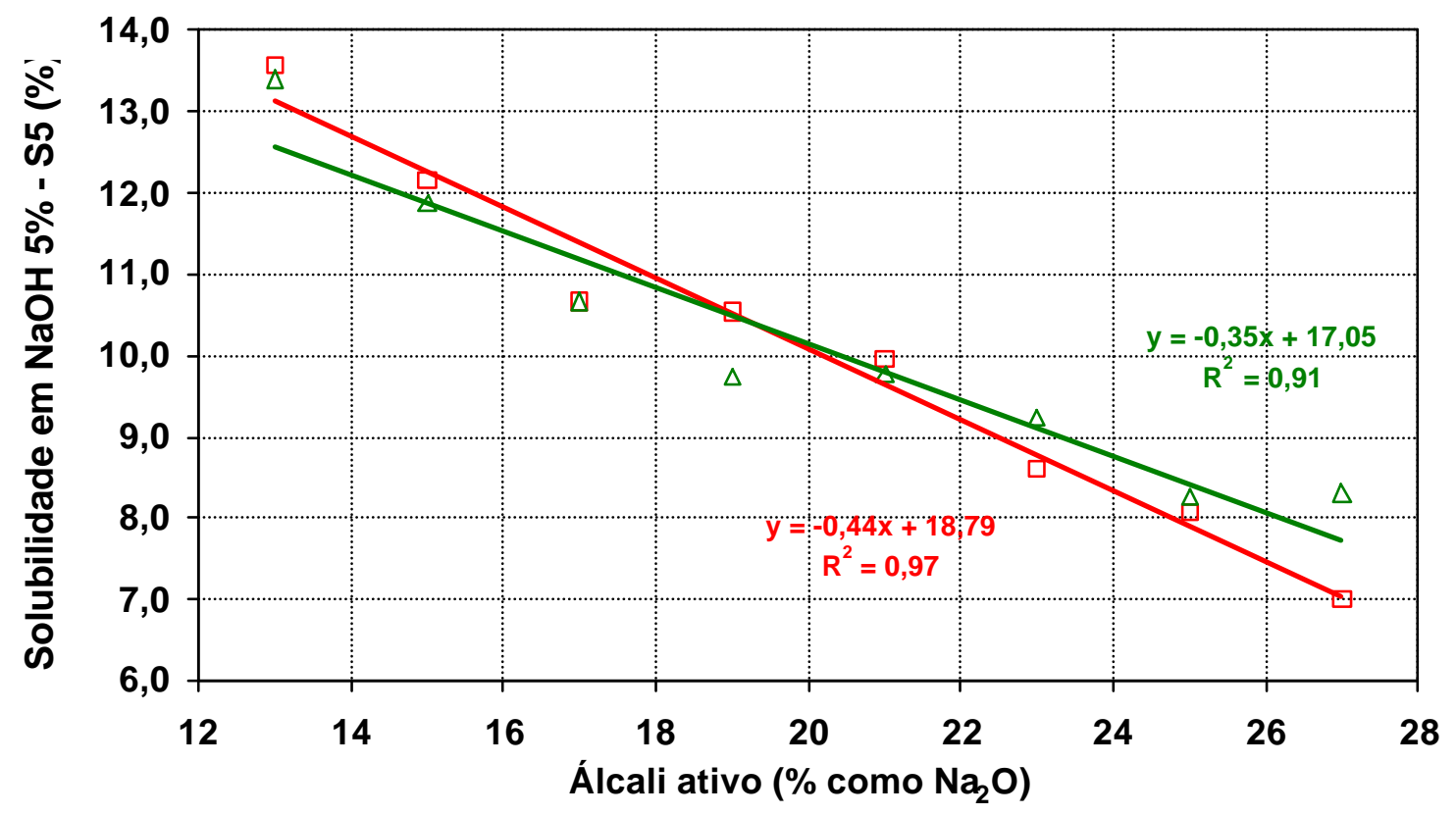

$\square$ E. grandis x E. urophylla P4299

$\triangle E$. grandis $x$ E. urophylla C085

Figura 18 - Solubilidade da polpa em $\mathrm{NaOH}$ 5\% (S5) x álcali ativo

Os resultados da Frgura 18 mostram que o incremento da carga alcalina no processo de polpação proporciona uma redução significativa na solubilidade da polpa em álcali 5\%, indicando uma menor quantidade de hemiceluloses presentes na polpa, o que pode ser atribuído à dissolução dos polímeros de baixo peso molecular e também as reações de degradação (hidrólise).

A Figura 19 apresenta a relação entre a solubilidade da polpa em álcali a 5\% e o rendimento do processo de polpação para os materiais estudados quando submetidos as diferentes cargas de álcali ativo. 


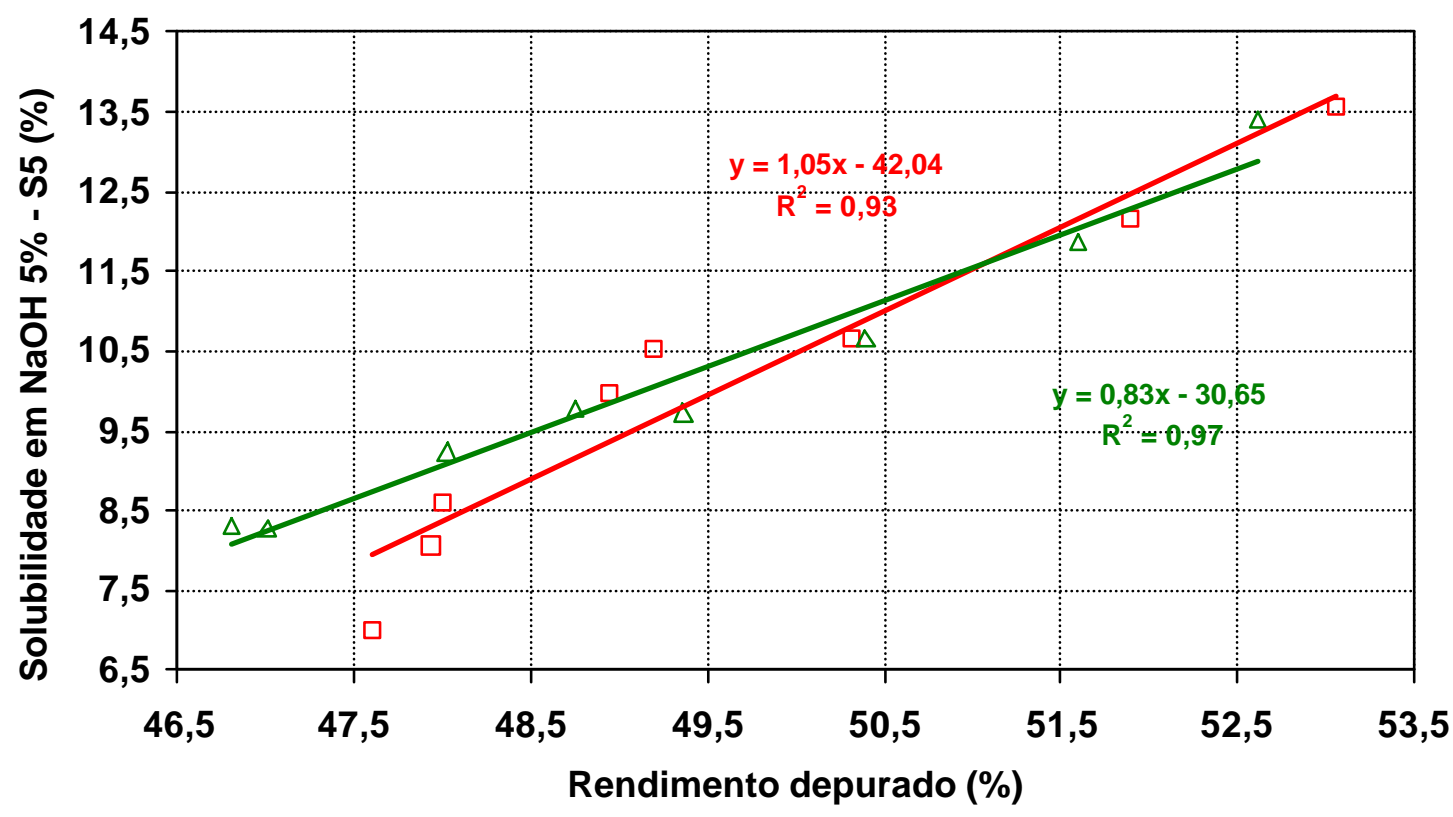

$\square$ E. grandis x E. urophylla P4299

$\triangle E$. grandis $x$ E. urophylla $C 085$

Figura 19 - Solubilidade da polpa em $\mathrm{NaOH}$ 5\% (S5) x rendimento depurado

Nota-se pela Figura 19 a existência de uma correlação entre o teor de hemiceluloses e o rendimento do processo de polpação, indicando que as hemiceluloses da polpa devem ser preservadas, tendo em vista os impactos econômicos ligados ao menor rendimento do processo de polpação. Verifica-se também que os materiais não apresentam diferenças significativas.

A Figura 20 mostra a relação entre a solubilidade da polpa em álcali a 5\% e o número kappa. 


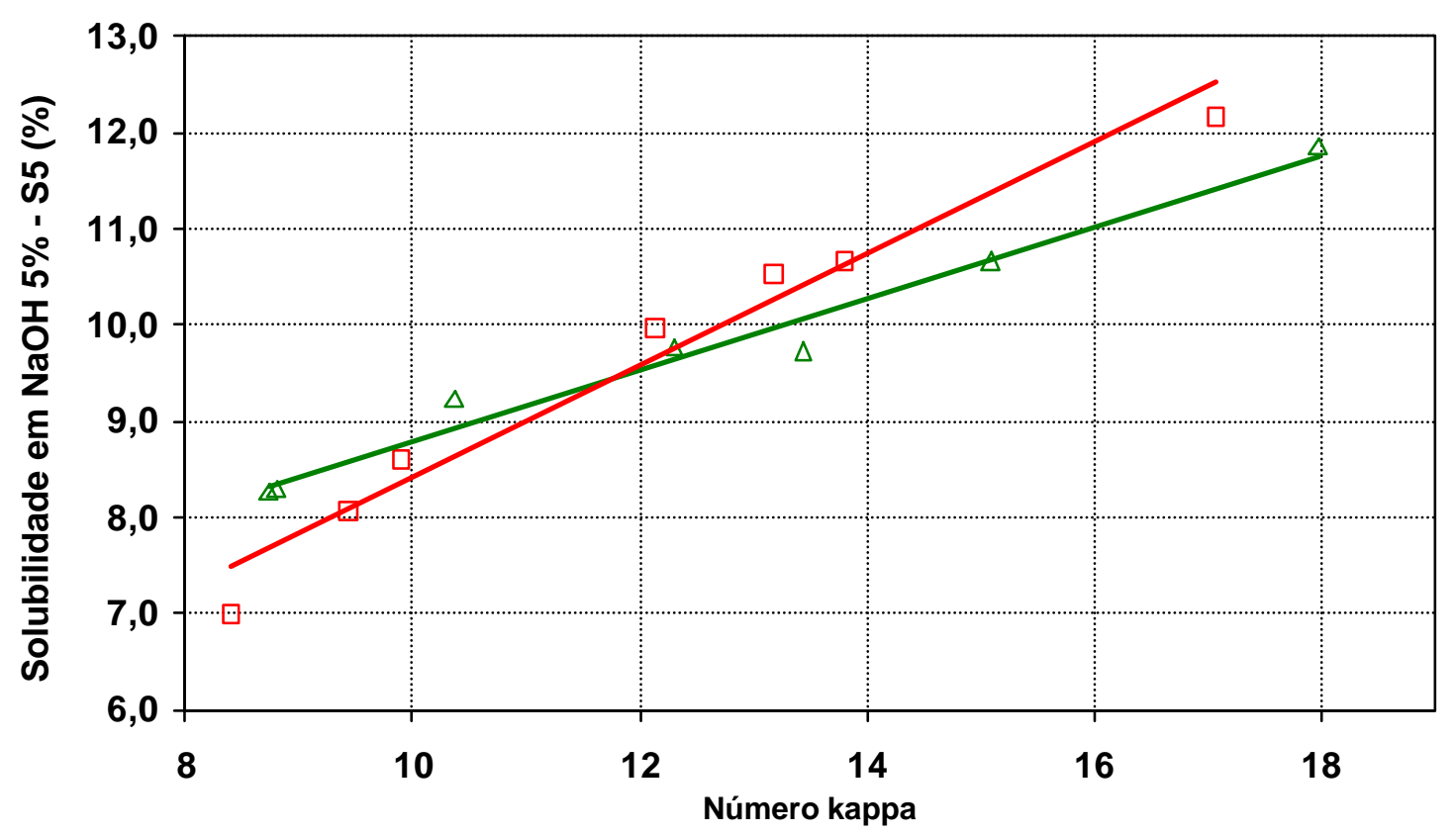

$\square$ E. grandis x E. urophylla P4299

$\triangle E$. grandis $x$ E. urophylla C085

Figura 20 - Solubilidade da polpa em $\mathrm{NaOH}$ 5\% (S5) x número kappa da polpa

Os resultados da Figura 20 indicam que existe uma correlação entre o número kappa e o a solubilidade da polpa em álcali, possivelmente devido à associação da primeira variável com o nível de álcali utilizado no cozimento. Tais resultados indicam que o número kappa pode ser utilizado como parâmetro de controle no processo de polpação quando na produção de polpa destinada a fabricação de papéis para fins sanitários, uma vez que esse tipo de polpa requer menor teor de hemiceluloses que à polpa destinada a produção de papéis imprimir e escrever, conforme descreve Ratnieks \& Foelkel (1996).

A Figura 21 mostra o teor de pentosanas da polpa para os materiais estudados quando submetidos as diferentes cargas de álcali ativo. 


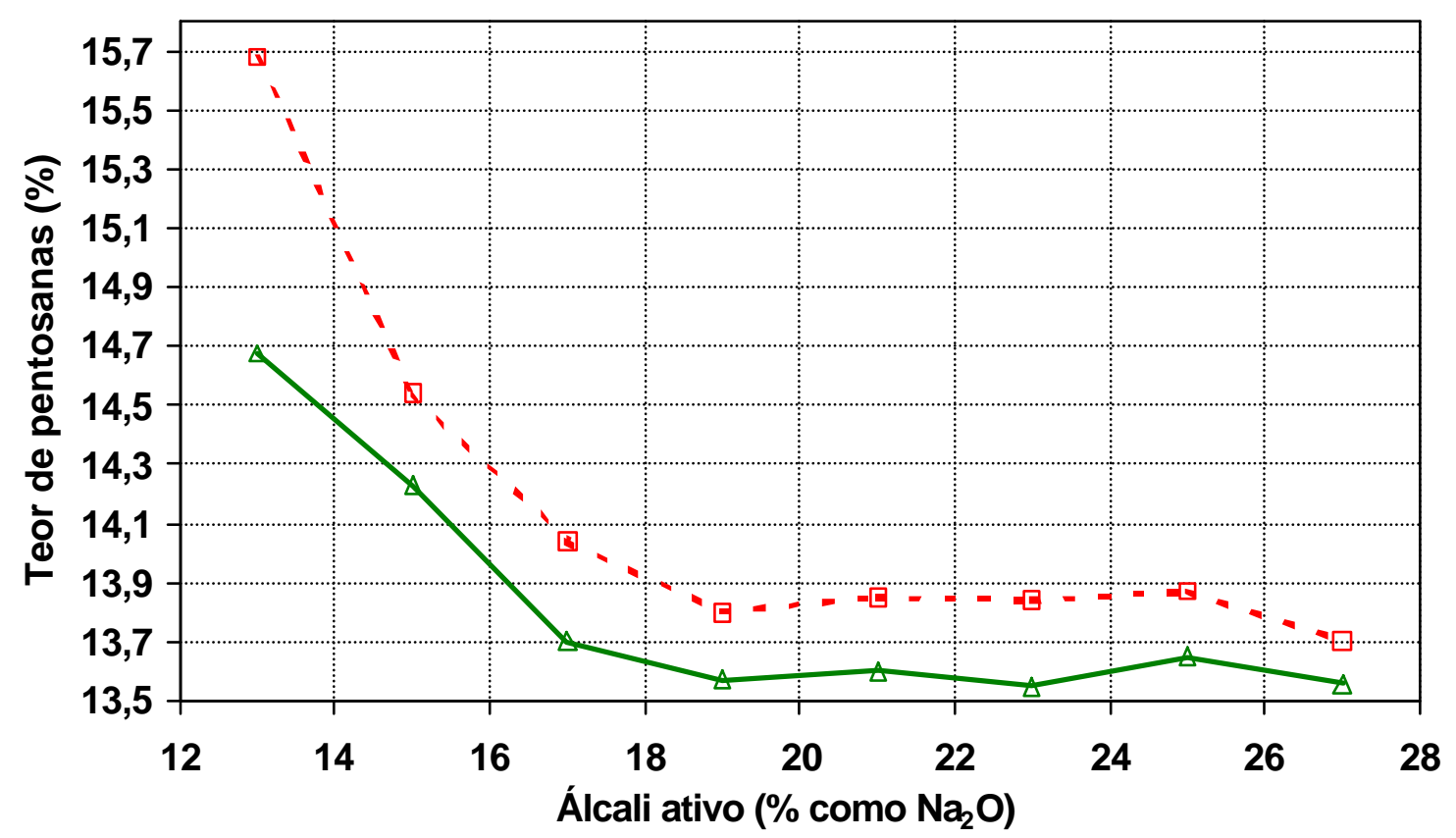

- 'E. grandis x E. urophylla P4299

$\triangle$ E. grandis x E. urophylla C085

Figura 21 - Teor de pentosanas da polpa x álcali ativo

Nota-se pelos resultados da Figura 21 que o material P4299 apresenta valores de pentosanas ligeiramente superiores que o material $\mathrm{C085}$, independente da carga de álcali aplicada. Observa-se que há uma redução no teor de pentosanas da polpa até $17 \%$ de álcali e, ao contrário do que se esperava, para maiores dosagens de álcali os valores permanecem semelhantes.

Figura 22 mostra o percentual de xilanas removido da madeira durante 0 processo de polpação para as diferentes dosagens de álcali ativo. Os resultados obtidos em cromatografia líquidos de alto desempenho (metodologia já descrita) baseiam-se nas seguintes variáveis: quantidade de xilanas presentes inicialmente na madeira, rendimento do processo de polpação e quantidade de xilanas presentes na polpa celulósica após cozimento. 


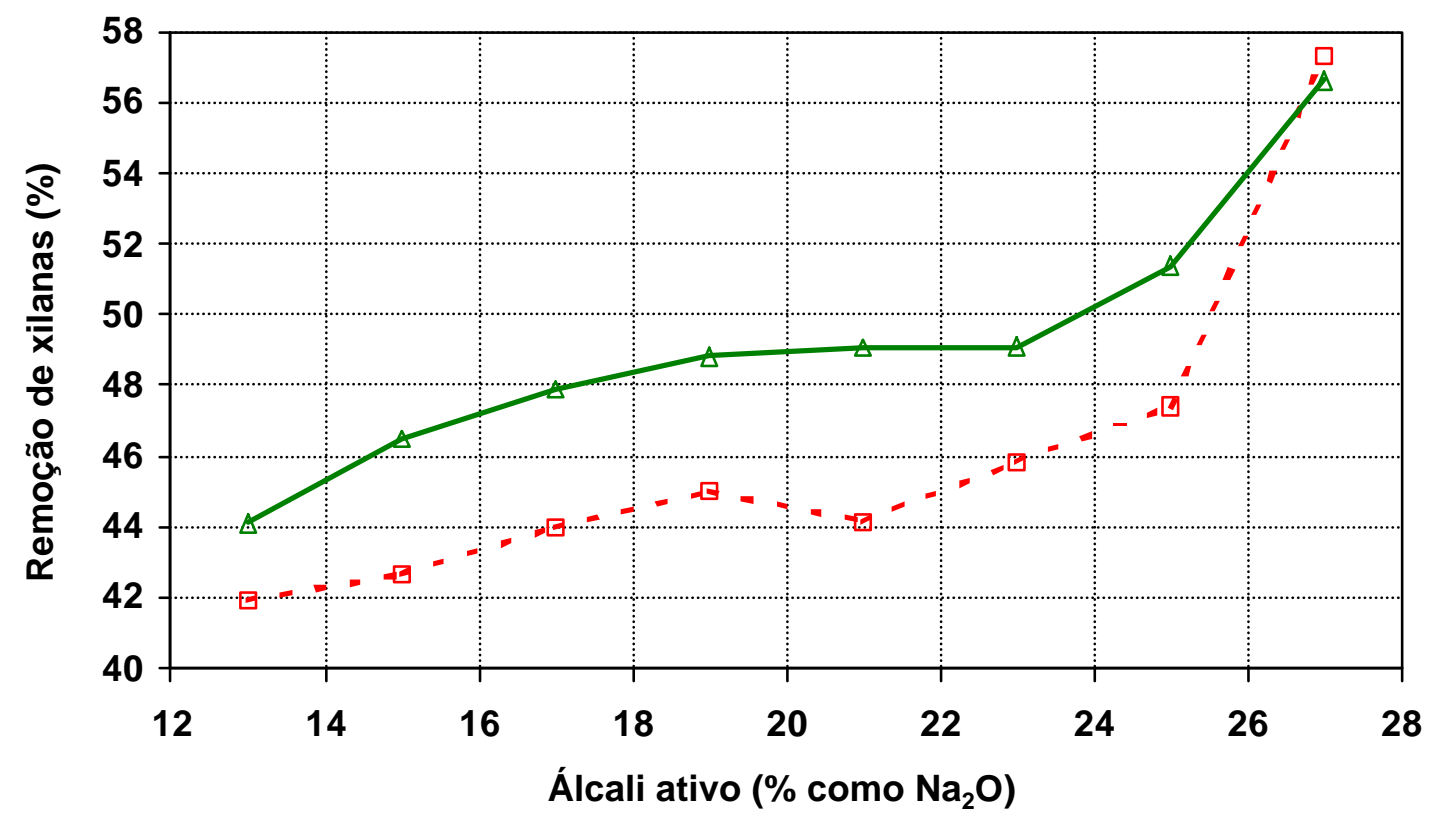

- $\square$ 'E. grandis x E. urophylla P4299 $\triangle$ E. grandis x E. urophylla C085

Figura 22 - Percentual de xilanas removido x álcali ativo

Nota-se pela Figura 22 que para uma carga alcalina aplicada de 15\% álcali ativo e número kappa em torno de 17 , tem-se a remoção de mais de $40 \%$ das xilanas da madeira, evidenciando a maior sensibilidade dos polissacarídeos de baixo peso molecular ao aumento da carga alcalina e justificando o rendimento relativamente baixo do processo de kraft.

A Figura 23 apresenta o percentual de glucanas removido durante o processo de polpação para os materiais estudados. 


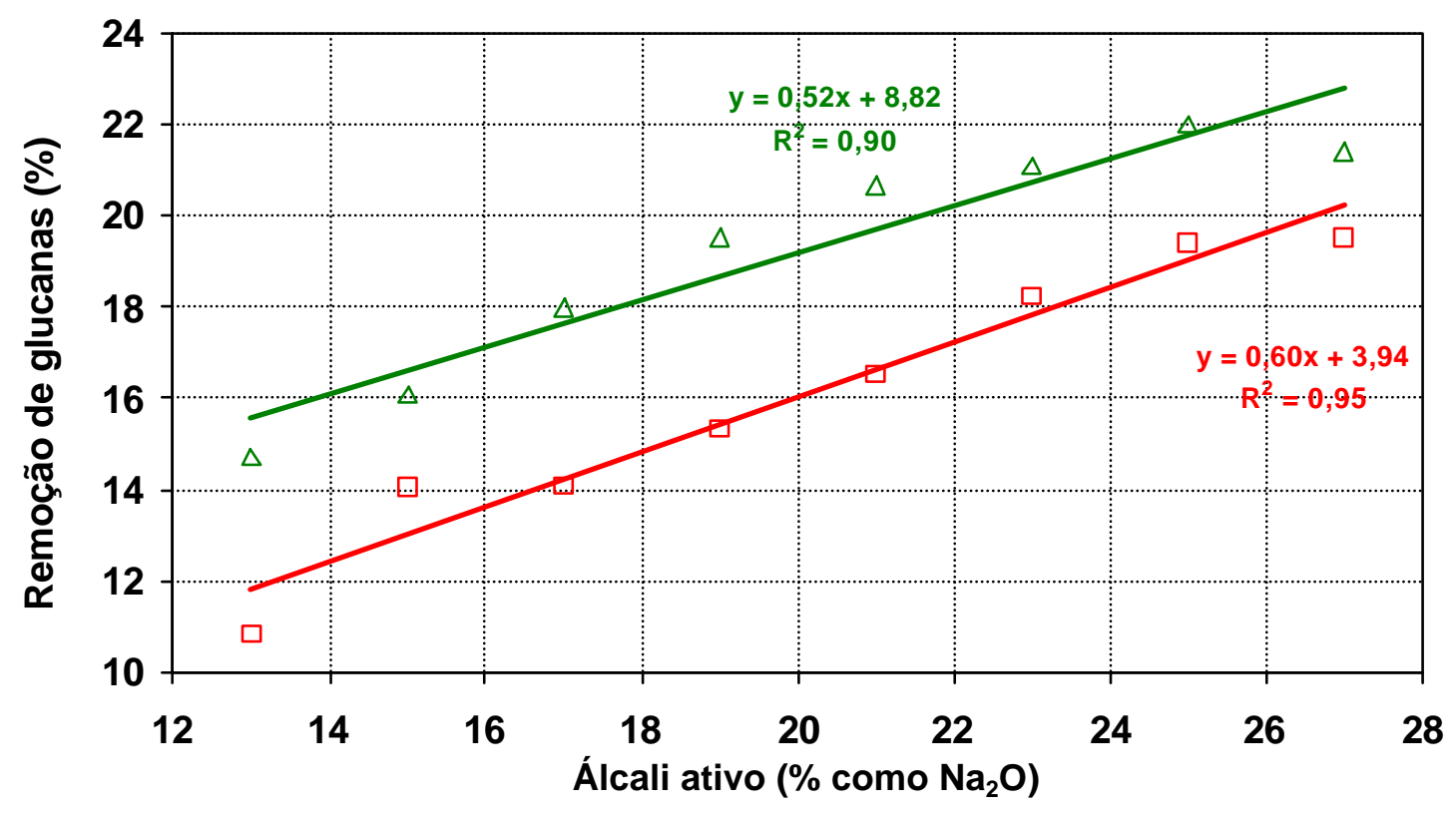

$\square$ E. grandis x E. urophylla P4299

$\triangle$ E. grandis $x$ E. urophylla C085

Figura 23 - Percentual de glucanas removido x álcali ativo

Apesar da glucanas serem menos sensíveis que as xilanas, por serem monômeros constituintes por polissacarídeos de alto peso molecular e com cadeia não ramificada como as hemicelulses, nota-se uma remoção das mesmas da polpa com o aumento da carga alcalina do processo de polpação. Tal comportamento ocorre devido às reações de despolimerização terminal e também hidrólise dos polímeros de celulose, estando esses resultados de acordo com os menores valores de rendimento e também de viscosidade em decorrência do incremento na dosagem de álcali, conforme observado anteriormente.

A Figura 24 apresenta o percentual de grupo glucoronil removido durante 0 processo de polpação para os materiais P4299 e C085. 


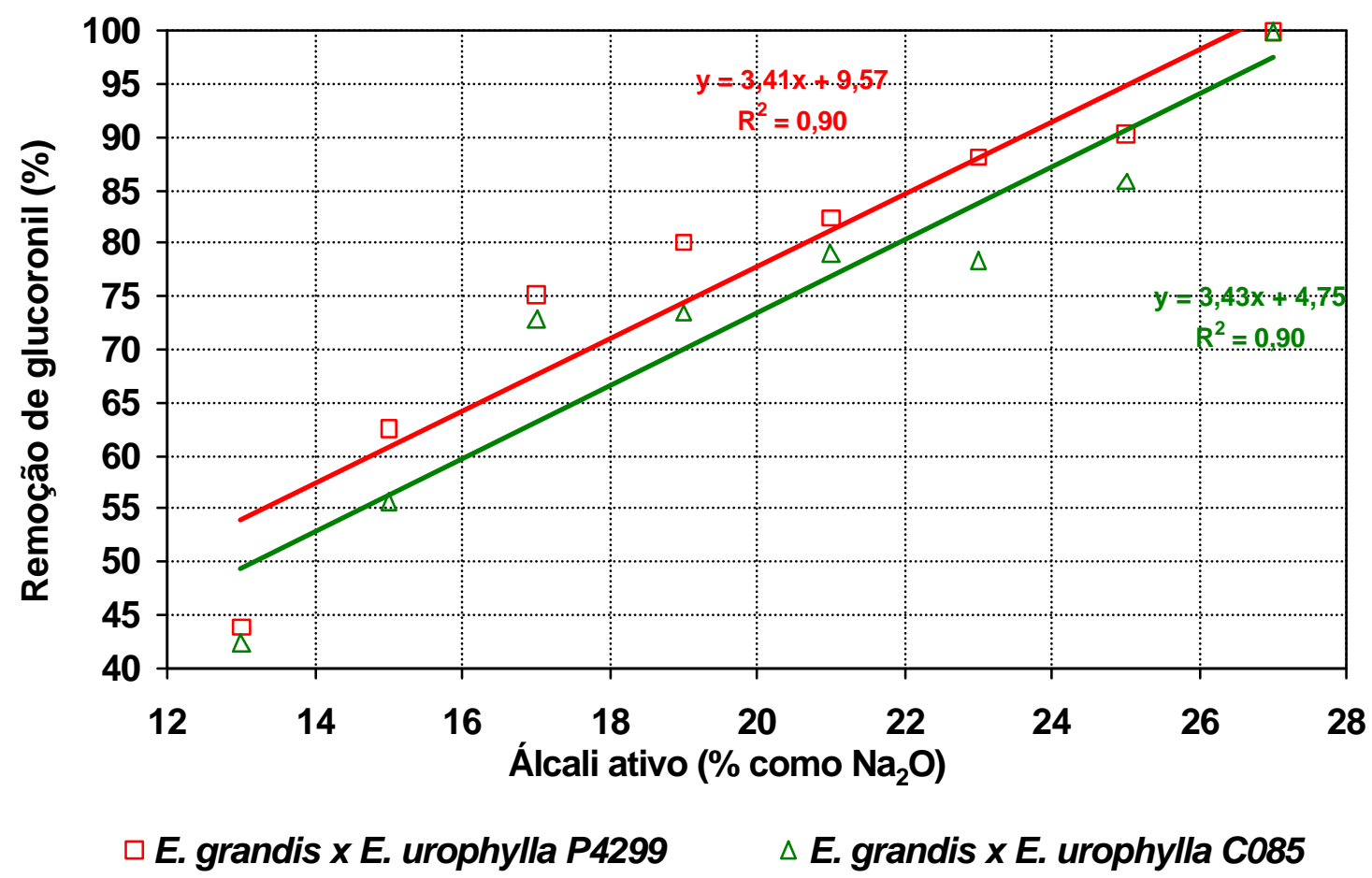

Figura 24 - Percentual de glucoronil removido x álcali ativo

Os resultados da Figura 24 indicam que os grupos glucoronil são também sensíveis à dosagem de álcali, sendo mais de 70\% dos mesmos removidos para uma carga alcalina de $17 \%$ de álcali ativo, o que está possivelmente associado a degradação dos carboidratos.

\subsection{Dimensões das fibras das polpas}

Nos Quadros 5 e 6 são apresentados os resultados médios (3 repetições), desvio padrão e coeficiente de variação das características morfológicas das fibras obtidas nos tratamentos para o híbrido E. grandis x E. urophylla P4299 e C085. 


\begin{tabular}{|c|c|c|c|c|c|c|c|c|}
\hline \multirow{2}{*}{\multicolumn{2}{|c|}{ Parâmetros - \% AA $\left(\mathrm{Na}_{\mathrm{z}} \mathrm{O}\right)$}} & \multicolumn{7}{|c|}{ Híbrido E. grandis x E. urophylla P4299 } \\
\hline & & \multirow{2}{*}{$\begin{array}{c}15 \\
0,82\end{array}$} & \multirow{2}{*}{$\begin{array}{c}\mathbf{1 7} \\
0,77\end{array}$} & \multirow{2}{*}{$\begin{array}{c}19 \\
0,76\end{array}$} & \multirow{2}{*}{$\begin{array}{c}21 \\
0,76\end{array}$} & \multirow{2}{*}{$\begin{array}{c}23 \\
0,74\end{array}$} & \multirow{2}{*}{$\begin{array}{c}25 \\
0,74\end{array}$} & \multirow{2}{*}{$\begin{array}{c}27 \\
0,76\end{array}$} \\
\hline \multirow{3}{*}{$\begin{array}{l}\text { Comprimento de fibra } \\
(\mathrm{mm})\end{array}$} & nédia & & & & & & & \\
\hline & 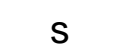 & 0,02 & 0,01 & 0,01 & 0,01 & 0,01 & 0,01 & 0,00 \\
\hline & $\mathrm{cV}$ & 1,87 & 1,51 & 0,76 & 0,76 & 0,78 & 1,35 & 0,00 \\
\hline \multirow{3}{*}{$\begin{array}{l}\text { Largura de fibra } \\
\qquad(\mu \mathrm{m})\end{array}$} & média & 15,27 & 14,93 & 14,57 & 13,90 & 14,27 & 14,07 & 13,53 \\
\hline & $\mathrm{s}$ & 0,25 & 0,23 & 0,15 & 0,26 & 0,12 & 0,06 & 0,40 \\
\hline & 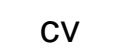 & 1,65 & 1,55 & 1,05 & 1,90 & 0,81 & 0,41 & 2,99 \\
\hline \multirow{3}{*}{$\begin{array}{l}\text { Espessura de parede } \\
\qquad(\mu \mathrm{m})\end{array}$} & ia & 4,80 & 4,67 & 4,59 & 4,33 & 4,27 & 4,27 & 4,00 \\
\hline & 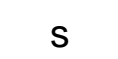 & 0,10 & 0,06 & 0,02 & 0,06 & 0,25 & 0,12 & 0,20 \\
\hline & cV & 2,08 & 1,24 & 0,33 & 1,49 & 5,90 & 2,71 & 5,00 \\
\hline \multirow{3}{*}{$\begin{array}{l}\text { Diâmetro de lume } \\
(\mu \mathrm{m})\end{array}$} & nédia & 5,47 & 5,40 & 5,45 & 5,37 & 5,43 & 5,40 & 5,53 \\
\hline & 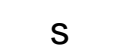 & 0,12 & 0,00 & 0,07 & 0,06 & 0,06 & 0,17 & 0,06 \\
\hline & $\mathrm{cV}$ & 2,11 & 0,00 & 1,29 & 1,08 & 1,06 & 3,21 & 1,04 \\
\hline \multirow{3}{*}{$\begin{array}{c}\text { Fração parede } \\
(\%)\end{array}$} & nédia & 63 & 63 & 63 & 62 & 60 & 61 & 59 \\
\hline & $S$ & 0,30 & 1,66 & 0,74 & 0,70 & 3,17 & 1,49 & 1,20 \\
\hline & $\mathrm{cV}$ & 0,48 & 2,65 & 1,17 & 1,13 & 5,29 & 2,45 & 2,03 \\
\hline \multirow{3}{*}{$\begin{array}{c}\text { Coarseness } \\
(\mathrm{mg} / 100 \mathrm{~m})\end{array}$} & média & 0,079 & 0,078 & 0,074 & 0,073 & 0,074 & 0,072 & 0,067 \\
\hline & $\mathrm{s}$ & 0,00 & 0,00 & 0,00 & 0,00 & 0,00 & 0,00 & 0,00 \\
\hline & $\mathrm{cV}$ & 0,73 & 0,74 & 1,55 & 1,57 & 1,57 & 0,80 & 1,49 \\
\hline \multirow{3}{*}{$\begin{array}{l}\text { Fibras por grama } \\
\qquad\left(n^{\circ} \times 10^{6}\right)\end{array}$} & média & 18,82 & 20,89 & 21,94 & 22,73 & 23,01 & 23,31 & 24,61 \\
\hline & $\mathrm{s}$ & 0,40 & 0,48 & 0,14 & 0,36 & 0,19 & 0,57 & 0,20 \\
\hline & $\mathrm{CV}$ & 2,14 & 2,32 & 0,62 & 1,59 & 0,85 & 2,47 & 0,83 \\
\hline \multirow{3}{*}{$\begin{array}{c}\text { Teor de finos } \\
(\%)\end{array}$} & média & 3,43 & 3,73 & 3,87 & 4,20 & 4,73 & 4,87 & 5,23 \\
\hline & $\mathrm{s}$ & 0,12 & 0,06 & 0,12 & 0,20 & 0,06 & 0,12 & 0,31 \\
\hline & $\mathrm{CV}$ & 3,36 & 1,55 & 2,99 & 4,76 & 1,22 & 2,37 & 5,84 \\
\hline
\end{tabular}

Quadro 5 - Dimensões de fibras da polpa celulósica não branqueada para E. grandisx E. urophylla P4299

$\mathrm{S}=$ desvio padrão; $\mathrm{cv}$ = coeficiente de variação 


\begin{tabular}{|c|c|c|c|c|c|c|c|c|}
\hline \multirow{2}{*}{\multicolumn{2}{|c|}{$\begin{array}{c}\text { Parâmetros - } \% \mathrm{AA} \\
\left(\mathrm{Na}_{2} \mathrm{O}\right)\end{array}$}} & \multicolumn{7}{|c|}{ Híbrido E. grandis x E. urophylla C085 } \\
\hline & & 15 & 17 & 19 & 21 & 23 & 25 & 27 \\
\hline \multirow{3}{*}{$\begin{array}{l}\text { Comprimento de } \\
\text { fibra }(\mathrm{mm})\end{array}$} & média & 0,88 & 0,85 & 0,83 & 0,82 & 0,82 & 0,82 & 0,82 \\
\hline & $\mathrm{s}$ & 0,01 & 0,01 & 0,01 & 0,00 & 0,01 & 0,01 & 0,01 \\
\hline & $\mathrm{cv}$ & 0,65 & 0,68 & 0,70 & 0,00 & 1,22 & 1,22 & 0,71 \\
\hline \multirow{3}{*}{$\begin{array}{l}\text { Largura de fibra } \\
\qquad(\mu \mathrm{m})\end{array}$} & média & 14,90 & 14,23 & 14,07 & 14,10 & 13,80 & 13,53 & 13,13 \\
\hline & $\mathrm{s}$ & 0,30 & 0,35 & 0,51 & 0,72 & 0,36 & 0,12 & 0,06 \\
\hline & $\mathrm{cv}$ & 2,01 & 2,47 & 3,65 & 5,11 & 2,61 & 0,85 & 0,44 \\
\hline \multirow{3}{*}{$\begin{array}{l}\text { Espessura de } \\
\text { parede }(\mu \mathrm{m})\end{array}$} & média & 5,00 & 4,77 & 4,63 & 4,47 & 4,43 & 4,40 & 4,20 \\
\hline & $\mathrm{s}$ & 0,26 & 0,15 & 0,06 & 0,12 & 0,13 & 0,20 & 0,20 \\
\hline & $\mathrm{cv}$ & 5,29 & 3,20 & 1,31 & 2,59 & 2,87 & 4,55 & 4,76 \\
\hline \multirow{3}{*}{$\begin{array}{c}\text { Diâmetro de lume } \\
(\mu \mathrm{m})\end{array}$} & média & 4,90 & 4,97 & 5,00 & 4,87 & 5,00 & 4,85 & 4,92 \\
\hline & $\mathrm{s}$ & 0,10 & 0,16 & 0,30 & 0,23 & 0,10 & 0,08 & 0,16 \\
\hline & $\mathrm{cV}$ & 2,04 & 3,25 & 6,00 & 4,75 & 2,00 & 1,67 & 3,23 \\
\hline \multirow{3}{*}{$\begin{array}{c}\text { Fração parede } \\
(\%)\end{array}$} & média & 67 & 67 & 66 & 63 & 64 & 65 & 64 \\
\hline & $s$ & 2,19 & 2,21 & 2,19 & 0,69 & 0,60 & 0,55 & 3,09 \\
\hline & $c v$ & 3,27 & 3,29 & 3,32 & 1,09 & 0,94 & 0,84 & 4,83 \\
\hline \multirow{3}{*}{$\begin{array}{l}\text { Coarseness } \\
(\mathrm{mg} / 100 \mathrm{~m})\end{array}$} & média & 0,087 & 0,083 & 0,080 & 0,079 & 0,079 & 0,076 & 0,069 \\
\hline & $\mathrm{s}$ & 0,00 & 0,00 & 0,00 & 0,00 & 0,00 & 0,00 & 0,00 \\
\hline & $c v$ & 1,32 & 1,20 & 1,44 & 0,73 & 0,00 & 1,53 & 0,84 \\
\hline \multirow{3}{*}{$\begin{array}{l}\text { Fibras por grama } \\
\left(\mathrm{n}^{\circ} \times 10^{6}\right)\end{array}$} & média & 15,83 & 17,55 & 18,22 & 18,98 & 19,33 & 19,93 & 21,42 \\
\hline & $s$ & 0,29 & 0,35 & 0,11 & 0,18 & 0,17 & 0,26 & 0,18 \\
\hline & $\mathrm{cV}$ & 1,86 & 1,99 & 0,60 & 0,94 & 0,86 & 1,32 & 0,84 \\
\hline \multirow{3}{*}{$\begin{array}{l}\text { Teor de finos } \\
(\%)\end{array}$} & média & 3,20 & 3,80 & 4,07 & 4,10 & 4,25 & 4,63 & 5,20 \\
\hline & $\mathrm{s}$ & 0,26 & 0,20 & 0,15 & 0,15 & 0,21 & 0,17 & 0,26 \\
\hline & $\mathrm{cV}$ & 8,27 & 5,26 & 3,75 & 3,73 & 4,90 & 3,74 & 5,09 \\
\hline
\end{tabular}

Quadro 6 - Dimensões de fibras da polpa celulósica não branqueada para E. grandisx E. urophylla C085

$\mathrm{S}=$ desvio padrão c $\mathrm{c}$ = coeficiente de variação

As análises de dimensões das fibras da polpa não-branqueada foram obtidas empregando-se o equipamento Kajaan. Não foram realizadas análises nos tratamentos com $13 \%$ de álcali ativo, uma vez que essa carga de álcali foi insuficiente para efetuar por completo o processo de deslignificação, ou seja, materiais não completamente cozidos foram verificados, mesmo após o processo de depuração.

A Tabela 16 apresenta a análise de variância e teste $F$ para o parâmetro comprimento de fibra em função da carga alcalina aplicada para os materiais estudados, bem como suas interações. 
Tabela 16. Análise de variância e teste $\mathrm{F}$ para comprimento médio ponderado de fibra (base comprimento)

\begin{tabular}{lrrrrr}
\hline & GL & SQ & QM & \multicolumn{1}{c}{ F } & Prob>F \\
\hline Dosagem de Álcali & 6 & 0,0234 & 0,0039 & 32,83 & 0,0002 \\
Material & 1 & 0,0572 & 0,0572 & 480,50 & 0,0001 \\
Dosagem de Álcali X Material & 6 & 0,0007 & 0,0001 & 1,92 & 0,1119 \\
Resíduo & 28 & 0,0002 & 0,0001 & & \\
\hline Total & 41 & 0,0831 & & & \\
\hline
\end{tabular}

$\mathrm{GL}=$ grau de liberdade $\mathrm{SQ}=$ soma de quadrados $\mathrm{QM}=$ quadrado médio Prob = probabilidade

Os resultados da Tabela 16 mostram que o fator dosagem de álcali apresenta efeito significativo sobre o comprimento de fibra. Nota-se também pela análise de variância que há efeito significativo dos materiais sobre o comprimento de fibra, o que pode estar associado a densidade básica dos materiais. Observa-se também que não há efeito significativo da interação entre os fatores dosagem de álcali e material, ou seja, o padrão de variação para os materiais é semelhante.

Conforme já mencionado, a flexibilidade das fibras influência praticamente todas as propriedades do papel e, embora o comprimento de fibra não seja a única variável que afeta a flexibilidade da fibra, a maioria dos autores concorda que fibras mais longas são menos flexíveis. Já quanto ao efeito do comprimento de fibra sobre a resistência ao rasgo os pesquisadores descrevem que, quanto maior comprimento de fibra maior será a resistência do papel ao rasgo.

A Figura 25 apresenta o comprimento médio ponderado de fibras da polpa não branqueada para os materiais P4299 e C085. 


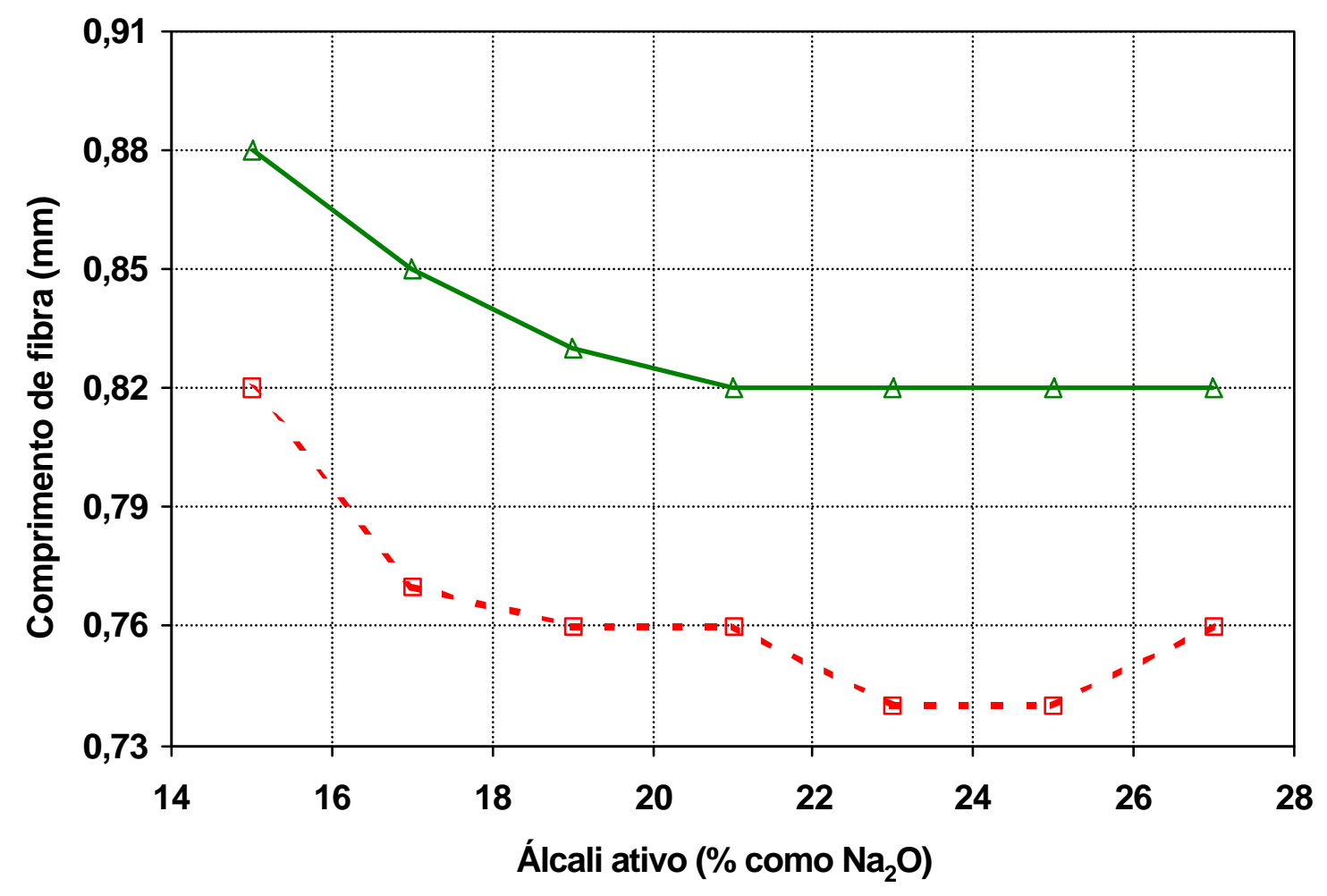

- $\square$. E. grandis x E. urophylla P4299 $\triangle$ E. grandis x E. urophylla C085

Figura 25 - Comprimento médio ponderado de fibras (base comprimento) x álcali ativo

Os resultados da Figura 25 mostram que o híbrido C085 apresenta maior comprimento médio de fibras quando comparado ao híbrido P4299. Esses resultados estão de acordo com os observados por Foelkel et al. (1992), quando o autor verificou que madeiras mais densas apresentam também maior comprimento médio de fibra, devido à maturidade das células da região do câmbio. Já Carpim et al. (1987) descreve que a densidade básica da madeira exerce pouca influência sobre o comprimento de fibras.

Embora Silva Júnior \& Mcdonough (2001) descrevam que não é de se esperar um efeito negativo do álcali sobre ao comprimento de fibra, notas-se que o aumento carga proporcionou produziu polpas com menor comprimento médio de fibras para os materiais estudados. Vale ressaltar que, os estudos explorando um nível de deslignificação tão elevado como no presente trabalho são raros. 
O menor comprimento de fibra observado com o incremento da carga alcalina aplicada pode ter ocorrido devido a fragmentação das células, o que estaria de acordo com os teores finos encontrados na polpa, conforme mostra a figura 26.

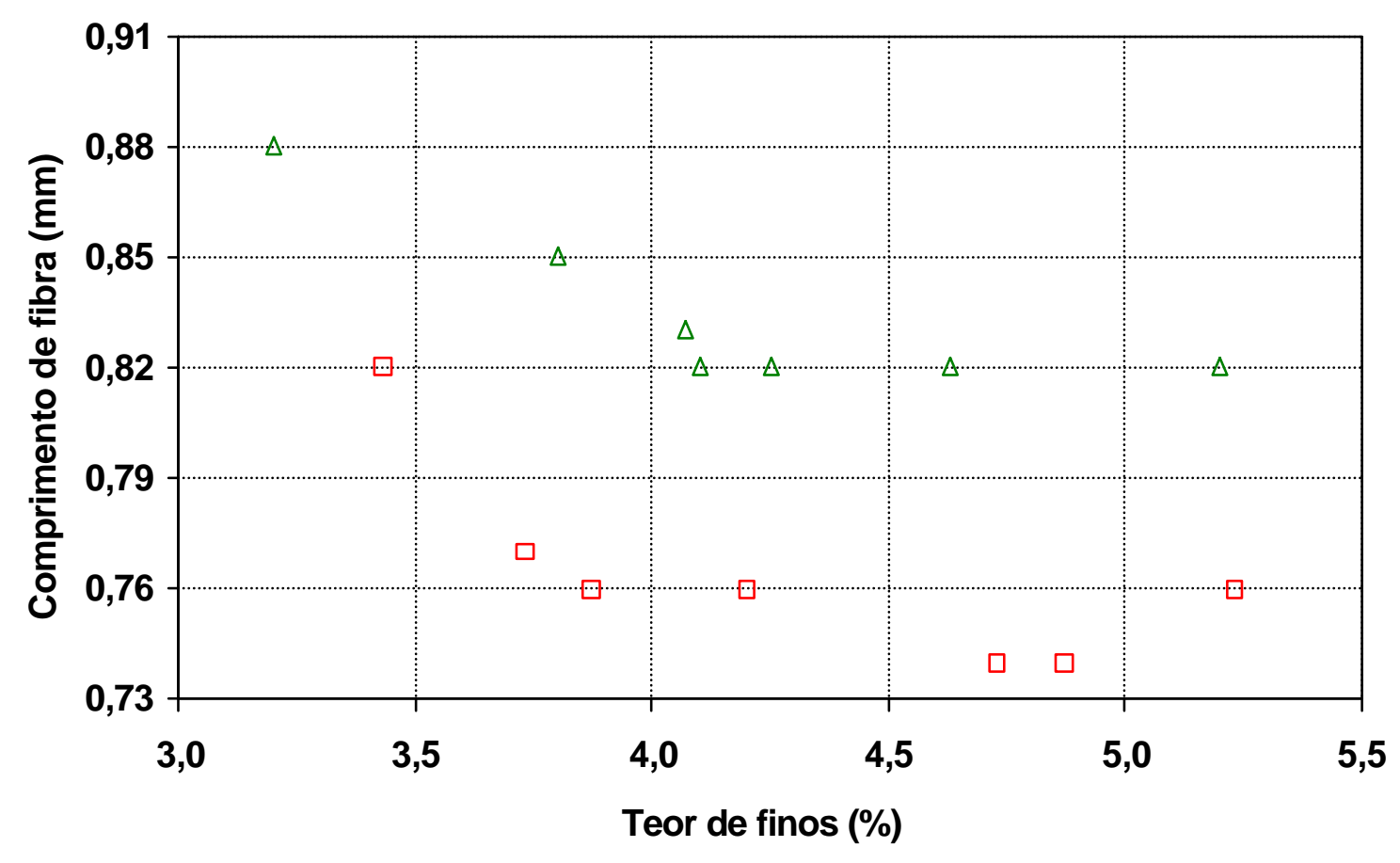

$\square$ E. grandis x E. urophylla P4299

$\triangle$ E. grandis x E. urophylla C085

Figura 26 - Comprimento médio ponderado de fibras (base comprimento) x teor de finos da polpa

Acredita-se que a carga alcalina, quando em excesso, pode atingir regiões susceptíveis das fibras e promover a fragmentação das mesmas, proporcionando alterações nas dimensões de fibras e gerando maior teor de finos.

A Tabela 17 apresenta a análise de variância e teste $\mathrm{F}$ para o teor de finos da polpa em função da carga alcalina aplicada para os materiais estudados, bem como suas interações. 
Tabela 17. Análise de variância e teste F para o parâmetro teor de finos

\begin{tabular}{lrrrrr}
\hline & GL & SQ & QM & F & Prob>F \\
\hline Dosagem de Álcali & 7 & 12,37 & 2,06 & 7,47 & 0,0137 \\
Material & 1 & 0,33 & 0,33 & 1,18 & 0,3188 \\
Dosagem de Álcali X Material & 7 & 1,65 & 0,28 & 8,05 & 0,0001 \\
Resíduo & 32 & 0,96 & 0,03 & & \\
\hline Total & 47 & 15,31 & & & \\
\hline
\end{tabular}

$\mathrm{GL}=$ grau de liberdade $\mathrm{SQ}=$ soma de quadrados $\mathrm{QM}=$ quadrado médio $\mathrm{Prob}=$ probabilidade

Os resultados da Tabela 17 mostram que a dosagem de álcali apresenta efeito significativo sobre o teor de finos da polpa, o que indica fragmentação da fibras. Notase também que não há efeito significativo dos materiais sobre esse parâmetro, mas se observa que há efeito significativo da interação entre os fatores dosagem de álcali e material.

$\mathrm{Na}$ Figura 27 encontram-se os valores de finos encontrados nas polpas celulósicas obtidas nos tratamentos realizados para os materiais estudados.

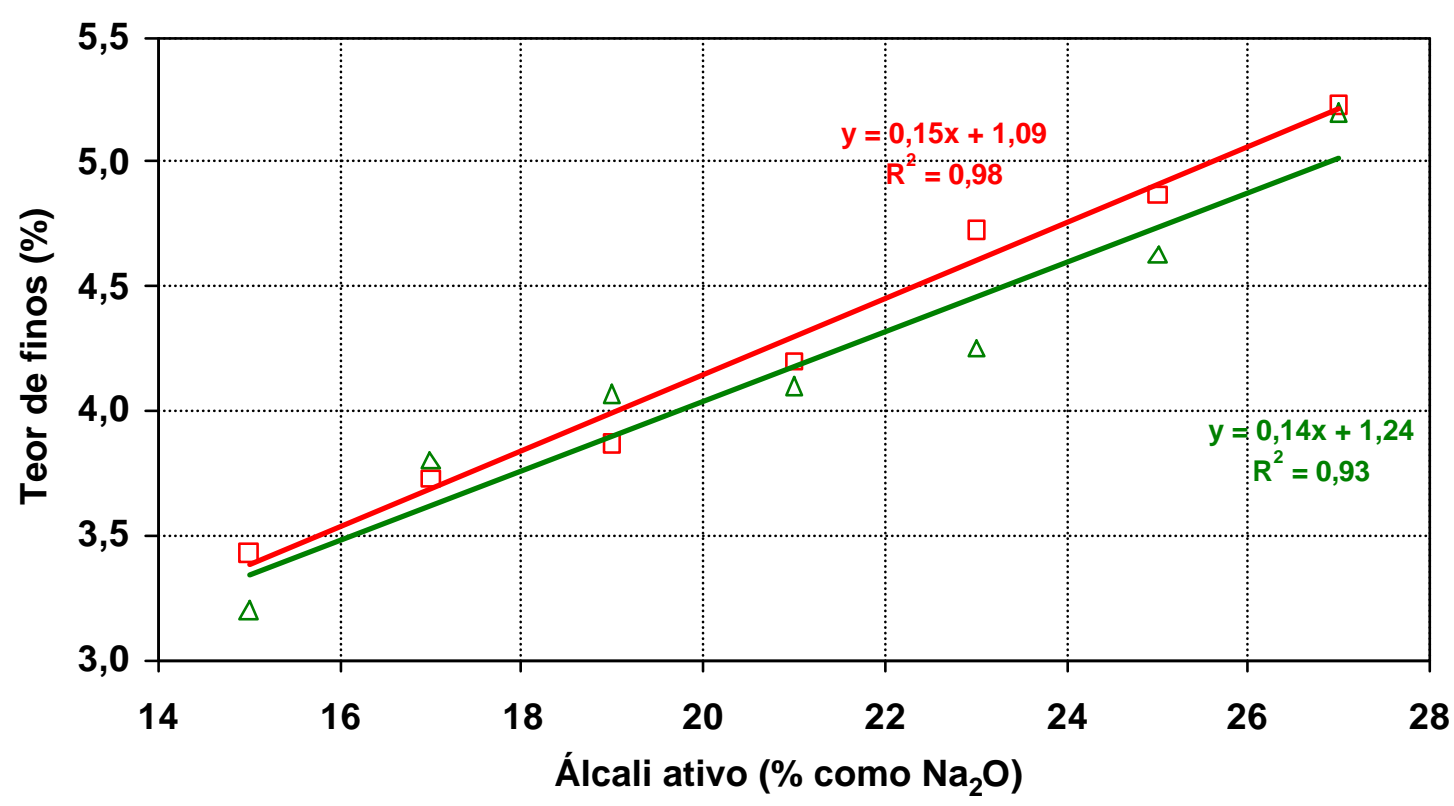

$\square$ E. grandis $x$ E. urophylla P4299

$\triangle E$. grandis $x$ E. urophylla C085

Figura 27 - Teor de finos da polpa x álcali ativo 
A Figura 27 mostra para os dois materiais estudados um incremento no teor de finos gerados à medida que se aumenta carga alcalina aplicada. Os resultados podem estar relacionados às alterações nas dimensões das fibras, conforme discutido anteriormente.

A Tabela 18 apresenta a análise de variância e teste $F$ para largura de fibra em função da carga alcalina aplicada para os materiais avaliados, bem como suas interações.

Tabela 18. Análise de variância e teste $F$ para o parâmetro largura de fibra

\begin{tabular}{lrrrrr}
\hline & GL & SQ & QM & \multicolumn{1}{l}{ F } & \multicolumn{1}{c}{ Prob>F } \\
\hline Dosagem de Álcali & 7 & 11,46 & 1,91 & 15,82 & 0,0019 \\
Material & 1 & 1,64 & 1,64 & 13,58 & 0,0100 \\
Dosagem de Álcali X Material & 7 & 0,72 & 0,12 & 1,10 & 0,3854 \\
Resíduo & 32 & 3,07 & 0,11 & & \\
\hline Total & 47 & 16,90 & & & \\
\hline
\end{tabular}

$\mathrm{GL}=$ grau de liberdade $\mathrm{SQ}=$ soma de quadrados $\mathrm{QM}=$ quadrado médio Prob = probabilidade

Os resultados da Tabela 18 mostram que a dosagem de álcali apresenta efeito significativo sobre largura de fibra, o que pode estar associado a ocorrência de erosões na parede da fibra. Nota-se também que há efeito significativo dos materiais sobre esse parâmetro, podendo este último parâmetro estar relacionado com a densidade básica dos materiais.

Na Figura 28 são apresentados os resultados de largura de fibra para as polpas obtidas quando submetidas as diferentes dosagens de álcali ativo. 


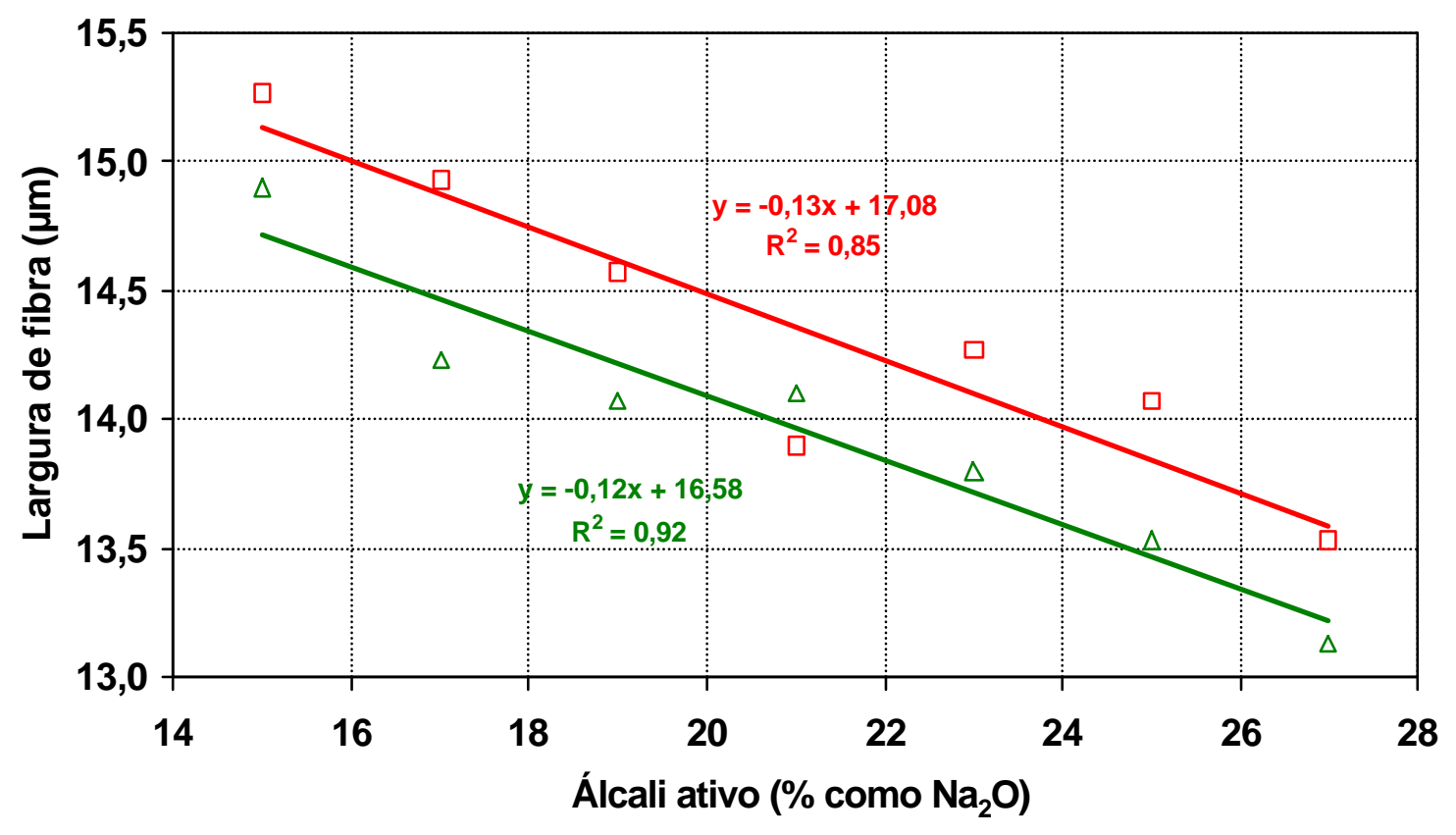

$\square$ E. grandis $x$ E. urophylla $P 4299$

$\triangle E$. grandis x E. urophylla C085

Figura 28 - Largura de fibra x álcali ativo

Nota-se pela Figura 28 menor largura da fibra para os dois materiais estudados quando submetidos as diferentes cargas de álcali ativo. Os resultados estão também consoantes com os obtidos para a espessura de parede, ou seja, a redução da largura de fibra em função da carga alcalina dá-se devido à própria redução da espessura de parede.

Verificase também que o material P4299 apresenta largura de fibras um pouco superior ao material C085, o que pode também estar associado ao menor valor de densidade básica dos materiais.

A espessa da parede da fibra é um parâmetro de dimensão também importante. Fibras mais espessas quando submetidas a um mesmo nível de refino apresentam maior resistência à ação de forças de consolidação durante a formação da folha de papel, resultando em papel com menor resistência, com estrutura mais aberta, com maior volume específico ("bulk") e porosidade. Madeiras mais densas apresentam também fibras menos flexíveis, em conseqüência da maior espessura de parede, o que diminui o por de ligação entre as fibras. 
A Tabela 19 apresenta a análise de variância e teste $F$ para espessura de parede da fibra em função da carga alcalina aplicada para os materiais avaliados, bem como suas interações.

Tabela 19. Análise de variância e teste $\mathrm{F}$ para espessura de parede

\begin{tabular}{lrrrrr}
\hline & GL & SQ & QM & \multicolumn{1}{c}{$F$} & Prob>F \\
\hline Dosagem de Álcali & 6 & 2,641 & 0,440 & 88,43 & 0,0001 \\
Material & 1 & 0,202 & 0,202 & 40,51 & 0,0007 \\
Dosagem de Álcali X Material & 6 & 0,030 & 0,005 & 0,20 & 0,9725 \\
Resíduo & 28 & 0,682 & 0,024 & & \\
\hline Total & 41 & 3,554 & & & \\
\hline
\end{tabular}

$\mathrm{GL}=$ grau de liberdade $\mathrm{SQ}=$ soma de quadrados $\mathrm{QM}=$ quadrado médio Prob = probabilidade

Os resultados da Tabela 19 indicam que a dosagem de álcali apresenta efeito significativo sobre espessura de parede da fibra. Apesar da análise estatística mostrar que há efeito significativo dos materiais sobre a espessura de parede da fibra, os resultados da Figura 29 não mostram diferenças expressivas entre os materiais. Verifica-se que não há efeito significativo da interação entre os fatores dosagem de álcali e material, ou seja, os materiais apresentam uma variação semelhante quando submetidos ao tratamento.

A Figura 29 apresenta os valores de espessura de parede da fibra obtidos para os híbridos de E. grandis $\times$ E. urophylla estudados quando submetidos aos diferentes tratamentos. 


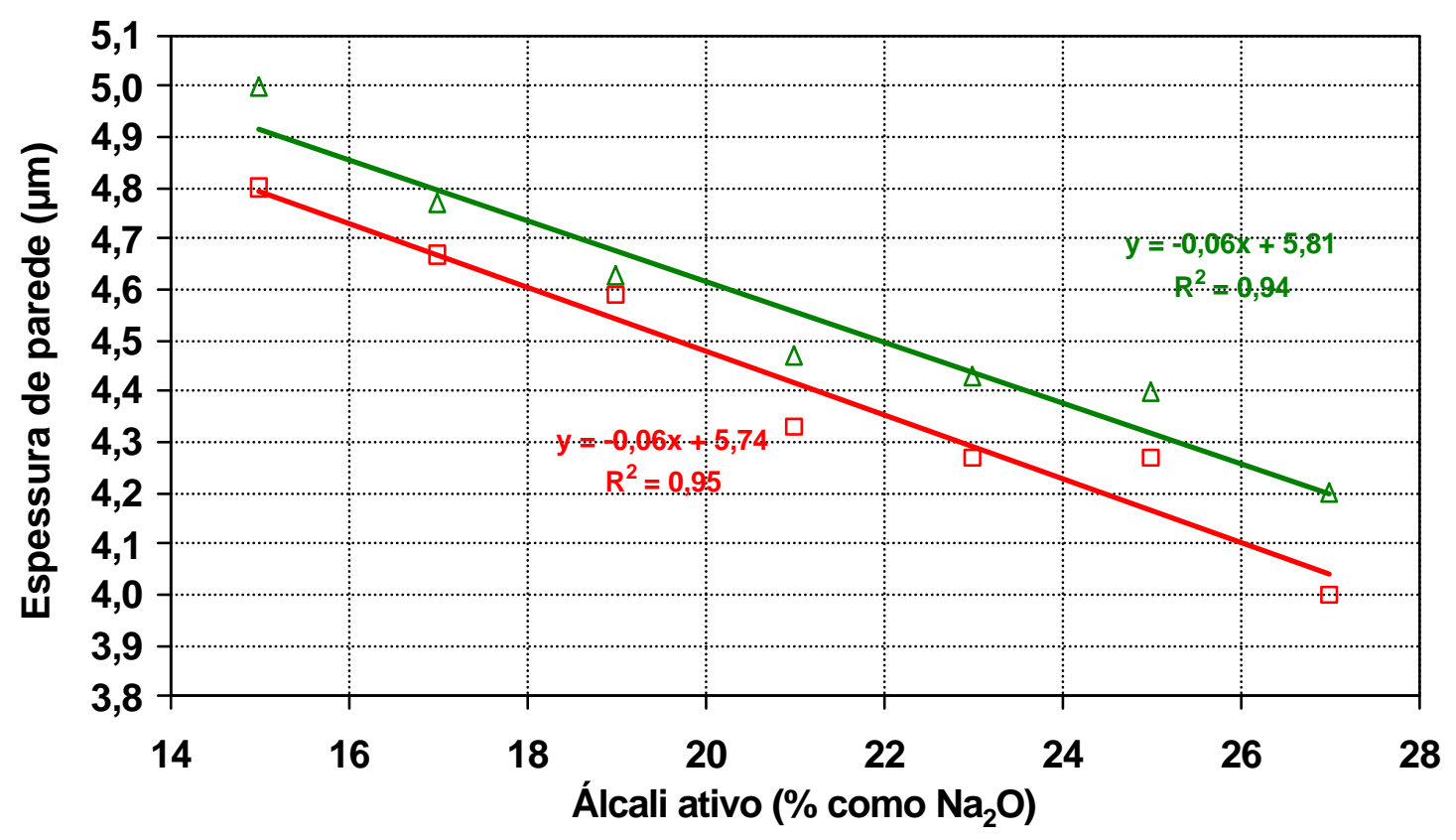

$\square$ E. grandis x E. urophylla P4299

$\triangle$ E. grandis $x$ E. urophylla C085

Figura 29 - Espessura de parede da fibra x álcali ativo

A análise estatística mostrou efeito significativo dos materiais sobre a espessura de parede da fibra para a polpa não branqueada, sendo os valores obtidos para o híbrido C085 um pouco superior ao P4299. De certa forma os resultados estão de acordo com a correlação existente entre densidade básica e a espessura de parede, conforme descreve Demuner eat al. (1991).

Os resultados obtidos mostram menor espessura de parede da fibra com 0 aumento da carga alcalina aplicada para os materiais avaliados, o que pode estar associados à remoção de constituintes da parede das células.

A Figura 30 mostra o diâmetro do lume da fibra das polpas obtidas nos tratamentos realizados para os dois materiais avaliados. 


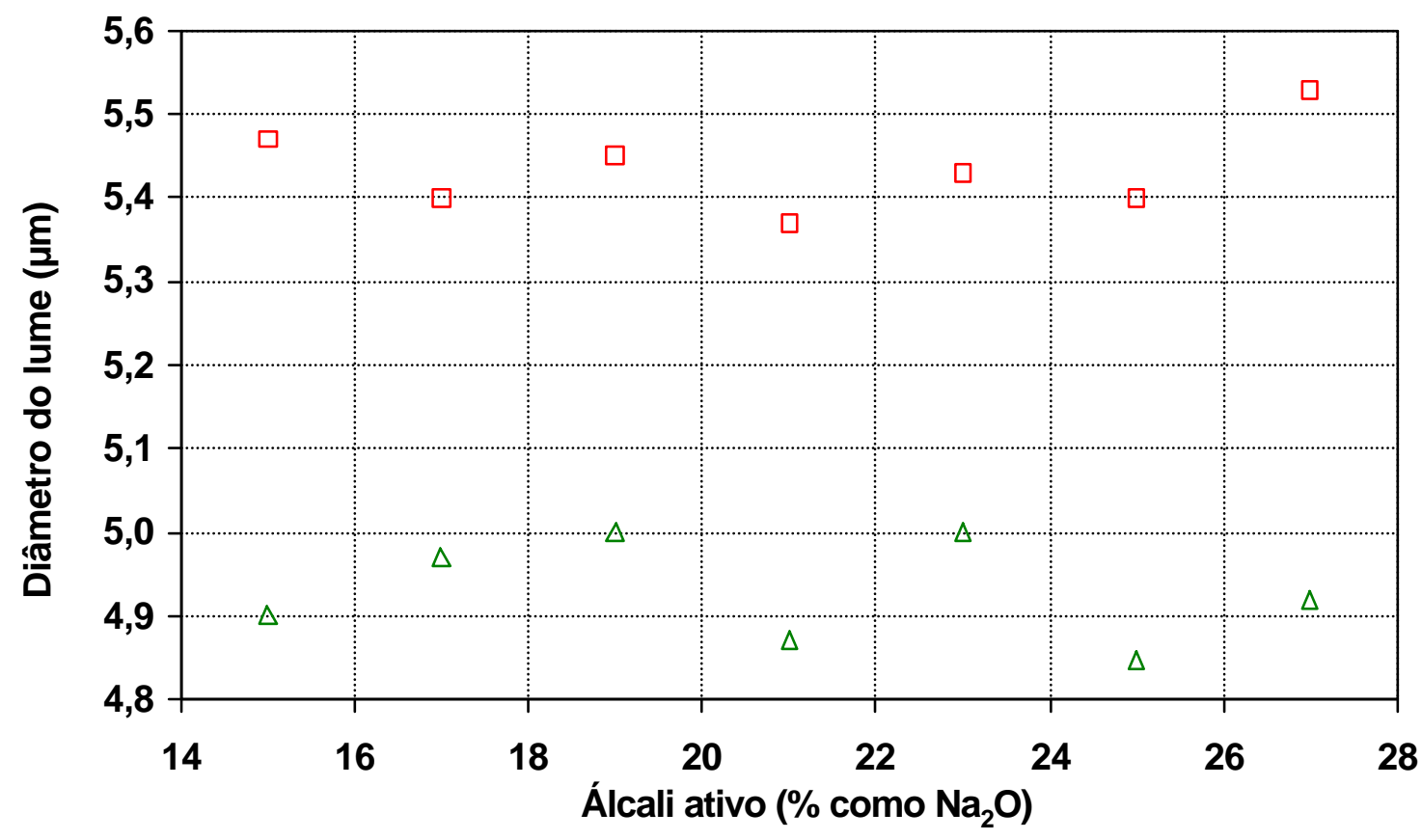

$\square$ E. grandis $x$ E. urophylla $P 4299$

$\triangle$ E. grandis x E. urophylla C085

Figura 30 - Diâmetro do lume da fibra x álcali ativo

Conforme mostra a Figura 30, e comprovado estatisticamente, não se verifica efeito da carga alcalina aplicada sobre o diâmetro de lume das fibras, o que indica as alterações com relação à dimensão ocorrem em áreas externas da fibra, as quais são susceptíveis aos reagentes químicos do licor de cozimento.

Nota-se também que o material P4299 apresenta menor diâmetro do lume quando comparado ao híbrido C085. Isso pode estar relacionado ao menor valor de densidade básica apresentado pelo material P4299, uma vez que o mesmo apresenta também menor largura de fibra quando comparado ao híbrido C085.

A Tabela 20 apresenta a análise de variância e teste $F$ para o coarseness de fibra em função da carga alcalina aplicada para os materiais estudados, bem como suas interações. 
Tabela 20. Análise de variância e teste $\mathrm{F}$ para o parâmetro coarseness de fibra

\begin{tabular}{lrcccr}
\hline & GL & SQ & QM & F & Prob>F \\
\hline Dosagem de Álcali & 6 & 0,000962 & 0,0001440 & 23,73 & 0,0006 \\
Material & 1 & 0,000263 & 0,0002630 & 43,35 & 0,0006 \\
Dosagem de Álcali X Material & 6 & 0,000036 & 0,0000061 & 7,27 & 0,0001 \\
Resíduo & 28 & 0,000023 & 0,0000008 & & \\
\hline Total & 41 & 0,001184 & & & \\
\hline
\end{tabular}

$\mathrm{GL}=$ grau de liberdade $\mathrm{SQ}=$ soma de quadrados $\mathrm{QM}=$ quadrado médio Prob = probabilidade

Os resultados da Tabela 20 indicam que a dosagem de álcali apresenta efeito significativo sobre o coarseness de fibra, o que pode ser justificado devido às alterações constatadas nas dimensões das fibras (comprimento, espessura e largura). Nota-se também que há efeito significativo dos materiais sobre esse parâmetro, o qual também está relacionado às diferenças observadas entre os materiais para as dimensões das fibras da polpa. Nota-se também que há efeito significativo da interaçào ente os fatores dosagem de álcali e material, indicando que o padrão de variação para os materiais não é o mesmo.

A Figura 31 apresenta os valores de coarseness de fibras das polpas celulósicas obtidas nos diferentes tratamentos. 


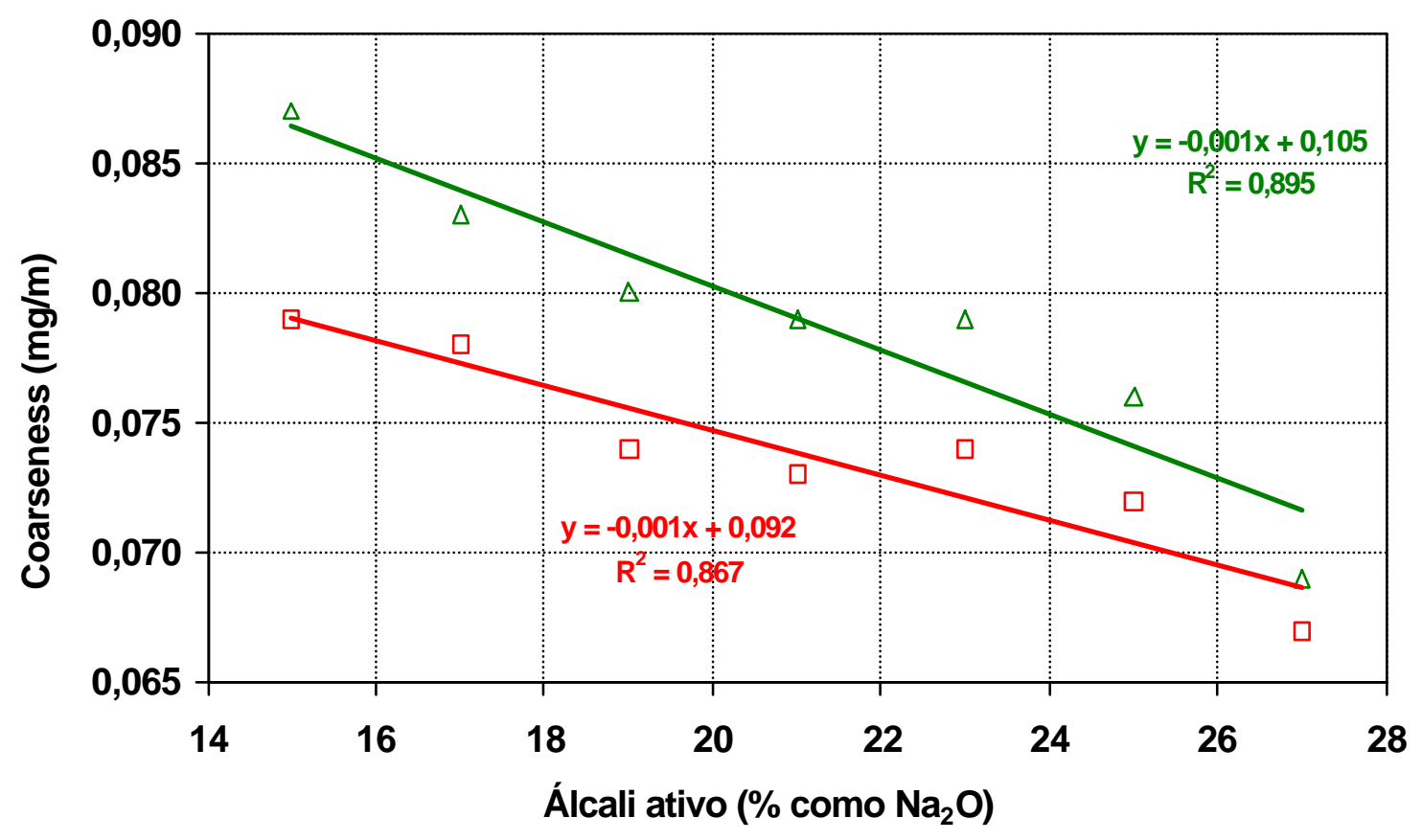

$\square$ E. grandis x E. urophylla P4299

$\triangle$ E. grandis X E. urophylla C085

Figura 31 - Coarseness de fibra x álcali ativo

O coarseness representa o peso (em $\mathrm{mg}$ ) de $1 \mathrm{~m}$ de fibras dispostas de forma alinhadas. Este parâmetro, conforme mencionado anteriormente é dependente do diâmetro do lume da fibra, da largura e da densidade da parede celular das fibras.

O híbrido C085 apresenta maior valor de coarseness que o material P4299, o que confirma os resultados obtidos por por Demuner et al. (1991), quando verificaram que madeiras de maior densidade básica têm fibras com maior coarseness devido, principalmente, a maior espessura de parede.

Os resultados obtidos no presente estudo mostram também que quanto maior a carga alcalina aplicada menor é o valor de coarseness obtidos para os dois materiais estudados. Esses resultados estão também de acordo com o descrito por Edvins \& Foelkel (1996), quando relatam que o coarseness de polpas químicas dependem do coarseness do tipo de madeira e da intensidade do rendimento do processo de deslignificação. Esses autores descrevem que quanto menor rendimento do processo de polpação menor é o coarseness devido à remoção dos constituintes da parede celular. 
A Figura 32 apresenta os valores de coarseness em função do rendimento depurado obtido para os materiais.

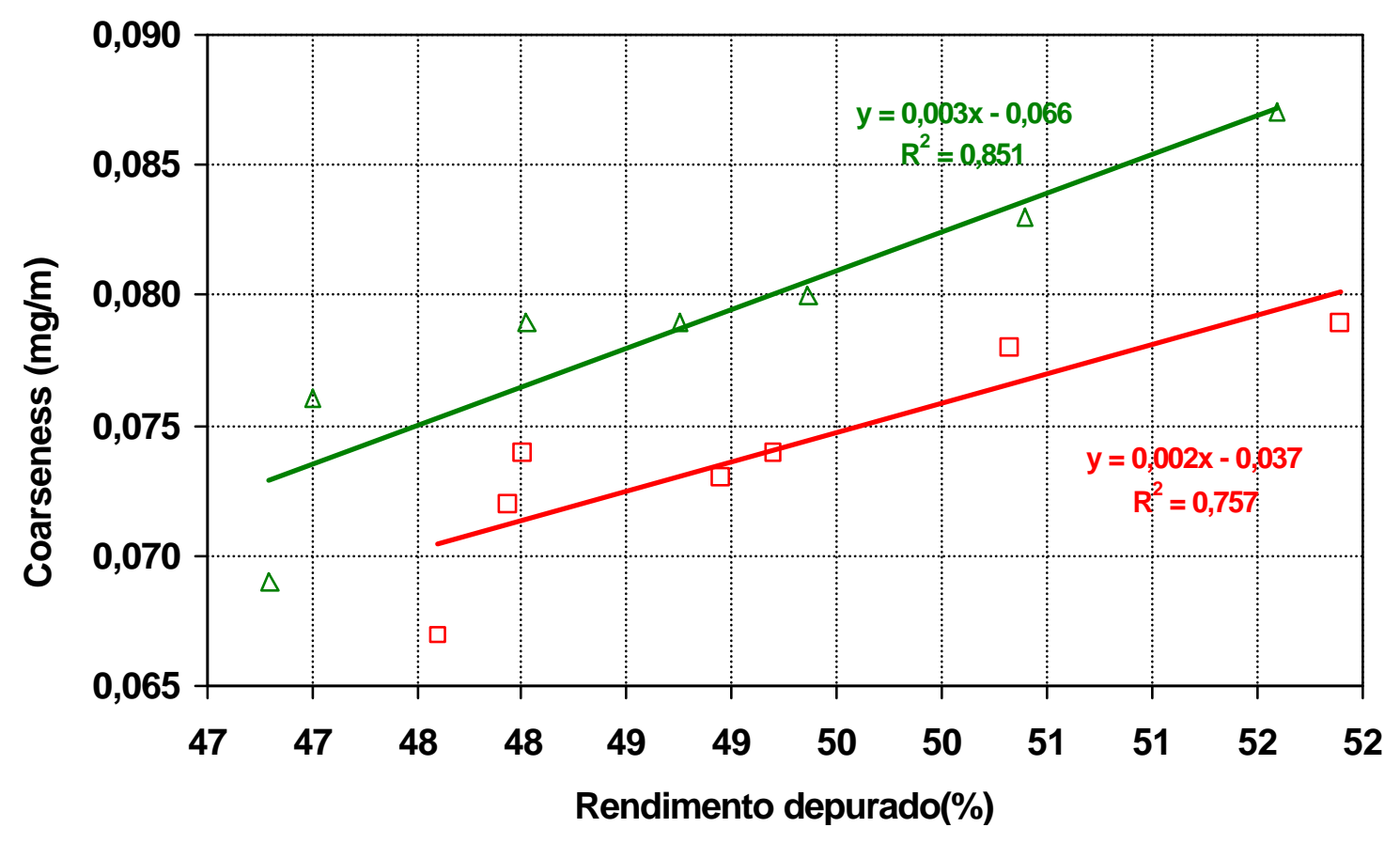

$\square$ E. grandis x E. urophylla P4299

$\triangle$ E. grandis $x$ E. urophylla C085

Figura 32 - Coarseness de fibra $x$ rendimento depurado

O coarseness de fibra também se correlaciona com o índice de retenção de água da fibra, o qual expressa a afinidade da fibra por água quando submetida a uma força centrífuga sob condições específica, indicando a capacidade de drenagem e a facilidade de secagem da folha de papel. Quanto maior o coarseness menor será o número de fibras por grama e também o índice de retenção de água da fibra, indicando maior facilidade de drenagem e secagem da fibra.

A Figura 33 mostra o número de fibras por grama de polpa celulósica dos tratamentos realizados. 


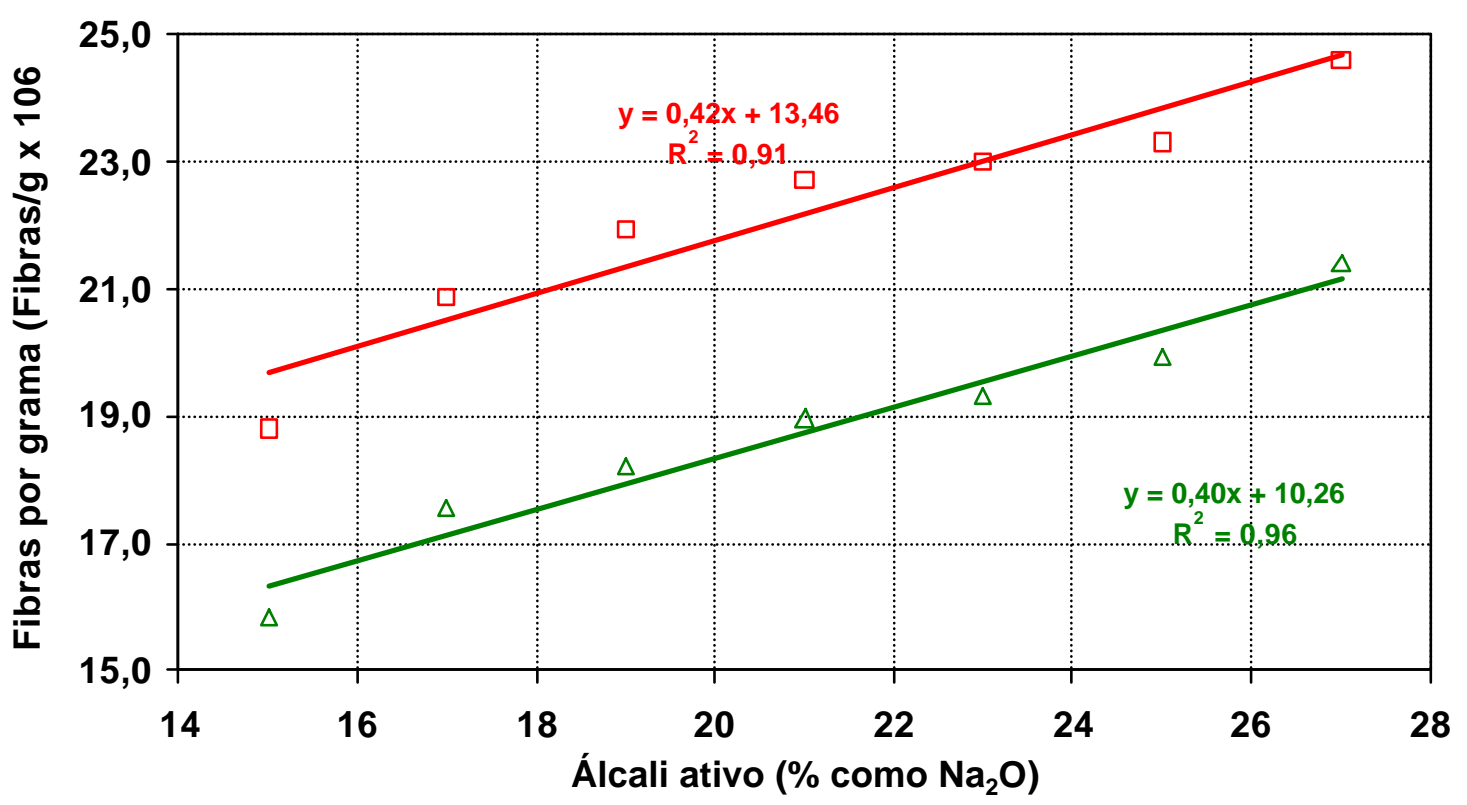

$\square$ E. grandis $x$ E. urophylla $P 4299$

$\triangle$ E. grandis $x$ E. urophylla C085

Figura 33 - Número de fibras por grama de polpa x álcali ativo

Como o coarseness de fibras é um parâmetro inversamente proporcional ao número de fibras por grama de polpa, portanto era de se esperar um comportamento oposto para o número de fibras por gramas em função da carga alcalina aplicada, conforme mostra os resultados.

Os resultados de número de fibras por grama obtido para os materiais estudados estão de acordo com a literatura, uma vez que a mesma descreve que madeiras mais densas produzem polpas com menor número de fibras por grama.

O número de fibras por grama, além de influenciar de forma direta a formação do papel, o mesmo tem importância significativa na resposta da polpa ao tratamento de refinação e também influência a conformabilidade das fibras na folha de papel. $A$ densidade aparente, o índice de tração, índice de estouro e a porosidade da folha de papel são propriedades que dependem fortemente do grau de interligação (pontos de contato) das fibras, mostrando uma correlação muito forte com a flexibilidade das fibras e também com o número de fibras por grama de polpa. Polpas com maior número de fibras por grama apresentam também maior área de exposição das fibras e mais 
interfaces fibra-ar, aumentando com isso o espalhamento da luz e a opacidade do papel.

Polpa celulósica com maior número de fibras por grama, associado normalmente à madeira de menor densidade básica, produzem folhas com maior volume específico ("bulk") e maior opacidade. Porém esse tipo de polpa desenvolve facilmente propriedades físico-mecânicas quando submetidas ao processo de refino. Portanto, o maior volume específico apresentado inicialmente pela fibra, assim como a opacidade da folha; propriedades associadas ao maior número de fibras por grama, podem ser comprometidos facilmente durante o processo de fabricação do papel.

A Figura 34 apresenta o número de fibras por grama da polpa em função do teor de finos encontrados para os materiais híbridos estudados e quando submetidos às diferentes dosagens de álcali ativo.

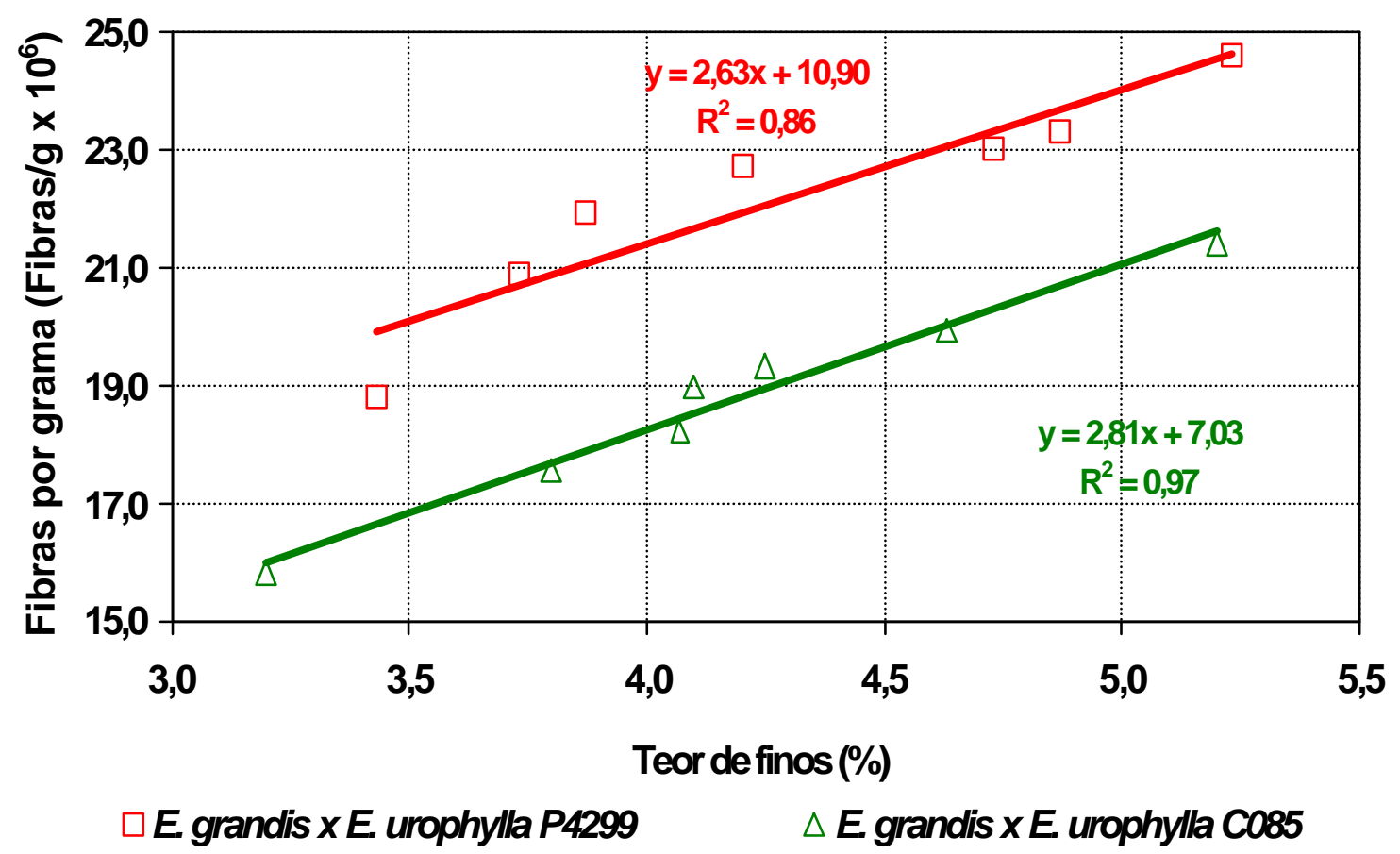

Figura 34 - Número de fibras por grama de polpa x teor de finos 


\subsection{Características dos licores negros}

Nos Quadros 7, 8, 9 e 10 encontram-se os resultados médios do teor de sólidos, $\mathrm{pH}$, e residual de álcali do licor negro para os dois materiais avaliados, sendo que as duas primeiras tabelas apresentam os valores da fase de substituição e as duas últimas da fase de lavagem. 


\begin{tabular}{|c|c|c|c|c|c|c|c|}
\hline \multicolumn{2}{|c|}{ Parâmetros } & \multicolumn{6}{|c|}{ Fase de Substituição - Tempo (min.) } \\
\hline & & 40 & 55 & 70 & 85 & 100 & 115 \\
\hline \multirow{5}{*}{$\begin{array}{c}13 \% \mathrm{AA} \\
\left(\mathrm{Na}_{2} \mathrm{O}\right)\end{array}$} & Teor de Sólidos & 6,97 & 7,57 & 8,27 & 8,66 & 9,13 & 9,61 \\
\hline & $\mathrm{pH}$ & 11,37 & 10,63 & 10,73 & 11,00 & 11,47 & 12,07 \\
\hline & $\mathrm{AE} \mathrm{g} / \mathrm{L} \mathrm{Na}{ }_{2} \mathrm{O}$ & 1,06 & 0,53 & 0,85 & 1,06 & 2,12 & 2,76 \\
\hline & $\mathrm{AA} \mathrm{g} / \mathrm{L} \mathrm{Na}{ }_{2} \mathrm{O}$ & 3,93 & 3,04 & 3,40 & 3,72 & 4,25 & 5,84 \\
\hline & AT g/L $\mathrm{Na}_{2} \mathrm{O}$ & 9,35 & 8,71 & 9,66 & 10,20 & 11,26 & 12,53 \\
\hline \multirow{5}{*}{$\begin{array}{c}15 \% \mathrm{AA} \\
\left(\mathrm{Na}_{2} \mathrm{O}\right)\end{array}$} & Teor de Sólidos & 7,04 & 7,50 & 8,03 & 8,44 & 8,84 & 9,23 \\
\hline & $\mathrm{pH}$ & 11,90 & 11,85 & 11,85 & 12,00 & 12,35 & 12,30 \\
\hline & $\mathrm{AE} \mathrm{g} / \mathrm{L} \mathrm{Na}{ }_{2} \mathrm{O}$ & 1,27 & 2,23 & 2,71 & 1,43 & 3,82 & 3,19 \\
\hline & $\mathrm{AA} \mathrm{g} / \mathrm{L} \mathrm{Na}{ }_{2} \mathrm{O}$ & 2,71 & 2,63 & 4,30 & 2,71 & 5,26 & 4,46 \\
\hline & AT g/L Na ${ }_{2} \mathrm{O}$ & 10,67 & 11,79 & 12,90 & 11,95 & 13,54 & 13,70 \\
\hline \multirow{5}{*}{$\begin{array}{c}17 \% \mathrm{AA} \\
\left(\mathrm{Na}_{2} \mathrm{O}\right)\end{array}$} & Teor de Sólidos & 6,66 & 8,16 & 8,93 & 9,58 & 10,07 & 10,52 \\
\hline & $\mathrm{pH}$ & 12,41 & 12,07 & 12,41 & 12,53 & 12,97 & 13,19 \\
\hline & $\mathrm{AE} \mathrm{g} / \mathrm{L} \mathrm{Na}{ }_{2} \mathrm{O}$ & 2,63 & 3,05 & 3,50 & 4,41 & 5,57 & 6,73 \\
\hline & $\mathrm{AA} \mathrm{g} / \mathrm{L} \mathrm{Na}{ }_{2} \mathrm{O}$ & 4,31 & 5,36 & 5,99 & 6,62 & 8,30 & 9,78 \\
\hline & AT $\mathrm{g} / \mathrm{L} \mathrm{Na}{ }_{2} \mathrm{O}$ & 12,09 & 14,09 & 15,03 & 16,08 & 17,77 & 19,35 \\
\hline \multirow{5}{*}{$\begin{array}{c}19 \% \mathrm{AA} \\
\left(\mathrm{Na}_{2} \mathrm{O}\right)\end{array}$} & Teor de Sólidos & 8,09 & 8,69 & 9,52 & 10,11 & 10,49 & 10,80 \\
\hline & $\mathrm{pH}$ & 13,10 & 13,00 & 12,90 & 13,10 & 13,17 & 13,30 \\
\hline & $\mathrm{AE} \mathrm{g} / \mathrm{L} \mathrm{Na}{ }_{2} \mathrm{O}$ & 4,10 & 4,52 & 4,84 & 6,10 & 6,52 & 7,46 \\
\hline & $\mathrm{AA} \mathrm{g} / \mathrm{L} \mathrm{Na}{ }_{2} \mathrm{O}$ & 6,41 & 6,94 & 7,04 & 8,41 & 8,72 & 10,20 \\
\hline & AT g/L $\mathrm{Na}_{2} \mathrm{O}$ & 14,82 & 15,66 & 15,46 & 17,24 & 17,56 & 18,82 \\
\hline \multirow{5}{*}{$\begin{array}{c}21 \% \mathrm{AA} \\
\left(\mathrm{Na}_{2} \mathrm{O}\right)\end{array}$} & Teor de Sólidos & 8,71 & 9,03 & 9,97 & 10,85 & 11,11 & 11,27 \\
\hline & $\mathrm{pH}$ & 13,33 & 13,27 & 13,23 & 13,30 & 13,37 & 13,40 \\
\hline & $\mathrm{AE} \mathrm{g} / \mathrm{L} \mathrm{Na}{ }_{2} \mathrm{O}$ & 6,38 & 5,96 & 6,91 & 6,91 & 7,86 & 9,25 \\
\hline & $\mathrm{AA} \mathrm{g} / \mathrm{L} \mathrm{Na}{ }_{2} \mathrm{O}$ & 8,61 & 8,71 & 9,36 & 9,90 & 11,56 & 12,55 \\
\hline & AT $\mathrm{g} / \mathrm{L} \mathrm{Na}{ }_{2} \mathrm{O}$ & 17,01 & 17,01 & 17,43 & 18,30 & 18,80 & 20,84 \\
\hline \multirow{5}{*}{$\begin{array}{c}23 \% \mathrm{AA} \\
\left(\mathrm{Na}_{2} \mathrm{O}\right)\end{array}$} & Teor de Sólidos & 9,25 & 9,97 & 11,14 & 11,71 & 11,91 & 12,26 \\
\hline & $\mathrm{pH}$ & 12,63 & 12,83 & 12,73 & 12,80 & 12,80 & 12,97 \\
\hline & $\mathrm{AE} \mathrm{g} / \mathrm{L} \mathrm{Na}{ }_{2} \mathrm{O}$ & 5,97 & 5,86 & 5,65 & 6,51 & 7,28 & 9,12 \\
\hline & $\mathrm{AA} \mathrm{g} / \mathrm{L} \mathrm{Na}{ }_{2} \mathrm{O}$ & 9,23 & 8,69 & 8,04 & 10,10 & 10,42 & 14,01 \\
\hline & AT g/L $\mathrm{Na}_{2} \mathrm{O}$ & 15,64 & 15,85 & 15,31 & 17,37 & 17,59 & 20,85 \\
\hline \multirow{5}{*}{$\begin{array}{c}25 \% \mathrm{AA} \\
\left(\mathrm{Na}_{2} \mathrm{O}\right)\end{array}$} & Teor de Sólidos & 8,15 & 10,80 & 12,18 & 12,87 & 13,22 & 13,54 \\
\hline & $\mathrm{pH}$ & 13,07 & 13,07 & 13,07 & 13,03 & 13,07 & 13,10 \\
\hline & $\mathrm{AE} \mathrm{g} / \mathrm{L} \mathrm{Na}{ }_{2} \mathrm{O}$ & 8,07 & 8,39 & 8,71 & 9,35 & 10,83 & 10,83 \\
\hline & $\mathrm{AA} \mathrm{g} / \mathrm{L} \mathrm{Na}{ }_{2} \mathrm{O}$ & 12,53 & 11,40 & 13,70 & 14,13 & 15,61 & 15,08 \\
\hline & AT g/L Na & 18,69 & 19,44 & 20,07 & 20,18 & 22,73 & 22,94 \\
\hline \multirow{5}{*}{$\begin{array}{c}27 \% \mathrm{AA} \\
\left(\mathrm{Na}_{2} \mathrm{O}\right)\end{array}$} & Teor de Sólidos & 10,17 & 11,47 & 13,00 & 13,92 & 14,26 & 14,52 \\
\hline & $\mathrm{pH}$ & 13,35 & 13,35 & 13,40 & 13,35 & 13,40 & 13,35 \\
\hline & $\overline{A E} \mathrm{~g} / \mathrm{L} \mathrm{Na}{ }_{2} \mathrm{O}$ & 9,36 & 9,24 & 10,21 & 10,06 & 12,57 & 11,18 \\
\hline & $\mathrm{AA} \mathrm{g} / \mathrm{L} \mathrm{Na}{ }_{2} \mathrm{O}$ & 11,42 & 9,96 & 13,16 & 13,04 & 14,59 & 13,22 \\
\hline & AT g/L Na ${ }_{2} \mathrm{O}$ & 21,50 & 22,77 & 24,20 & 23,60 & 26,40 & 25,65 \\
\hline
\end{tabular}

Quadro 7 - Teor de sólidos, $\mathrm{pH}$, e residual de álcali para o Híbrido E. grandis X E. urophylla P4299: fase de substituição

$\mathrm{AE}$ = álcali efetivo; $\mathrm{AA}$ = álcali ativo; $\mathrm{AT}$ = álcali total 


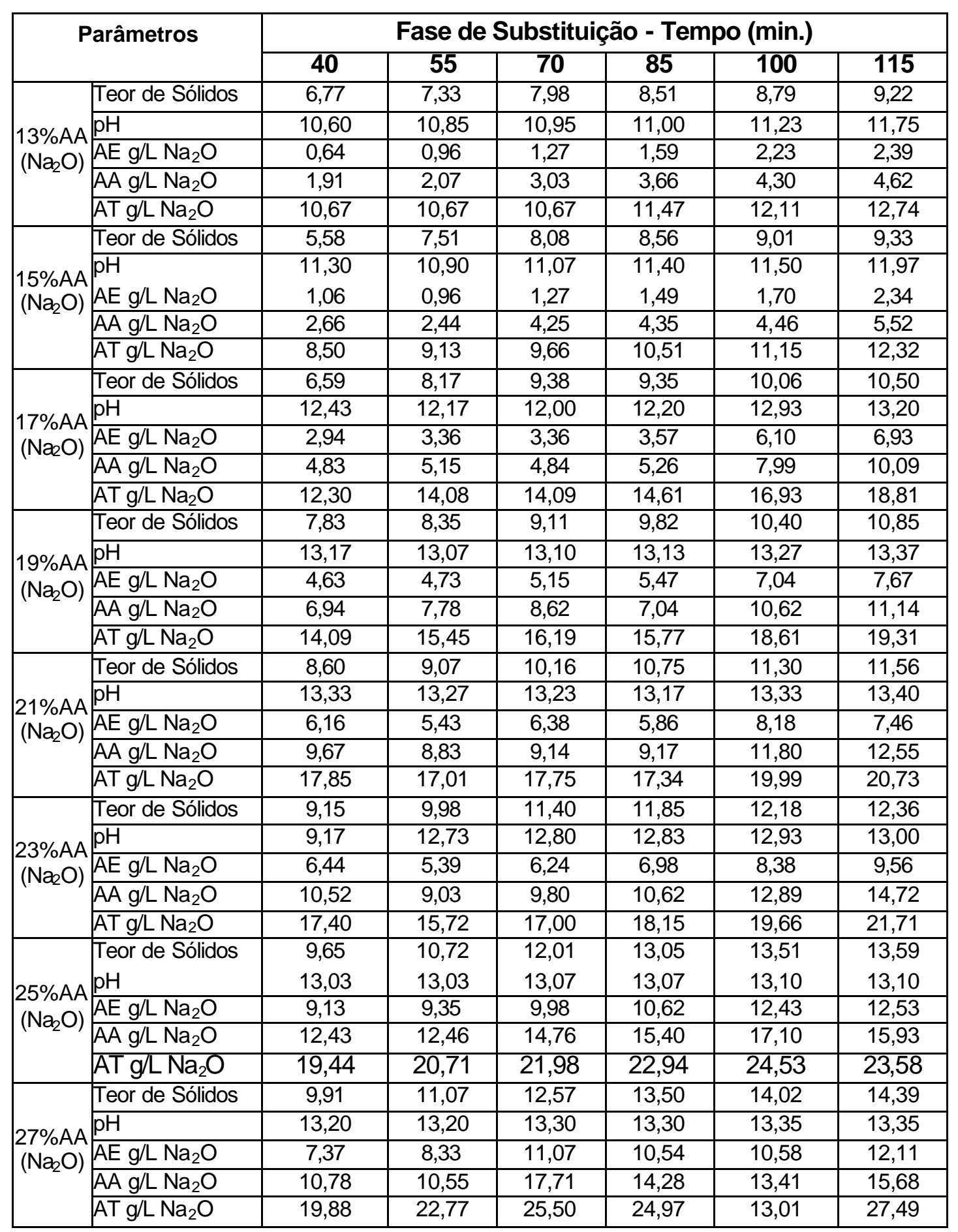

Quadro 8 - Teor de sólidos, $\mathrm{pH}$, e residual de álcali para o Híbrido E. grandis X E. urophylla C085: Fase de substituição

$\mathrm{AE}=$ álcali efetivo; $\mathrm{AA}$ = álcali ativo; $\mathrm{AT}$ = álcali total 


\begin{tabular}{|c|c|c|c|c|c|c|c|}
\hline \multirow{2}{*}{\multicolumn{2}{|c|}{ Parâmetros }} & \multicolumn{6}{|c|}{ Fase de Lavagem - Tempo (min.) } \\
\hline & & 185 & 225 & 265 & 305 & 345 & 385 \\
\hline \multirow{5}{*}{$\begin{array}{c}13 \% \mathrm{AA} \\
\left(\mathrm{Na}_{2} \mathrm{O}\right)\end{array}$} & Teor de Sólidos & 10,30 & 10,66 & 10,68 & 10,53 & 10,57 & 10,54 \\
\hline & $\mathrm{pH}$ & 11,53 & 11,50 & 11,57 & 12,00 & 11,97 & 12,30 \\
\hline & $\mathrm{AE} \mathrm{g} / \mathrm{L} \mathrm{Na}{ }_{2} \mathrm{O}$ & 2,23 & 2,44 & 3,19 & 3,40 & 3,08 & 3,72 \\
\hline & $\mathrm{AA} \mathrm{g} / \mathrm{L} \mathrm{Na}{ }_{2} \mathrm{O}$ & 5,42 & 5,52 & 6,05 & 6,90 & 6,37 & 7,97 \\
\hline & AT $\mathrm{g} / \mathrm{L} \mathrm{Na} \mathrm{Na}_{2} \mathrm{O}$ & 12,32 & 13,06 & 13,17 & 13,81 & 13,59 & 14,76 \\
\hline \multirow{5}{*}{$\begin{array}{c}15 \% \mathrm{AA} \\
\left(\mathrm{Na}_{2} \mathrm{O}\right)\end{array}$} & Teor de Sólidos & 10,16 & 10,75 & 10,85 & 10,89 & 10,74 & 10,45 \\
\hline & $\mathrm{pH}$ & 12,45 & 12,40 & 12,10 & 12,50 & 12,10 & 12,75 \\
\hline & $\mathrm{AE} \mathrm{g} / \mathrm{L} \mathrm{Na}_{2} \mathrm{O}$ & 4,14 & 5,10 & 4,62 & 4,94 & 4,62 & 5,42 \\
\hline & $\overline{\mathrm{AA}} \mathrm{g} / \mathrm{L} \mathrm{Na} \mathrm{Na}_{2} \mathrm{O}$ & 6,85 & 7,17 & 7,01 & 6,69 & 7,01 & 11,15 \\
\hline & AT $\mathrm{g} / \mathrm{L} \mathrm{Na}{ }_{2} \mathrm{O}$ & 15,45 & 16,57 & 15,77 & 15,13 & 15,77 & 17,05 \\
\hline \multirow{5}{*}{$\begin{array}{c}17 \% \mathrm{AA} \\
\left(\mathrm{Na}_{2} \mathrm{O}\right)\end{array}$} & Teor de Sólidos & 11,38 & 11,82 & 11,53 & 11,31 & 11,12 & 10,58 \\
\hline & $\overline{\mathrm{pH}}$ & 12,99 & 12,85 & 12,89 & 13,07 & 13,13 & 13,29 \\
\hline & $\mathrm{AE} \mathrm{g} / \mathrm{L} \mathrm{Na}{ }_{2} \mathrm{O}$ & 6,31 & 6,30 & 6,52 & 7,78 & 7,99 & 8,20 \\
\hline & $\overline{\mathrm{AA}} \mathrm{g} / \mathrm{L} \mathrm{Na}{ }_{2} \mathrm{O}$ & 9,46 & 9,46 & 9,25 & 10,83 & 11,35 & 11,77 \\
\hline & AT $\mathrm{g} / \mathrm{L} \mathrm{Na}_{2} \mathrm{O}$ & 18,50 & 19,13 & 18,82 & 19,13 & 19,87 & 20,61 \\
\hline \multirow{5}{*}{$\begin{array}{c}19 \% \mathrm{AA} \\
\left(\mathrm{Na}_{2} \mathrm{O}\right)\end{array}$} & Teor de Sólidos & 11,28 & 11,53 & 11,34 & 11,21 & 10,77 & 10,98 \\
\hline & $\mathrm{pH}$ & 13,30 & 13,23 & 13,27 & 13,33 & 13,33 & 13,40 \\
\hline & $\overline{A E} \mathrm{~g} / \mathrm{L} \mathrm{Na} a_{2} \mathrm{O}$ & 7,30 & 7,99 & 8,20 & 8,62 & 9,46 & 9,67 \\
\hline & AA g/L $\mathrm{Na}_{2} \mathrm{O}$ & 11,88 & 10,72 & 10,62 & 11,67 & 12,41 & 13,14 \\
\hline & AT g/L Na ${ }_{2} \mathrm{O}$ & 20,29 & 19,87 & 19,45 & 20,18 & 20,50 & 21,97 \\
\hline \multirow{5}{*}{$\begin{array}{c}21 \% \mathrm{AA} \\
\left(\mathrm{Na}_{2} \mathrm{O}\right)\end{array}$} & Teor de Sólidos & 11,66 & 11,77 & 11,65 & 11,12 & 10,91 & 10,71 \\
\hline & $\mathrm{pH}$ & 13,43 & 13,37 & 13,40 & 13,50 & 13,43 & 13,57 \\
\hline & $\mathrm{AE} \mathrm{g} / \mathrm{L} \mathrm{Na} \mathrm{Na}_{2} \mathrm{O}$ & 9,04 & 8,83 & 8,83 & 9,90 & 9,48 & 10,11 \\
\hline & $\mathrm{AA} \mathrm{g} / \mathrm{L} \mathrm{Na}{ }_{2} \mathrm{O}$ & 12,87 & 11,71 & 11,49 & 14,13 & 12,24 & 14,04 \\
\hline & AT $\mathrm{g} / \mathrm{L} \mathrm{Na}_{2} \mathrm{O}$ & 20,84 & 20,42 & 20,31 & 21,15 & 20,52 & 21,79 \\
\hline \multirow{5}{*}{$\begin{array}{c}23 \% \mathrm{AA} \\
\left(\mathrm{Na}_{2} \mathrm{O}\right)\end{array}$} & Teor de Sólidos & 12,38 & 12,38 & 12,48 & 12,33 & 12,13 & 12,15 \\
\hline & $\mathrm{pH}$ & 12,97 & 12,93 & 12,97 & 13,03 & 13,00 & 13,03 \\
\hline & $\mathrm{AE} \mathrm{g} / \mathrm{L} \mathrm{Na} \mathrm{Na}_{2} \mathrm{O}$ & 8,58 & 8,25 & 8,36 & 10,32 & 9,45 & 10,97 \\
\hline & $\mathrm{AA} \mathrm{g} / \mathrm{L} \mathrm{Na}{ }_{2} \mathrm{O}$ & 12,27 & 12,38 & 11,94 & 14,88 & 13,57 & 16,18 \\
\hline & AT $\mathrm{g} / \mathrm{L} \mathrm{Na}{ }_{2} \mathrm{O}$ & 19,76 & 20,20 & 20,20 & 22,26 & 21,28 & 23,24 \\
\hline \multirow{5}{*}{$\begin{array}{c}25 \% \mathrm{AA} \\
\left(\mathrm{Na}_{2} \mathrm{O}\right)\end{array}$} & Teor de Sólidos & 13,50 & 13,52 & 13,36 & 12,96 & 12,18 & 12,17 \\
\hline & $\mathrm{pH}$ & 13,13 & 13,13 & 13,13 & 13,13 & 13,13 & 13,13 \\
\hline & $\mathrm{AE} \mathrm{g} / \mathrm{L} \mathrm{Na}{ }_{2} \mathrm{O}$ & 12,00 & 12,43 & 11,68 & 13,06 & 13,70 & 14,34 \\
\hline & $\mathrm{AA} \mathrm{g} / \mathrm{L} \mathrm{Na}{ }_{2} \mathrm{O}$ & 17,95 & 16,99 & 16,36 & 19,33 & 19,86 & 19,97 \\
\hline & AT $\mathrm{g} / \mathrm{L} \mathrm{Na}_{2} \mathrm{O}$ & 24,64 & 24,75 & 22,62 & 25,70 & 26,34 & 24,43 \\
\hline \multirow{5}{*}{$\begin{array}{c}27 \% \mathrm{AA} \\
\left(\mathrm{Na}_{2} \mathrm{O}\right)\end{array}$} & Teor de Sólidos & 14,40 & 14,10 & 14,08 & 14,29 & 14,02 & 13,40 \\
\hline & $\mathrm{pH}$ & 13,45 & 13,40 & 13,35 & 13,50 & 13,40 & 13,35 \\
\hline & $\mathrm{AE} \mathrm{g/L} \mathrm{Na}{ }_{2} \mathrm{O}$ & 15,29 & 12,86 & 11,46 & 15,29 & 15,02 & 12,60 \\
\hline & AA g/L $\mathrm{Na}_{2} \mathrm{O}$ & 20,15 & 16,42 & 13,67 & 20,15 & 18,36 & 14,48 \\
\hline & AT $\mathrm{g} / \mathrm{L} \mathrm{Na}{ }_{2} \mathrm{O}$ & 30,68 & 28,89 & 26,72 & 31,14 & 29,50 & 27,88 \\
\hline
\end{tabular}

Quadro 9 - Teor de sólidos, $\mathrm{pH}$, e residual de álcali para o Híbrido E. grandis X E. urophylla P4299: Fase de Lavagem

$\mathrm{AE}$ = álcali efetivo; $\mathrm{AA}$ = álcali ativo; $\mathrm{AT}=$ álcali total; Coz. = cozimento 


\begin{tabular}{|c|c|c|c|c|c|c|c|}
\hline \multirow{2}{*}{\multicolumn{2}{|c|}{ Parâmetros }} & \multicolumn{6}{|c|}{ Fase de Lavagem - Tempo (min.) } \\
\hline & & 185 & 225 & 265 & 305 & 345 & 385 \\
\hline \multirow{5}{*}{$\begin{array}{c}13 \% \mathrm{AA} \\
\left(\mathrm{Na}_{2} \mathrm{O}\right)\end{array}$} & Teor de Sólidos & 10,13 & 10,65 & 10,33 & 10,58 & 10,53 & 10,21 \\
\hline & $\mathrm{pH}$ & 11,50 & 11,15 & 11,30 & 11,75 & 11,95 & 12,25 \\
\hline & $\mathrm{AE} \mathrm{g} / \mathrm{L} \mathrm{Na}{ }_{2} \mathrm{O}$ & 2,87 & 3,19 & 3,19 & 3,35 & 3,66 & 4,46 \\
\hline & $\mathrm{AA} \mathrm{g} / \mathrm{L} \mathrm{Na} \mathrm{Na}_{2} \mathrm{O}$ & 4,94 & 5,10 & 4,46 & 5,58 & 6,05 & 6,69 \\
\hline & AT g/L Na $2 \mathrm{O}$ & 13,22 & 13,38 & 12,90 & 14,02 & 14,34 & 14,50 \\
\hline \multirow{5}{*}{$\begin{array}{c}15 \% \mathrm{AA} \\
\left(\mathrm{Na}_{2} \mathrm{O}\right)\end{array}$} & Teor de Sólidos & 9,89 & 10,86 & 10,90 & 10,88 & 10,84 & 10,88 \\
\hline & $\mathrm{pH}$ & 11,70 & 11,50 & 11,63 & 11,50 & 12,07 & 12,27 \\
\hline & $\mathrm{AE} \mathrm{g/L} \mathrm{Na}{ }_{2} \mathrm{O}$ & 2,66 & 2,44 & 2,55 & 2,76 & 3,50 & 3,72 \\
\hline & $\mathrm{AA} \mathrm{g} / \mathrm{L} \mathrm{Na} \mathrm{Na}_{2}$ & 6,05 & 6,05 & 5,10 & 5,95 & 6,80 & 7,33 \\
\hline & AT g/L Na ${ }_{2} \mathrm{O}$ & 12,74 & 13,49 & 12,64 & 13,59 & 14,55 & 14,55 \\
\hline \multirow{5}{*}{$\begin{array}{c}17 \% \mathrm{AA} \\
\left(\mathrm{Na}_{2} \mathrm{O}\right)\end{array}$} & Teor de Sólidos & 11,43 & 11,96 & 11,52 & 11,62 & 11,32 & 10,79 \\
\hline & $\mathrm{pH}$ & 13,03 & 13,00 & 13,07 & 13,13 & 13,13 & 13,23 \\
\hline & $\mathrm{AE} \mathrm{g/L} \mathrm{Na}{ }_{2} \mathrm{O}$ & 6,83 & 7,25 & 7,46 & 7,88 & 8,20 & 8,94 \\
\hline & $\mathrm{AA} g / \mathrm{L} \mathrm{Na}{ }_{2} \mathrm{O}$ & 9,57 & 10,83 & 11,04 & 11,25 & 11,67 & 13,14 \\
\hline & AT g/L Na ${ }_{2} \mathrm{O}$ & 19,03 & 19,87 & 19,66 & 20,29 & 20,71 & 21,45 \\
\hline \multirow{5}{*}{$\begin{array}{c}19 \% \mathrm{AA} \\
\left(\mathrm{Na}_{2} \mathrm{O}\right)\end{array}$} & Teor de Sólidos & 10,96 & 11,54 & 11,48 & 11,23 & 10,98 & 10,93 \\
\hline & $\mathrm{pH}$ & 13,37 & 13,30 & 13,30 & 13,37 & 13,37 & 13,43 \\
\hline & $\mathrm{AE} \mathrm{g} / \mathrm{L} \mathrm{Na}{ }_{2} \mathrm{O}$ & 8,51 & 8,41 & 8,52 & 9,46 & 8,62 & 9,78 \\
\hline & $\mathrm{AA} \mathrm{g} / \mathrm{L} \mathrm{Na}{ }_{2} \mathrm{O}$ & 12,51 & 11,56 & 11,98 & 12,30 & 11,36 & 13,67 \\
\hline & AT $\mathrm{g} / \mathrm{L} \mathrm{Na}{ }_{2} \mathrm{O}$ & 19,55 & 20,19 & 20,29 & 20,61 & 20,71 & 23,03 \\
\hline \multirow{5}{*}{$\begin{array}{c}21 \% \mathrm{AA} \\
\left(\mathrm{Na}_{2} \mathrm{O}\right)\end{array}$} & Teor de Sólidos & 11,78 & 12,09 & 11,92 & 11,51 & 11,36 & 11,61 \\
\hline & $\mathrm{pH}$ & 13,37 & 13,37 & 13,40 & 13,43 & 13,53 & 13,63 \\
\hline & $\mathrm{AE} \mathrm{g} / \mathrm{L} \mathrm{Na} \mathrm{Na}_{2}$ & 8,93 & 8,62 & 9,47 & 9,58 & 10,32 & 12,12 \\
\hline & $\mathrm{AA} g / \mathrm{L} \mathrm{Na} 2 \mathrm{O}$ & 12,66 & 12,97 & 13,29 & 12,98 & 13,83 & 15,54 \\
\hline & AT g/L $\mathrm{Na}_{2} \mathrm{O}$ & 20,84 & 21,58 & 22,01 & 21,37 & 22,01 & 24,25 \\
\hline \multirow{5}{*}{$\begin{array}{c}23 \% \mathrm{AA} \\
\left(\mathrm{Na}_{2} \mathrm{O}\right)\end{array}$} & Teor de Sólidos & 12,40 & 12,26 & 12,57 & 12,65 & 12,48 & 12,47 \\
\hline & $\mathrm{pH}$ & 13,03 & 13,03 & 13,03 & 13,03 & 13,03 & 13,07 \\
\hline & $\mathrm{AE} \mathrm{g} / \mathrm{L} \mathrm{Na}{ }_{2} \mathrm{O}$ & 9,67 & 9,78 & 10,10 & 10,21 & 10,75 & 11,28 \\
\hline & $\mathrm{AA} \mathrm{g} / \mathrm{L} \mathrm{Na} \mathrm{Na}_{2} \mathrm{O}$ & 14,83 & 14,83 & 15,37 & 15,58 & 15,69 & 16,76 \\
\hline & AT $\mathrm{g} / \mathrm{L} \mathrm{Na} \mathrm{Na}_{2} \mathrm{O}$ & 21,82 & 22,46 & 22,78 & 23,00 & 23,00 & 23,85 \\
\hline \multirow{5}{*}{$\begin{array}{c}25 \% \mathrm{AA} \\
\left(\mathrm{Na}_{2} \mathrm{O}\right)\end{array}$} & Teor de Sólidos & 13,96 & 13,88 & 13,83 & 13,46 & 13,06 & 12,42 \\
\hline & $\mathrm{pH}$ & 13,13 & 13,13 & 13,13 & 13,13 & 13,17 & 13,17 \\
\hline & $\mathrm{AE} \mathrm{g} / \mathrm{L} \mathrm{Na}{ }_{2} \mathrm{O}$ & 13,06 & 12,85 & 14,13 & 14,98 & 15,29 & 15,51 \\
\hline & $\mathrm{AA} g / \mathrm{L} \mathrm{Na}{ }_{2} \mathrm{O}$ & 17,10 & 17,52 & 19,86 & 20,60 & 20,07 & 21,67 \\
\hline & AT g/L $\mathrm{Na}_{2} \mathrm{O}$ & 24,96 & 25,49 & 27,51 & 28,25 & 28,14 & 28,99 \\
\hline \multirow{5}{*}{$\begin{array}{l}27 \% \mathrm{AA} \\
\left(\mathrm{Na}_{2} \mathrm{O}\right)\end{array}$} & Teor de Sólidos & 14,54 & 14,43 & 14,22 & 14,14 & 13,86 & 13,41 \\
\hline & $\mathrm{pH}$ & 13,35 & 13,30 & 13,30 & 13,45 & 13,40 & 13,40 \\
\hline & $\mathrm{AE} \mathrm{g} / \mathrm{L} \mathrm{Na}{ }_{2} \mathrm{O}$ & 12,49 & 11,79 & 12,25 & 14,67 & 12,68 & 12,92 \\
\hline & $\mathrm{AA} g / \mathrm{L} \mathrm{Na}{ }_{2} \mathrm{O}$ & 16,29 & 14,74 & 15,66 & 20,97 & 17,43 & 15,85 \\
\hline & AT $\mathrm{g} / \mathrm{L} \mathrm{Na}{ }_{2} \mathrm{O}$ & 27,58 & 27,65 & 28,74 & 31,49 & 29,20 & 28,46 \\
\hline
\end{tabular}

Quadro 10 - Teor de sólidos, pH, e residual de álcali para o Híbrido E. grandis X E. urophylla C085: fase de Lavagem

$\mathrm{AE}=$ álcali efetivo; $\mathrm{AA}$ = álcali ativo; $\mathrm{AT}=$ álcali total; Coz. = cozimento 
As Figuras 35 e 36 mostram os perfis de álcali residual do licor negro ao longo das fases de cozimento dos tratamentos realizados para o híbrido $E$. grandis $\times E$. urophylla P4299 e C085 respectivamente.

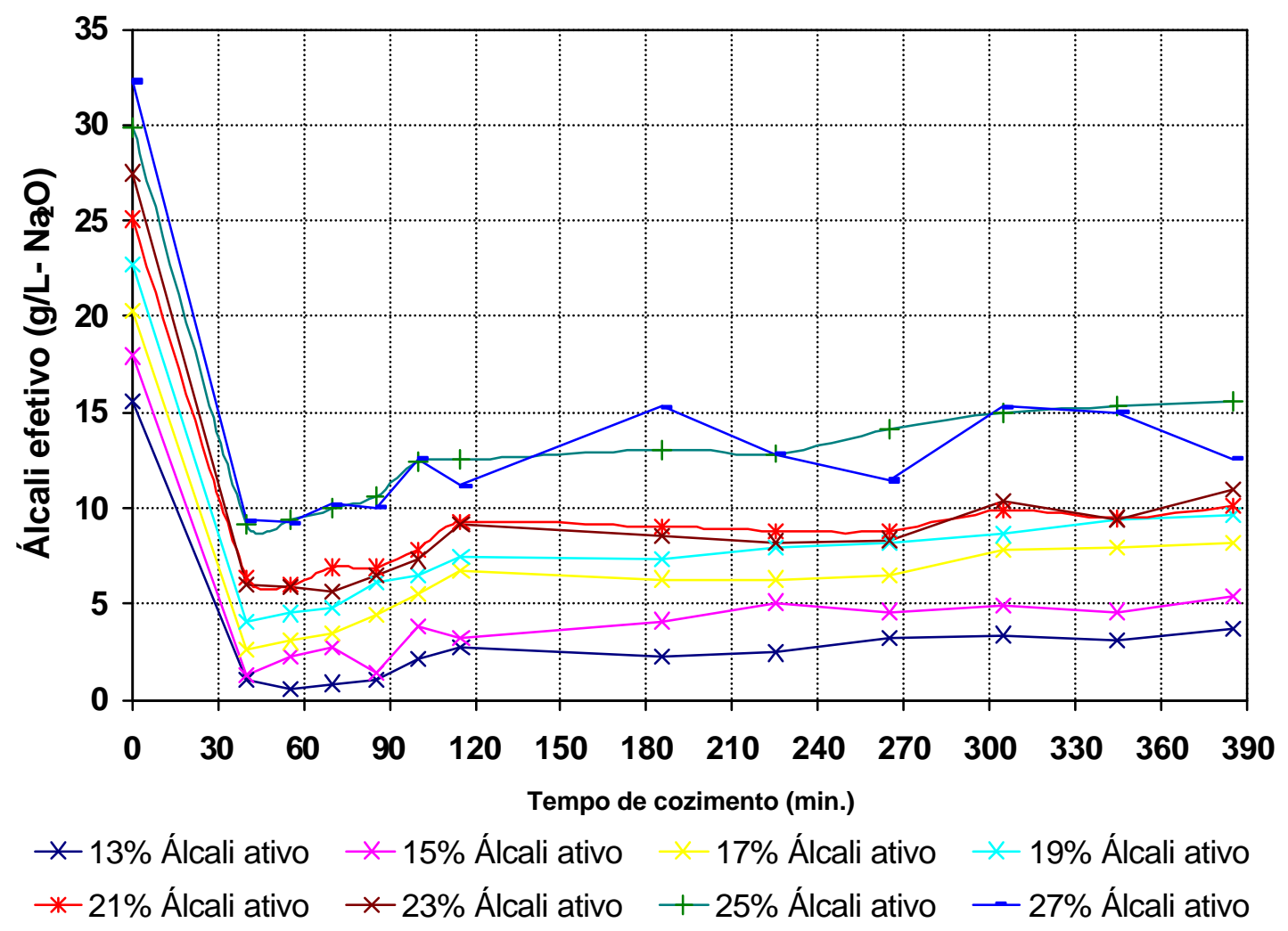

Figura 35 - Álcali efetivo residual no licor negro x álcali ativo aplicado - híbrido $E$. grandis $x$ E. urophylla P4299 


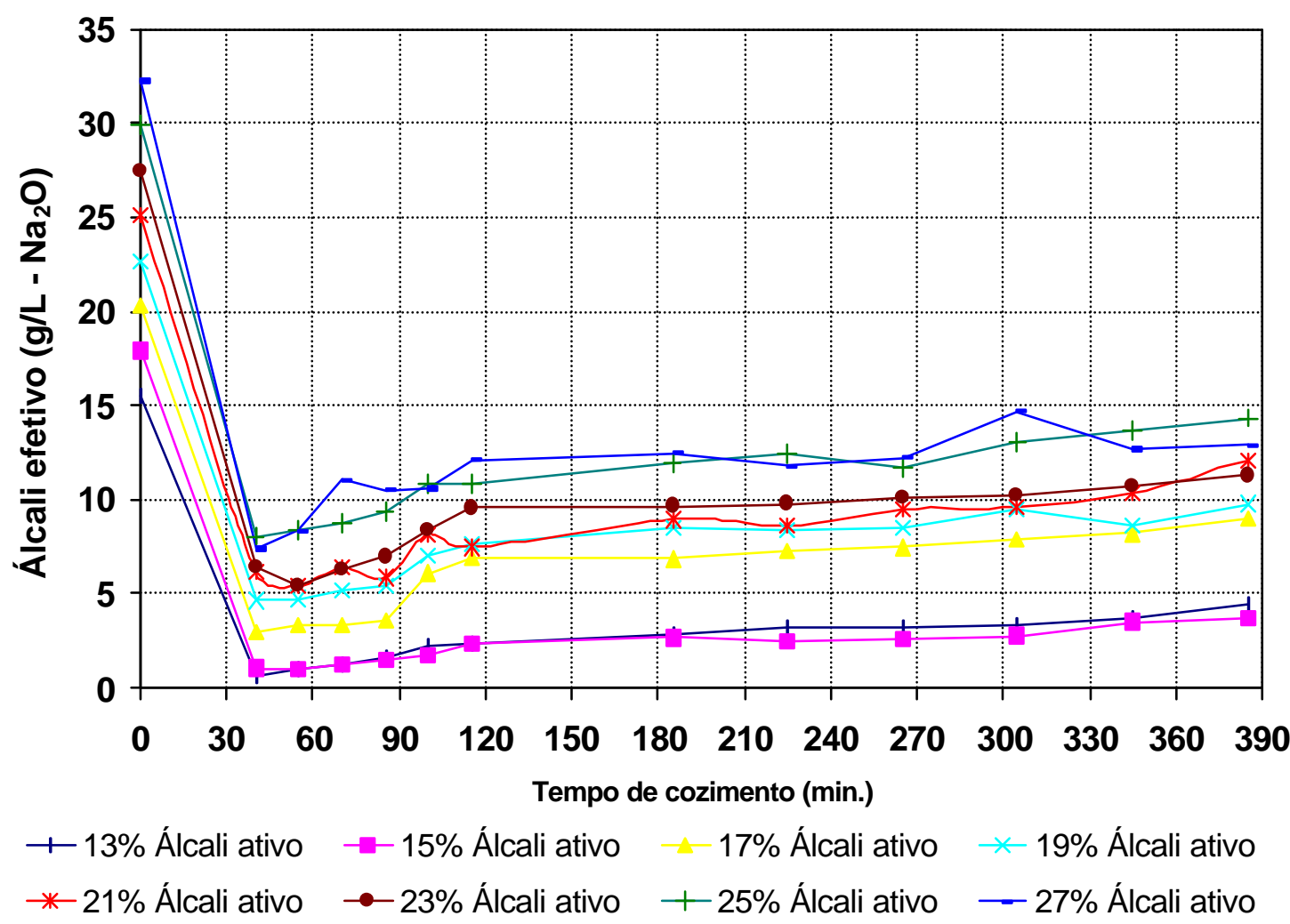

Figura 36 - Álcali efetivo residual no licor negro x álcali ativo aplicado - híbrido $E$. grandis x E. urophylla C085

Observa-se pelas Figuras 35 e 36 que durante a fase de impregnação dos cavacos ocorre uma acentuada redução da concentração de álcali efetivo do licor negro, muito provavelmente devido ao consumo desse reagente na neutralização dos produtos (ácidos orgânicos) das reações de degradação dos carboidratos de baixo peso molecular, principalmente as hemiceluloses. À medida que a carga alcalina é aumentada tem-se um incremento na quantidade de álcali residual presente no licor negro e, com exceção dos tratamentos com 13\% e 15\% de álcali, os demais tratamentos apresentam valores superiores à $5 \mathrm{~g} / \mathrm{L}$ de álcali efetivo residual (como $\mathrm{Na}_{2} \mathrm{O}$ ) residual no licor negro das fases de substituição e lavagem. O perfil de álcali residual obtido é também bastante uniforme e nenhuma diferença significativa entre os materiais avaliados pode ser observada, quando submetidos às mesmas cargas alcalinas. 
As Figuras 37 e 38 mostram os valores de $\mathrm{pH}$ do licor negro ao longo das fases de cozimentos para dos tratamentos realizados para o híbrido E. grandis $\times$ E. urophylla

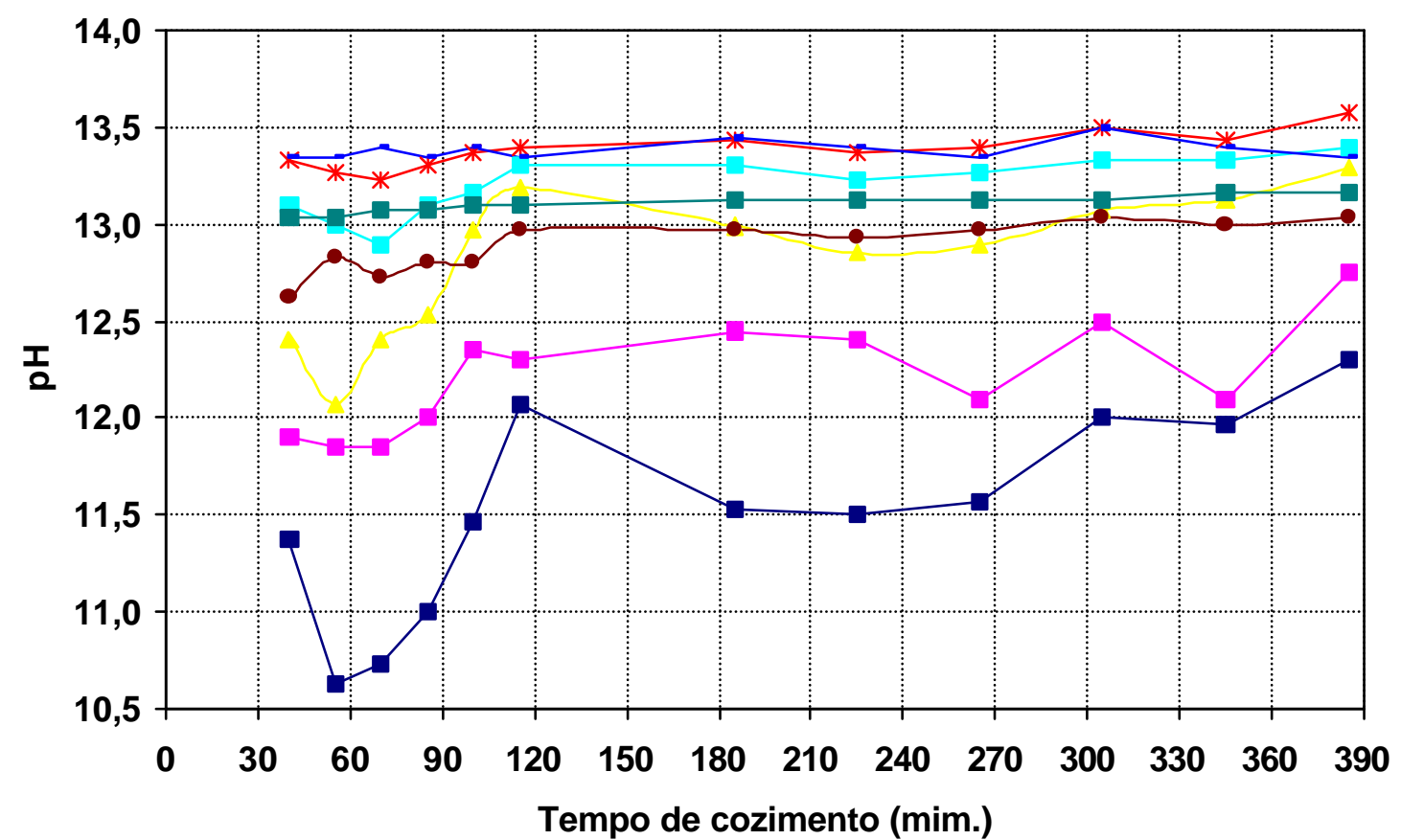

$-13 \%$ Álcali ativo $-15 \%$ Álcal ativo $-17 \%$ Álcali ativo $-19 \%$ Álcali ativo

$-21 \%$ Álcali ativo $-23 \%$ Álcali ativo $-25 \%$ Álcali ativo $-27 \%$ Álcali ativo P4299 e C085 respectivamente.

Figura 37 - pH do licor negro x álcali ativo - híbrido E. grandis x E. urophylla P4299 


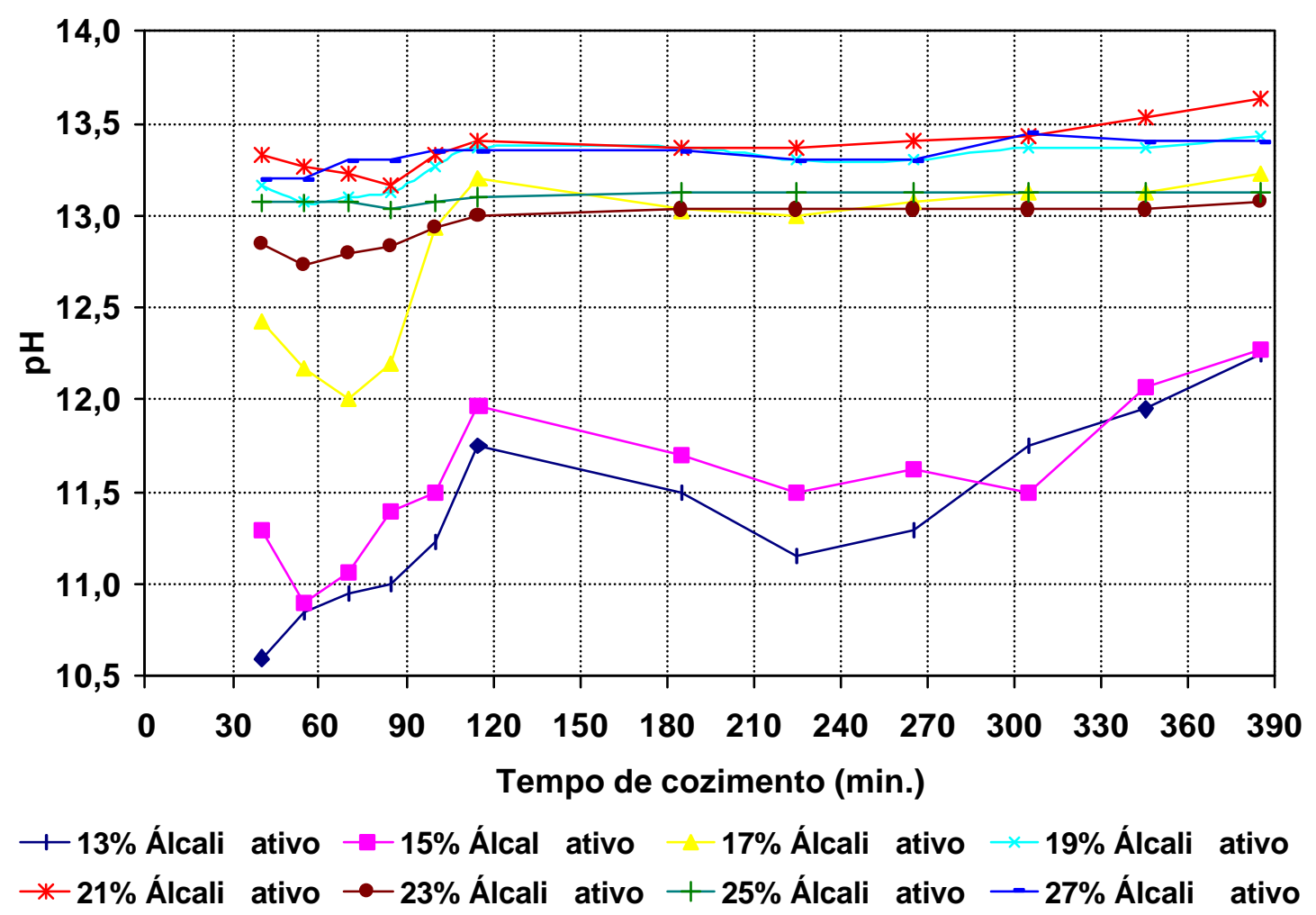

Figura 38 - pH do licor negro x álcali ativo - híbrido E. grandis x E. urophylla C085

Nota-se pelas Figuras 37 e 38 que maiores valores de $\mathrm{pH}$ do licor negro são obtidos à medida que uma maior carga alcalina é aplicada, sendo que os tratamentos com carga alcalina de 13 e 15\% de álcali ativo apresentam os menores valores ao longo de todo o perfil do cozimento. Na maior parte da fase de substituição o valor de $\mathrm{pH}$ ficou inferior a 11,5 para o tratamento com 13\% de álcali e material P4299 e inferior também a 11,5 para os tratamentos com 13\% e 15\% de álcali para o material C085; Já no final da fase de lavagem e final do cozimento o valor de $\mathrm{pH}$ variou de 11,3 a 12, 5 para os dois materiais e para os tratamentos com 13\% e 15\% de álcali. Para os demais tratamentos o perfil de $\mathrm{pH}$ do licor negro permaneceu bastante uniforme e com valores variando entre 12,5 a 13,5 na fase de substituição e entre 13 a 13,5 na fase de lavagem e final do cozimento. $\mathrm{O}$ pH do licor negro da fase de substituição e de lavagem foi ligeiramente inferior para os tratamentos com $13 \%$ e $15 \%$ de álcali ob material C085, muito provavelmente devido ao mesmo apresentar maior densidade básica e consumir um pouco mais de álcali nesses tratamentos. Portanto, não houve 
problemas com relação a reprecipitação de lignina, considerando-se o valor de pH obtido na fase final dos cozimentos.

As Figuras 39 e 40 mostram os teores de sólidos dissolvidos no licor negro ao longo das fases de cozimentos para dos tratamentos realizados para o híbrido $E$. grandis x E. urophylla P4299 e C085 respectivamente.

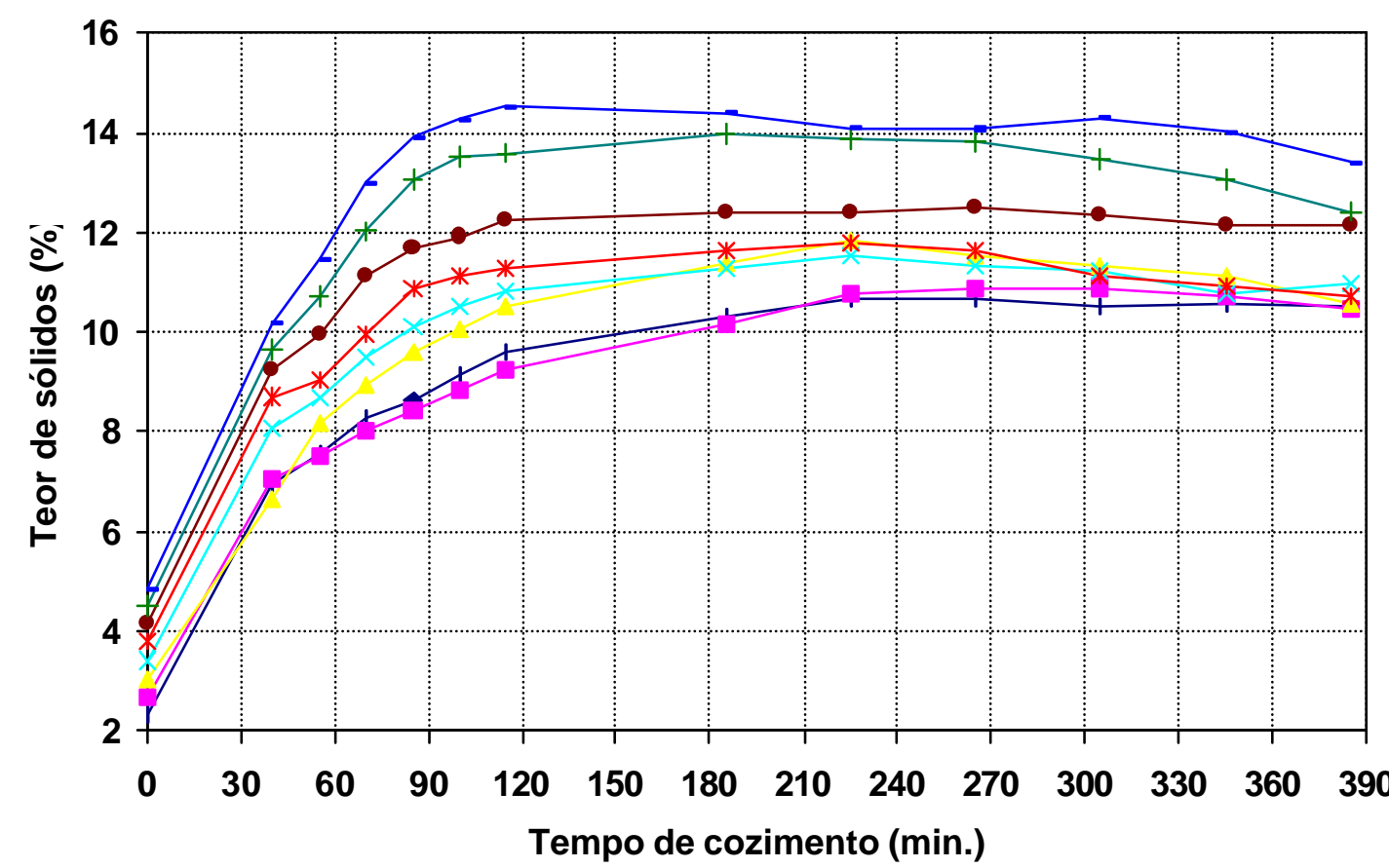

$+13 \%$ Álcali ativo $-15 \%$ Álcali ativo $-17 \%$ Álcali ativo $-19 \%$ Álcali ativo

* $21 \%$ Álcali ativo $\rightarrow 23 \%$ Álcali ativo $+25 \%$ Álcali ativo $-27 \%$ Álcali ativo

Figura 39 - Teor de sólidos dissolvidos no licor negro x álcali ativo - híbrido E. grandis $\mathrm{x}$ E. urophylla P4299 


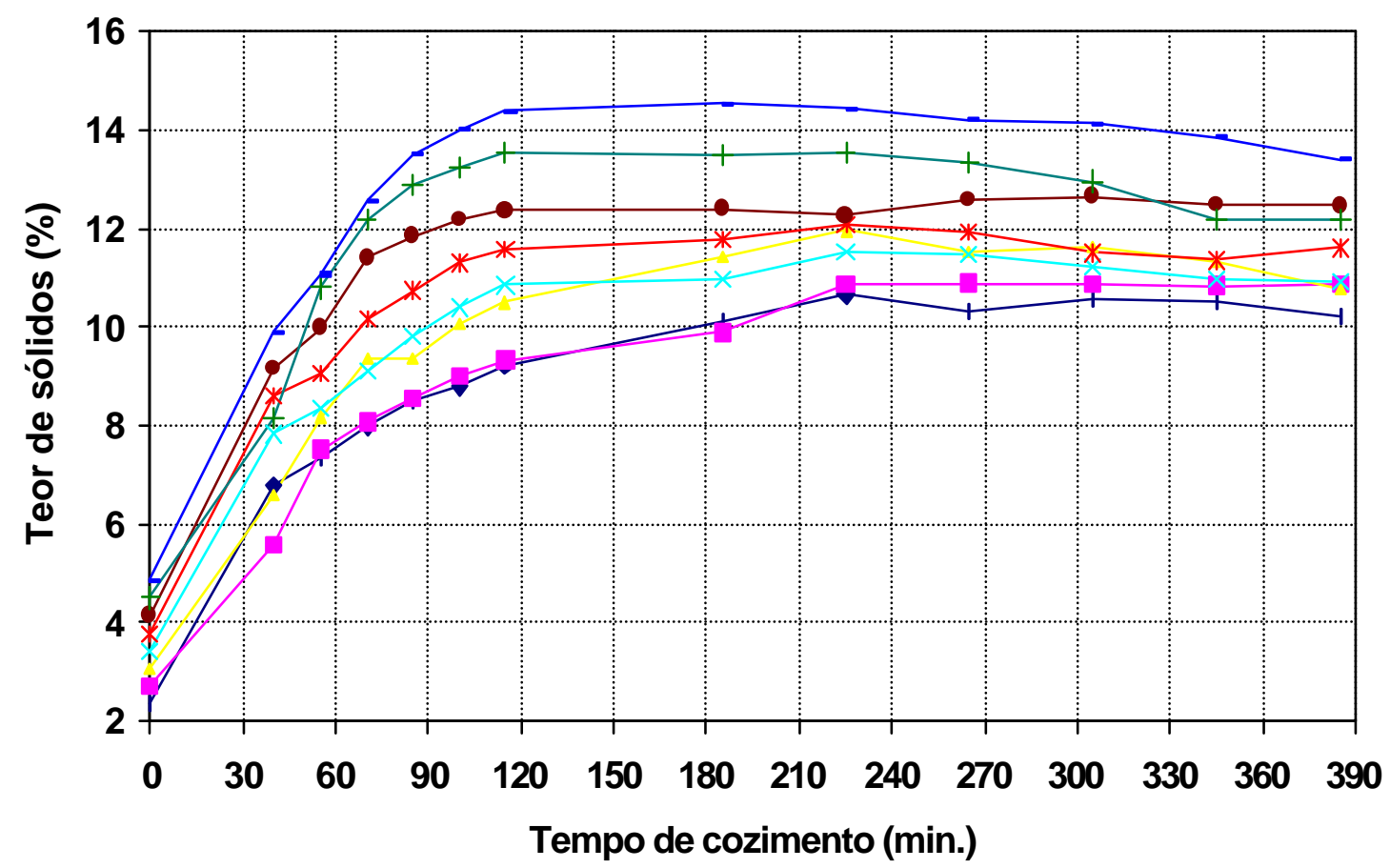

$+13 \%$ Álcali ativo $-15 \%$ Álcali ativo $-17 \%$ Álcali ativo $\leftarrow 19 \%$ Álcali ativo
$-21 \%$ Álcali ativo $\rightarrow-23 \%$ Álcali ativo $+25 \%$ Álcali ativo $-27 \%$ Álcali ativo

Figura 40 - Teor de sólidos dissolvidos no licor negro x álcali ativo - híbrido E. grandis x E. urophylla C085

Conforme mostram as Figuras 39 e 40, o perfil de sólidos dissolvidos no licor negro é maior para os tratamentos com maior carga alcalina, resultado da própria intensidade de deslignificação do processo de polpação, maior quantidade de material inorgânico adicionado e também devido às degradações dos carboidratos (fases iniciais de cozimento) para os tratamentos com maior carga alcalina. Não se observa também diferença significativa no teor de sólidos dissolvidos entre os materiais avaliados e percebe-se que após atingir da temperatura máxima de cozimento (fase de cozimento) o teor de sólidos dissolvidos se mantém constante, evidenciando os fundamentos da polpação Lo-Solids®, que é a manutenção estável do perfil de materiais sólidos dissolvidos no licor negro ao longo das fases de substituição e lavagem, por meio das injeções e remoções de licor negro, mantendo uniforme o perfil de álcali e preservando a relação licor madeira. 


\subsection{Carga alcalina consumida}

Os Quadros 11 e 12 mostram o álcali ativo aplicado, consumido, residual e a quantidade de álcali necessário para produzir uma tonelada de polpa celulósica seca.

\begin{tabular}{|c|c|c|c|}
\hline \multicolumn{4}{|c|}{ Híbrido E. grandis x E. urophylla P 4299 } \\
\hline \multicolumn{3}{|c|}{ Álcali Ativo (Na $\mathbf{O})$,\% } & Carga Alcalina \\
\hline Aplicado & Consumido & Residual & Kg AA (NaO)/odt \\
\hline 13 & 8,82 & 4,18 & 88,20 \\
15 & 9,51 & 5,49 & 95,10 \\
17 & 10,63 & 6,37 & 106,30 \\
19 & 12,20 & 6,80 & 122,00 \\
21 & 13,12 & 7,88 & 131,20 \\
23 & 14,22 & 8,78 & 142,20 \\
25 & 16,00 & 9,00 & 160,00 \\
27 & 17,55 & 9,45 & 175,50 \\
\hline
\end{tabular}

Quadro 11 - Álcali ativo aplicado, consumido, residual e quantidade necessária para produzir uma tonelada de polpa celulósica seca - Material P4299

$\mathrm{AA}=$ álcali ativo

\begin{tabular}{|c|c|c|c|}
\hline \multicolumn{4}{|c|}{ Híbrido E. grandis x E. urophylla C085 } \\
\hline \multicolumn{3}{|c|}{ Álcali Ativo (Na $\mathbf{N}_{2}$ ),\% } & Carga Alcalina \\
\hline Aplicado & Consumido & Residual & Kg AA (Na $\mathbf{O})$ /odt \\
\hline 13 & 9,49 & 3,51 & 94,90 \\
15 & 10,06 & 4,94 & 100,60 \\
17 & 11,09 & 5,91 & 110,90 \\
19 & 12,00 & 7,00 & 120,00 \\
21 & 12,45 & 8,55 & 124,53 \\
23 & 13,12 & 9,88 & 131,20 \\
25 & 15,00 & 10,00 & 150,00 \\
27 & 16,50 & 10,50 & 165,00 \\
\hline
\end{tabular}

Quadro 12 - Álcali ativo aplicado, consumido, residual e quantidade necessária para produzir uma tonelada de polpa celulósica seca para - Material C085

$\mathrm{AA}=$ álcali ativo 
A Figura 41 mostra a quantidade de álcali necessário para produzir uma tonelada de polpa celulósica seca para os tratamentos realizados.

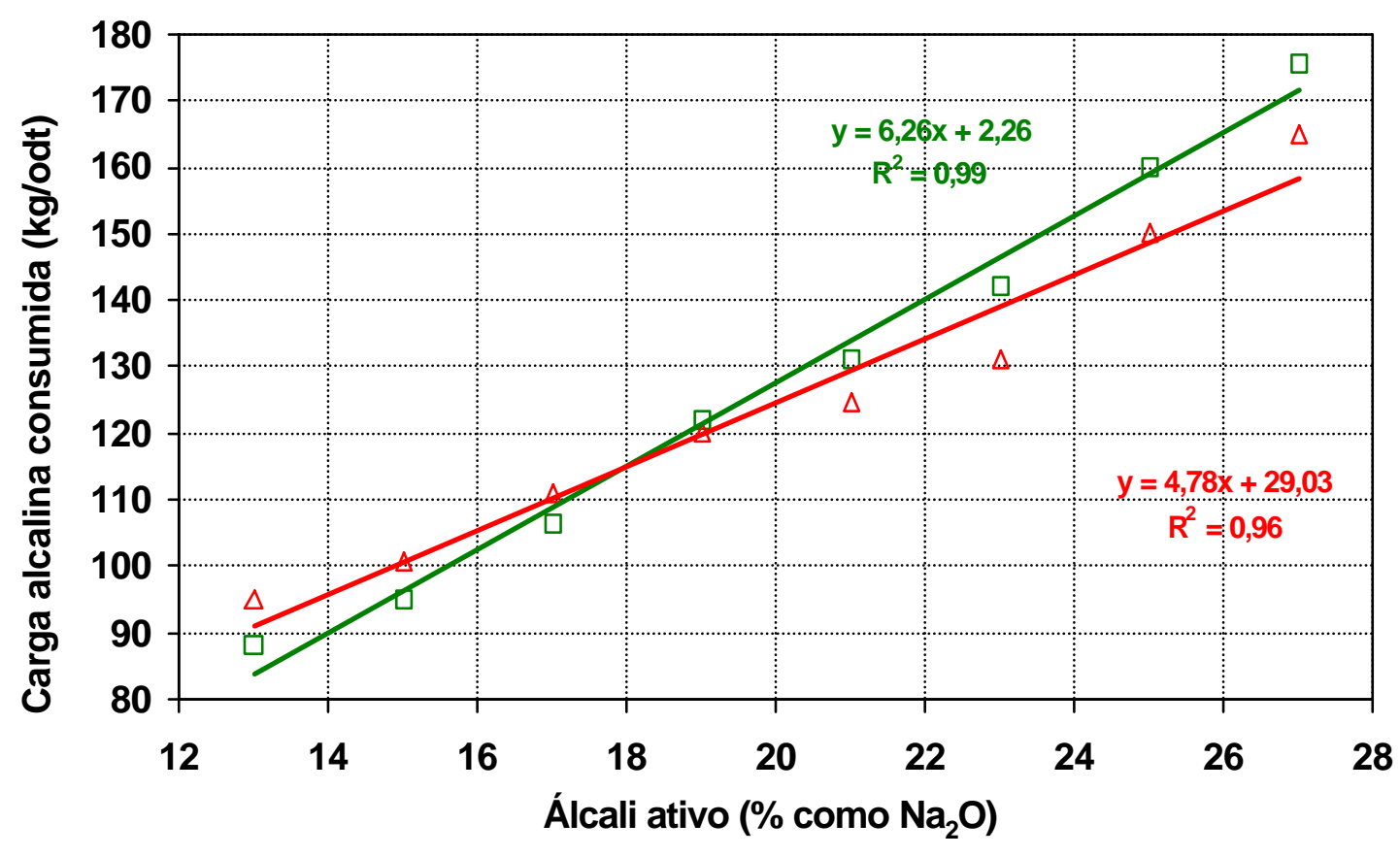

$\square$ E. grandis x E. urophylla P 4299

$\triangle$ E. grandis $x$ E. urophylla C 085

Figura 41 - Consumo de álcali por tonelada de polpa produzida x álcali ativo

Como esperado, o aumento do nível de deslignificação por meio do incremento da carga alcalina levou a um maior consumo de álcali por tonelada de celulose produzida, conforme mostra a Figura 41. Nota-se que o material C085 apresenta um maior consumo de álcali para os tratamentos com 13\%, 15\% e 17\% de álcali, muito provavelmente devido ao fato do mesmo apresentar maior densidade básica, oferecendo com isso um pouco mais de resistência a impregnação do dos cavacos pelo licor de cozimento. Já para os tratamentos com carga alcalina de $21 \%, 23 \%, 25 \%$ e $27 \%$, onde quantidade de álcali pas sa ser relativamente excessiva, o material C085 passa a consumir uma menor quantidade de álcali por tonelada de celulose produzida, não ficando evidente as razões porque isso ocorre; tendo em vista o próprio objetivo do estudo e as análises realizadas. 


\subsection{Estimativa do consumo específico de madeira}

A Tabela 21 mostra o consumo específico de madeira para os materiais estudados, levando em consideração o rendimento do processo de polpação obtido para os diferentes tratamentos e também a densidade básica dos mesmos.

Tabela 21. Consumo de madeira em $\mathrm{m}^{3}$ por tonelada de polpa celulósica seca produzida

\begin{tabular}{ccc}
\hline & \multicolumn{2}{c}{$\mathbf{m}^{3}$ madeira/ton polpa (odt) } \\
\cline { 2 - 3 }$\%$ AA $\left(\mathrm{Na}_{2} \mathrm{O}\right)$ & $\begin{array}{c}\text { Híbrido E. grandis } \mathbf{~ E .} \\
\text { urophylla P4299 }\end{array}$ & $\begin{array}{c}\text { Hibrido E. grandis } \mathbf{~} E . \\
\text { urophylla C085 }\end{array}$ \\
\hline 13 & 3,78 & 3,40 \\
15 & 3,86 & 3,47 \\
17 & 3,98 & 3,55 \\
19 & 4,07 & 3,62 \\
21 & 4,09 & 3,67 \\
23 & 4,18 & 3,73 \\
25 & 4,18 & 3,81 \\
27 & 4,21 & 3,82 \\
\hline
\end{tabular}

$\mathrm{AA}=$ álcali ativo

A Figura 42 mostra o consumo específico de madeira em $\mathrm{m}^{3}$ para os materiais estudados considerando-se o rendimento do processo de polpação obtido para os mesmos quando submetidos às dosagens de álcali. 


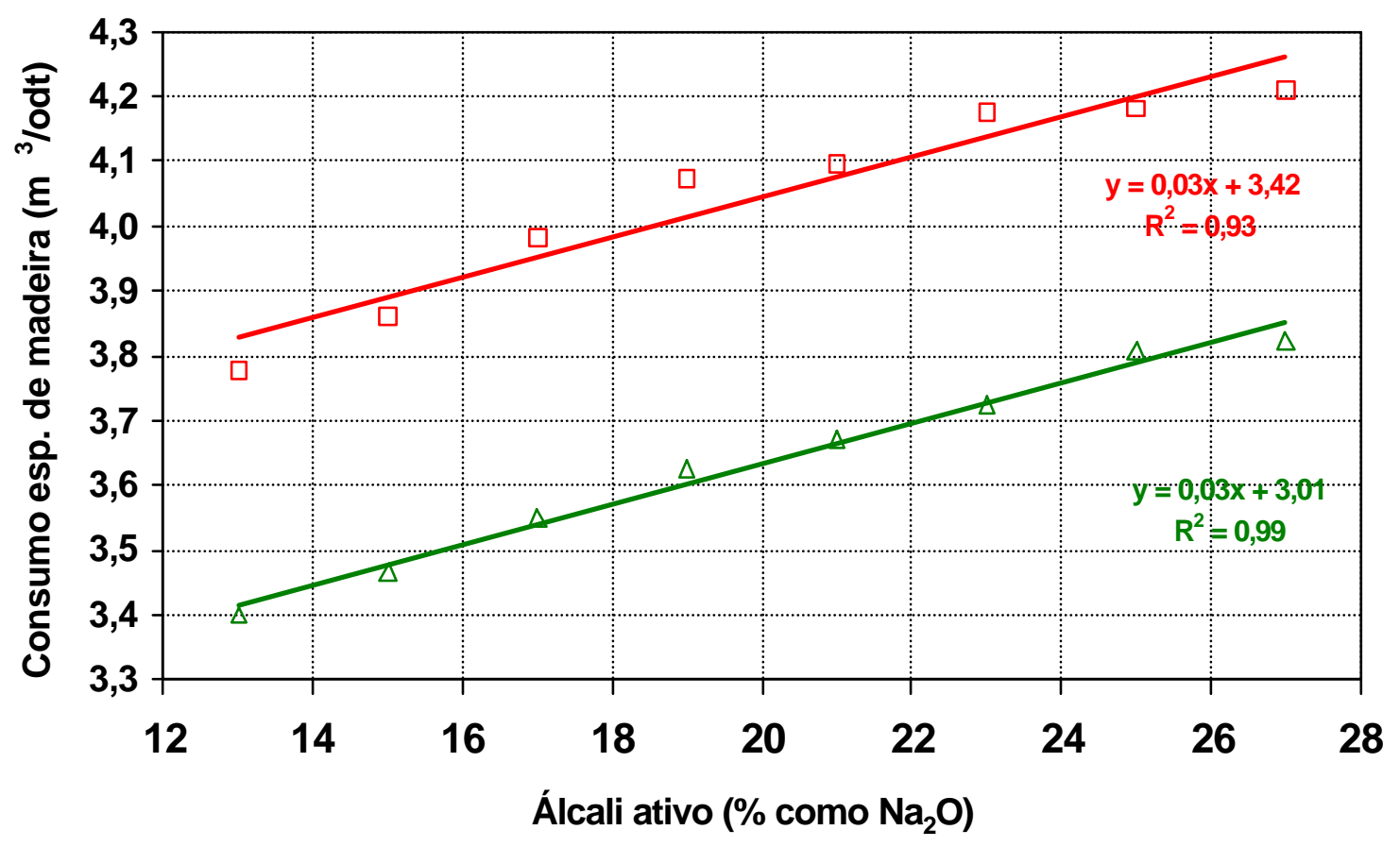

$\square$ E. grandis $x$ E. urophylla $P 4299$

$\triangle$ E. grandis $x$ E. urophylla C085

Figura 42 - Consumo específico de madeira $\mathrm{em}^{3}$ por tonelada de polpa produzida $\mathrm{x}$ álcali ativo

Pela Figura 42 evidencia a influência da densidade básica da madeira sobre o consumo de madeira no processo de polpação, confirmando a importância do emprego de madeiras mais de densas na fabricação de polpa celulósica, uma vez que a quantidade $\left(\mathrm{em} \mathrm{m}^{3}\right.$ ) necessária para produzir uma tonelada de polpa é menor, conseqüentemente a área de floresta a ser abatida. A Figura 42 mostra também o efeito significativo da carga alcalina sobre o consumo específico de madeira, tendo em vista exclusivamente os impactos com relação ao rendimento do processo de polpação. Vale o maior consumo específico de madeira está associado também ao menor nível de deslignificação da polpa, ou seja, a queda do rendimento na fase de branqueamento será menor para as polpas com menores números kappa. 
A Tabela 22 apresenta o consumo específico de madeira em toneladas para os materiais estudados levando em consideração apenas o rendimento do processo de polpação obtido para os diferentes tratamentos, ou seja, eliminando a influência da densidade básica da madeira; não se esquecendo que a mesma pode também influenciar o próprio parâmetro de rendimento do processo de polpação.

Tabela 22. Consumo de madeira em tonelada por tonelada de polpa celulósica seca produzida

\begin{tabular}{ccc}
\hline & \multicolumn{2}{c}{ ton madeira/ton polpa (odt) } \\
\cline { 2 - 3 }$\% \mathbf{A A}\left(\mathrm{Na}_{2} \mathbf{O}\right)$ & $\begin{array}{c}\text { Hibrido E. grandis X } E . \\
\text { urophylla P4299 }\end{array}$ & $\begin{array}{c}\text { Hibrido E. grandis } \mathbf{~} E . \\
\text { urophylla C085 }\end{array}$ \\
\hline 13 & 1,88 & 1,90 \\
15 & 1,93 & 1,94 \\
17 & 1,99 & 1,98 \\
19 & 2,03 & 2,03 \\
21 & 2,04 & 2,05 \\
23 & 2,08 & 2,08 \\
25 & 2,09 & 2,13 \\
27 & 2,10 & 2,14 \\
\hline
\end{tabular}

$\mathrm{AA}=$ álcali ativo

A Figura 43 mostra o consumo específico de madeira em toneladas para os híbridos de E. grandis x E. urophylla P4299 e C085, considerando apenas rendimento do processo de polpação obtido para os mesmos quando submetidos aos diferentes tratamentos. 


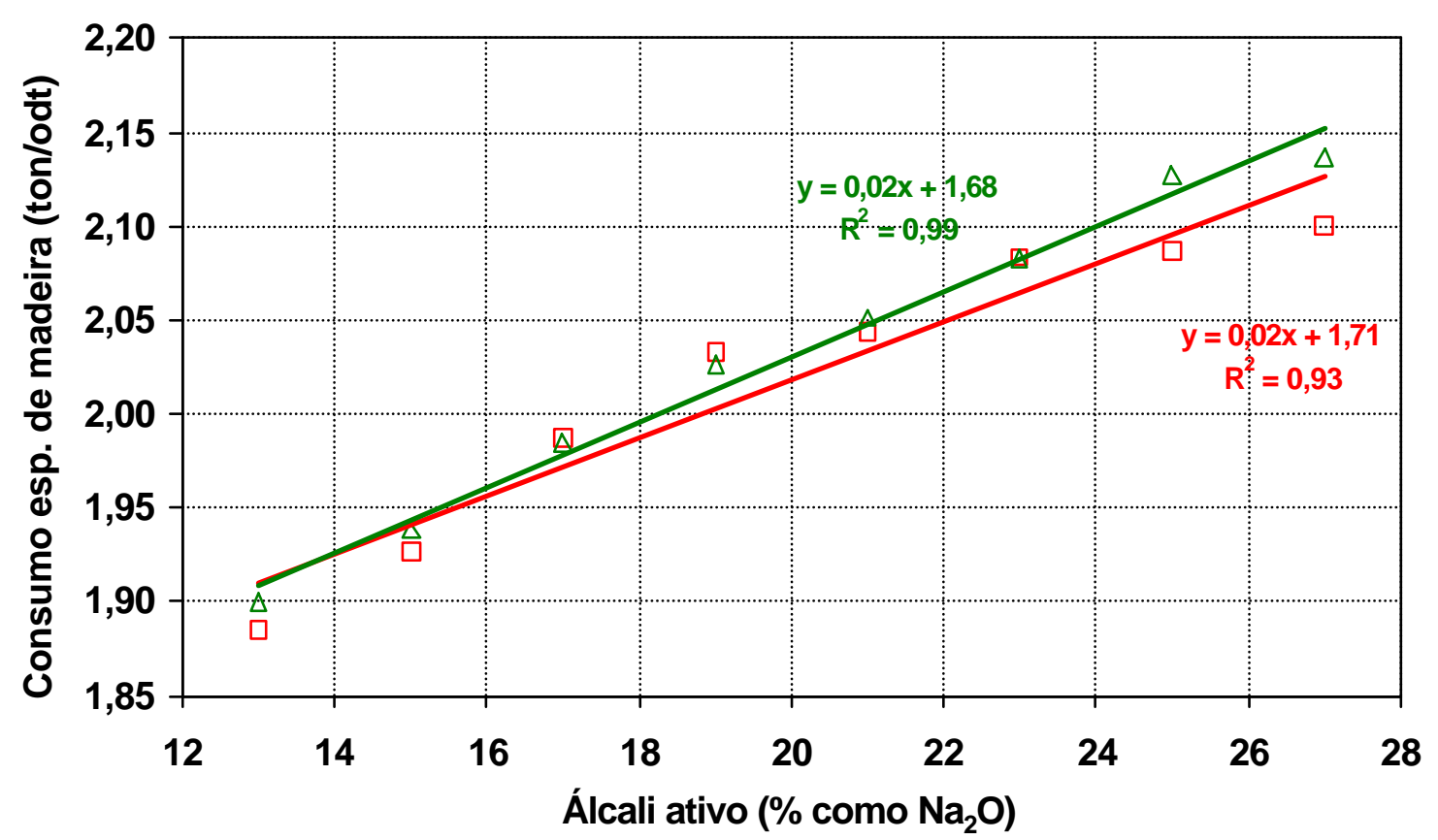

$\square$ E. grandis x E. urophylla P4299

$\triangle E$. grandis $x$ E. urophylla C085

Figura 43 - Consumo específico de madeira em tonelada por tonelada de polpa produzida x álcali ativo

A Figura 43 mostra que, se considerarmos apenas o rendimento do processo obtido para os diferentes tratamentos, nota-se que o consumo específico de madeira por tonelada de celulose produzida é muito semelhante para as diferentes cargas alcalinas paliçadas. 


\section{CONCLUSÕES}

- Os materiais híbridos de E. grandis x E. urophylla C085 e P4299 apresentaram composição química semelhantes, porém diferentes valores de densidade básica.

- Os materiais híbridos de E. grandis x E. urophylla C085 e P4299 estudados neste trabalho apresentaram valores semelhantes para os parâmetros de rendimento, número kappa, viscosidade, teor de rejeitos. Tais resultados estão associados à semelhança de composição química entre os materiais a boa impregnação dos cavacos no processo de polpação Lo-Solids ${ }^{\circledR}$, uma vez que os valores de densidade básica dos materiais dão diferentes.

- Os resultados indicam que o sistema de polpação Lo-Solids ${ }^{\circledR}$ é menos sensível ao parâmetro densidade básica da madeira, mostrando que ambas matériasprimas podem ser empregadas na produção de polpa celulósica, sem impactos no processo de polpação.

- A polpa celulósica não branqueada obtida a partir do material C085 apresentou fibras com maior espessura de parede, maior coarseness e menor número de fibras por grama quando comparada a polpa obtida do material P4299, parâmetros possivelmente associados ao maior valor de densidade básica do material C085.

- O material P4299 apresentou maior consumo específico de madeira $\left(\mathrm{em} \mathrm{m}^{3}\right)$ para produção de polpa celulósica, mostrando a importância econômica da densidade básica para o processo de polpação. 
- Para os materiais estudados neste trabalho verificou-se um maior consumo específico de madeira (em ton) à medida que se aumenta a carga alcalina aplicada, comportamento associado à redução do rendimento depurado devido a remoção dos carboidratos, principalmente as hemiceluloses.

- O aumento da carga alcalina proporcionou o aumento do nível de deslignificação e, consequentemente a redução do número kappa. Porém, não se verificou redução do teor lignina da polpa para carga alcalina aplicada superior a $21 \%$ de álcali ativo, não justificando a prática de maiores cargas alcalina visando exclusivamente a remoção da mesma.

- O teor de ácidos hexenurônicos presentes na polpa é influenciado pela carga alcalina aplicada e apresenta um modelo quadrático em função da carga alcalina e do número kappa, sendo o ponto de máximo obtido para dosagem de álcali de 17\% e número kappa de 13,8 para o material P4299 e 15,1 para o material $\mathrm{C} 085$.

- A análise do comprimento das fibras das polpas não branqueadas mostrou que - aumento da carga alcalina promove a geração de finos oriundos possivelmente da fragmentação das fibras, o que levou a obtenção de fibras com menor comprimento médio ponderado, menor coarseness e maior número de fibras por grama de polpa.

- A análise das dimensões de fibras das polpas não branqueadas mostrou também que o aumento da carga alcalina levou a obtenção de fibras com menor espessura de parede e, consequentemente, menor largura. O Diâmetro do lume da fibra uma vez que não se observou alterações no diâmetro do lume da fibra. 


\section{REFERÊNCIAS BIBLIOGRÁFICAS}

ABITZ, P.; LUNER, $P$. The relationship of wet fiber flexibility (WFF) to fiber and pulps properties. New York: ESPRI, 1991. 87p.

ALENCAR, G.S.B. Estudo da qualidade da madeira para produção de celulose relacionada à precocidade na seleção de híbrido $E$. grandis $x$ E. urophylla. Piracicaba, 2002. 145p. Dissertação (Mestrado) - Escola Superior de Agricultura "Luiz de Queiroz", Universidade de São Paulo.

ALMEIDA, J.M.; SILVA, D.J. Efeito da quantidade de extrativos e da acessibilidade do licor na polpação kraft de clones de Eucalyptus. In: CONGRESSO ANUAL DE CELULOSE E PAPEL DA ABTCP, 34., São Paulo, 2001. Anais. São Paulo: ABTCP, 2001. p.1-14.

ALMEIDA, J.M.; GOMIDE, J.L.; SILVA, D.J. Dissolução dos constituintes da madeira de eucalipto ao longo dos processos kraft contínuo convencional e aditivado. Revista Árvore, v.24, n.2, p.215-222, 2000.

AMIDON, T.E. Effect of wood properties of hardwood on kraft paper properties. Tappi Journal, v.64, n.3, p.123-126, Mar. 1981.

ASSIS, T.F. Melhoramento genético do eucalipto. Revista Informações Agropecuárias, v.8, n.185, p.40-51, 1996.

BARBOSA, F.E.V. The eucalyptus fiber for printing \& writing papers. In: BRAZILIAN SYMPOSIUM ON THE CHEMISTRY OF LIGNIN AND OTHER WOOD COMPONENTS. 7., Belo Horizonte, 2001. Proceedings. Belo Horizonte: Universidade Federal de Viçosa, 2001. p.313-314. 
BARRICHELO, L.E.G.; BRITO,J.O. A. A madeira das espécies de eucalipto como matéria-prima para a indústria de celulose e papel. Série Divulgação Prodepef, n.45, p.1-145, 1976.

BASSA, A. Processos de polpação kraft convencional e modificado de madeiras de $E$. grandis e Híbrido (E. grandis x E. urophylla). Piracicaba, 2002. 103p. Dissertação (Mestrado) - Escola Superior de Agricultura "Luiz de Queiroz", Universidade de São Paulo.

CARPIM, M.A.; BARRICHELLO, L.E.G.; SILVA JUNIOR, C.E. et al. A influência do número de fibras por grama nas propriedades óticas do papel. In: CONGRESSO ANUAL DE CELULOSE E PAPEL DA ABTCP, 20., São Paulo, 1987. Anais. São Paulo: ABTCP, 1997. p.183-205.

CHAI, X.S.; ZHU, J.Y.; LI, J. A simple and rapid method to determine hexenuronic acid groups in chemical pulp. Journal of Pulp and Paper Science, v.27, n.5, p.165-169. May 2001.

CHAKAR, F.S.; ALLISON, L.; RAGAUSKAS, T. et al. Influence of hexenuronic acids on U. S. bleaching operations. Tappi Journal, v.83, n.11, p.62-71, Nov. 2000.

COLODETTE, J.L.; GOMIDE, J.L.; GIRARD, R. et al. Influence of pulping conditions on hardwood pulp yield, quality and bleachability. In: INTERNATIONAL PULP BLEACHING CONFERENCE, Halifax, 2000. Proceedings. Montreal: PAPTAC, 2000. p.41-48.

COSTA, M.M.; MOUNTEER, A.H.; COLODETTE, J.L. Ácidos Hexenurônicos: parte I: origem, quantificação, reatividade e comportamento durante a polpação kraft. $\mathbf{O}$ Papel, v.57, n.5, p.75-85, maio 2001.

DEMUNER, B.J.; VIANNA DORIA, E.L.; SILVA JUNIOR, C.E et al. As propriedades do papel e as características das fibras de eucalipto. In: CONGRESSO ANUAL DE CELULOSE E PAPEL DA ABTCP, 24., São Paulo, 1991. Anais. São Paulo: ABTCP, 1991. p.621-641. 
DEMUNER, B.J.; VIANNA DORIA, E.L.; SILVA JUNIOR, C.E et al. The influence of eucalyptus fiber characteristics on paper properties. IN: INTERNATIONAL PAPER PHYSICS CONFERENCE, Kona, 1991. Proceedings. Kona:TAPPI, 1991. p.185196.

EK, M.; GUSTAVSSON, C.; KADIRIC, J.; TEDER, A. Formation and dissolution/degradation of hexenuronic acids during kraft pulping of eucalyptus globulus. In: BRAZILIAN SYMPOSIUM ON THE CHEMISTRY OF LIGNIN AND OTHER WOOD COMPONENTS. 7., Belo Horizonte, 2001. Proceedings. Belo Horizonte: UFV, 2001. p.99-106.

FOELKEL, C.E.B.; BRASIL, M.A.M.; BARRICHELO, L.E.G. Métodos de determinação da densidade básica de cavacos para coníferas e folhosas. IPEF, n.213, p.65-74, 1971.

FOELKEL, C.E.B.; DINIZ, A.S.; GARCIA, W. et al. Estudo da influência da densidade da madeira nas propriedades das celuloses kraft de $p$ elliottiobtidas a uma mesma condição de cozimento. O Papel, v.36, n.10, p.65-69, out. 1975.

FOELKEL, C.E.B.; MORA, E.; MENOCHELLI, S. Densidade básica: sua verdadeira utilidade como índice da na qualidade da madeira de eucalipto para produção de celulose. O Papel, v.53, n.5, p.35-40, maio 1992.

FOELKEL, C. Eucalyptus wood and pulp quality Requirements oriented to the manufacture of tissue and printing \& writing paper. In: ANNUAL GENERAL CONFERENCE, 52., Brisbane, 1998. Proceedings. Brisbane: APPITA, 1998. p.149-154.

GANQIANG, H.; ZENG, G.; ZHANG, B. et al. Modified kraft pulping of eucalyptus wood. South Chine University of Technology, n.1, p.195-202, 1998.

GARCIA, C.B. Anatomia, composição química e propriedade de cinco madeiras paraguaias. Viçosa, 1995. 126p. Dissertação (Mestrado) - Universidade Federal de Viçosa. 
GENGO, J.M.; BUSAYASAKUL, N.; MEDHORA, H.K. et al. Hemicellulose retention during kraft pulping. Tappi Journal, v.73, n.4, p.223-233, Apr. 1990.

GIDNERT, E.B.; TOMAI, P.E.; DAHLMAN, O. Influence on pulp quality of conditions during the removal of hexenuronic acids. Nordic Pulp and Paper Research Journal, v.13, n.4, p.310-316, Apr. 1998.

GOMIDE, J.L. Polpa de celulósica: química dos processos alcalinos de polpação. Viçosa: UFV, 1979. 50p.

JORDÃO, M.C.S.; MANGOLINI; N.J. Avaliação de pastas ligno-celulósicas para fins absorventes com ênfase em pasta fofa (fluff pulp). In: CONGRESSO ANUAL DE CELULOSE E PAPEL DA ABTCP, 21., São Paulo, 1988. Anais. São Paulo: ABTCP, 1988. p.295-309.

KUBES, G.J.; MACLEOD, J.M.; FLEMING, B.I. et al. The viscosity of unbleached alkaline pulps. In: PULPING CONFERENCE PROCEEDINGS, Denver, 1980. Proceedings. Denver: Pulp and Paper Institute, 1980. p.31-34.

LI, J.; GELLERSTEDT, G. On the structural significance of kappa number measurement. In: INTERNATIONAL SYMPOSIUM WOOD PULPING CHEMICAL, 9., Montreal, 1997. Proceedings. Montreal: TAPPI, 1997. p.56-71

MARCOCCIA, B.S.; STROMBERG, B.; PROUGH, J.R. Achieving major increases in hardwood yield with Lo-Solids cooking. In: BREAKING THE PULP YIELD BARRIER SYMPOSIUM, Atlanta, 1998. Proceedings. Atlanta: TAPPI, 1998. p.79-89.

OLIVEIRA, R.C. Produção de celulose kraft de misturas de madeiras de $P$. strobus var. Chiapensis e E. urophylla de origem híbrida. Viçosa, 1979. 177p. Dissertação (Mestrado) - Universidade Federal de Viçosa.

PACINI, P. Cozimento - processo sulfato de eucalipto no Brasil. O Papel, v.39, n.7, p.35-40, jul. 1978.

PANSHIN, A.J.; HARRAR, E.S.; BETHEL, J.S. Forest product: their sources, production and utilization. 2.ed. New York: Mcgraw-Hill, 1962. 538p. 
PIMENTEL, F.G; GARCIA, C.H. Estatística aplicada a experimentos agronômicos e florestais. Piracicaba: FEALQ, 2002. 309p.

QUEIROZ, S.C.S.; GOMIDE, J.L. Efeito das características anatômicas e químicas na densidade básica da madeira de clones híbridos de Eucalyptus gandis x Eucalyptus urophylla. O Papel, v.44, n.6, p.79-84, jun. 2003.

RATNIEKS, E.; FOELKEL, C. Uma discussão teórica -prática sobre polpas de eucalipto para a fabricação de papel "Tissue". In: CONGRESSO ANUAL DE CELULOSE E PAPEL DA ABTCP, 29., São Paulo, 1996. Anais. São Paulo: ABTCP, 1996. p.717734.

SANSÍGOLO, C.A. Efeitos da viscosidade nas propriedades da polpa de E. saligna. Piracicaba, 1988. 66p. Dissertação (Mestrado) - Escola Superior de Agricultura "Luiz de Queiroz", Universidade de São Paulo.

SANTOS, C.R. Métodos não-convencionais para determinação de celulose como parâmetro de seleção de árvores matrizes visando a produção de polpa kraft-AQ. Piracicaba, 2000. 117p. Dissertação (Mestrado) - Escola Superior de Agricultura "Luiz de Queiroz", Universidade de São Paulo.

SANTOS, C.R. Qualidade da madeira e sua influência nas características de papéis imprimir \& escrever e tissue. Viçosa, 2002. 45p. Monografia Curso de Pós Graduação Lato Sensu em Tecnologia de Celulose e Papel - Universidade Federal de Viçosa.

SHIMOYAMA, V.R.S. Variações da densidade básica e características anatômicas e químicas da madeira em Eucalyptus spp. Piracicaba, 1990. 93p. Dissertação (Mestrado) - Escola Superior de Agricultura "Luiz de Queiroz", Universidade de São Paulo.

SILVA JÚNIOR, F.G.; MUNER, J.C.G.; VALLE, C.F. Programa de qualidade da Madeira da Votorantim Celulose e Papel. In: CONGRESSO ANUAL DE CELULOSE E PAPEL DA ABTCP, 28., São Paulo, 1995. Anais. São Paulo: ABTCP, 1995. p.515-529. 
SILVA JÚNIOR, F.G. Polpação kraft do eucalipto com adição de antraquinona, polissulfeto e surfactante. Campinas, 1997. 117p. Tese (Doutorado). Universidade Estadual de Campinas.

SILVA JÚNIOR, F.G.; MCDONOUGH T.J. Polpação Lo_Solids de eucalipto: Efeito do ritmo de produção. In: CONGRESSO ANUAL DE CELULOSE E PAPEL DA ABTCP, 34., São Paulo, 2001. Anais: São Paulo: ABTCP, 2001. p.69-81.

SMOOK, G.A., Handbook for pulp \& paper technologists 2.ed. Vancouver: Angus Wilde, 1997. 419p.

TRURGILHO, F. P.; LIMA, J.T.; MENDES, L.M. Influência da idade nas características físicoquímicas e anatômicas da madeira de E. saligna. Revista Cerne, v.2, n.1, p.94-111, 1996.

TURQUETI, A. Tecnologias em uso e novas tecnologias de cozimento contínuo. In: Encontro de Operadores de Digestores, 1., São Paulo, 2001. São Paulo: ABTCP, 2001. p.21-27.

WEHR, T.F.A. Variações nas características da madeira de E. grandisHill ex maiden e suas influências na qualidade de cavacos em cozimento kraft. Piracicaba, 1991. 84p. Dissertação (Mestrado) - Escola Superior de Agricultura "Luiz de Queiroz", Universidade de São Paulo. 
APÊNDICES 


\title{
APÊNDICE 1.
}

\author{
Determinação Simultânea de Extrativos Totais, Lignina e Holocelulose \\ Laboratório de Química, Celulose e Energia \\ Departamento de Ciências Florestais \\ Escola Superior de Agricultura "Luiz de Queiroz" \\ Universidade de São Paulo
}

1. Pesar o equivalente a $1 \mathrm{~g}$ absolutamente seco (a. s.) de serragem e transferir para saquinho de papel de filtro.

2. Colocar a amostra no corpo do extrator.

3. Fazer a extração com álcool-tolueno (1:2) e álcool 96º GL, durante 8 horas em cada solvente, deixando secar ao ar após cada extração.

4. Ligar o banho-maria e mantê-lo em ebulição.

5. Transferir toda serragem do saquinho para erlenmeyer de $250 \mathrm{ml}$.

6. Adicionar $100 \mathrm{ml}$ de água destilada e colocar o erlenmeyer no banho-maria (que já deverá estar fervendo) e cobri-lo com um copo de $50 \mathrm{ml}$.

7. Agitar suavemente a cada 15 minutos.

8. Após 3 horas filtrar através de cadinho de vidro sinterizado tarado, transferindo toda a serragem do erlenmeyer para o cadinho.

9. Lavar (descontinuamente) o cadinho com $250 \mathrm{ml}$ de água quente (quase fervendo).

10. Mantê-lo na estufa até peso constante (normalmente deixa-se de um dia para outro).

11. Retirar o cadinho da estufa, esperar esfriar em dessecador e pesar.

12. Calcular a percentagem de "Extrativos Totais" através da expressão:

$\% \mathrm{ET}=(1-$ peso a. s. serragem $) \times 100$

13. Utilizando-se a mesma serragem do cadinho transferi-la para copo de 50 ou $100 \mathrm{ml}$.

14. Resfriar $\mathrm{O}_{2} \mathrm{SO}_{4} 72 \%$ a $10-12^{\circ} \mathrm{C}$.

15. Adicionar $15 \mathrm{ml}$ de $\mathrm{HSO}_{4} 72 \%$ para o copo e mantêlo no banho de água a 18 $20^{\circ} \mathrm{C}$.

16. Agitar e manter no banho durante 2 horas. Homogeneizar periodicamente e manter o bastão dentro do copo.

17. Após 2 horas transferir para erlenmeyer de 1 litro usando $560 \mathrm{ml}$ de água destilada. 
18. Ferver durante 4 horas mantendo constante o nível do erlenmeyer por adição periódica de água destilada.

19. Após 4 horas deixar a lignina sedimentar totalmente (equivale a deixar de um dia para outro).

20. Filtrar através de cadinho de vidro sinterizado tarado, fazendo um fundo com papel de filtro, e transferir toda a lignina do erlenmeyer para o cadinho.

21. Lavar o erlenmeyer com água quente (quase fervendo).

22. Larvar a lignina do cadinho com $250 \mathrm{ml}$ água quente (quase fervendo).

23. Mantê-lo na estufa até peso constante (normalmente deixa-se de um dia para outro).

24. Retirar o cadinho da estufa, esperar esfriar em Dessecador e pesar.

25. Calcular a porcentagem de lignina através da expressão:

$\%$ Lignina = Peso a. s. de resíduo x 100

26. Calcular a porcentagem de holocelulose através da expressão:

$\%$ Holocelulose = 100 - (\% ET - \% Lignina) 


\section{APÊNDICE 2.}

Teor de lignina, teor de holocelulose e densidade básica da madeira das 10 árvores do Híbrido E. grandis x E. urophylla P4299.

\begin{tabular}{|c|c|c|c|}
\hline $\begin{array}{c}\text { Árvores } \\
\left({ }^{*}\right)\end{array}$ & $\begin{array}{c}\text { Teor de Lignina Total } \\
(\%)\end{array}$ & $\begin{array}{c}\text { Teor de Holocelulose } \\
(\%)\end{array}$ & $\begin{array}{c}\text { Densidade Básica } \\
\left(\mathrm{g} / \mathrm{cm}^{3}\right)\end{array}$ \\
\hline 1 & 30,33 & 67,22 & 0,507 \\
\hline 1 & 29,91 & 67,20 & 0,506 \\
\hline 2 & 28,12 & 69,48 & 0,495 \\
\hline 2 & 28,63 & 68,79 & 0,485 \\
\hline 3 & 28,89 & 68,66 & 0,488 \\
\hline 3 & 29,52 & 68,37 & 0,499 \\
\hline 4 & 29,26 & 68,95 & 0,499 \\
\hline 4 & 26,93 & 71,34 & 0,499 \\
\hline 5 & 27,43 & 70,53 & 0,503 \\
\hline 5 & 29,20 & 68,17 & 0,590 \\
\hline 6 & 28,73 & 68,76 & 0,485 \\
\hline 6 & 28,80 & 68,23 & 0,493 \\
\hline 7 & 28,77 & 69,35 & 0,500 \\
\hline 7 & 28,32 & 68,50 & 0,483 \\
\hline 8 & 30,00 & 67,21 & 0,502 \\
\hline 8 & 28,40 & 69,10 & 0,510 \\
\hline 9 & 28,75 & 68,40 & 0,485 \\
\hline 9 & 29,62 & 70,50 & 0,490 \\
\hline 10 & 27,23 & 68,90 & 0,487 \\
\hline 10 & 28,50 & 69,30 & 0,493 \\
\hline Média & 28,77 & 68,85 & 0,500 \\
\hline $\mathbf{S}$ & 0,90 & 1,08 & 0,02 \\
\hline$\overline{\text { CV }}$ & 3,13 & 1,57 & 4,54 \\
\hline
\end{tabular}

$\mathrm{S}=$ desvio padrão; c.v = coeficiente de variação

$\left({ }^{*}\right)$ valores médio de 3 repetições, sendo 2 repetições para cada árvore. 


\section{APÊNDICE 3.}

Teor de lignina, teor de holocelulose e densidade básica da madeira das 10 árvores do Híbrido E. grandis x E. urophylla C085

\begin{tabular}{|c|c|c|c|}
\hline $\begin{array}{c}\text { Árvores } \\
\left({ }^{*}\right)\end{array}$ & $\begin{array}{l}\text { Teor de Lignina Total } \\
(\%)\end{array}$ & $\begin{array}{c}\text { Teor de Holocelulose } \\
(\%)\end{array}$ & $\begin{array}{c}\text { Densidade Básica } \\
\left(\mathrm{g} / \mathrm{cm}^{3}\right)\end{array}$ \\
\hline 1 & 29,51 & 69,00 & 0,564 \\
\hline 1 & 30,37 & 66,71 & 0,560 \\
\hline 2 & 29,33 & 67,02 & 0,560 \\
\hline 2 & 29,47 & 68,30 & 0,556 \\
\hline 3 & 28,24 & 68,00 & 0,557 \\
\hline 3 & 27,94 & 69,12 & 0,562 \\
\hline 4 & 31,94 & 69,02 & 0,564 \\
\hline 4 & 29,61 & 67,77 & 0,560 \\
\hline 5 & 28,68 & 69,54 & 0,564 \\
\hline 5 & 28,92 & 68,70 & 0,554 \\
\hline 6 & 29,59 & 69,12 & 0,558 \\
\hline 6 & 28,35 & 67,26 & 0,560 \\
\hline 7 & 31,32 & 68,12 & 0,550 \\
\hline 7 & 28,50 & 67,69 & 0,565 \\
\hline 8 & 28,54 & 66,40 & 0,563 \\
\hline 8 & 29,30 & 69,40 & 0,555 \\
\hline 9 & 28,50 & 69,50 & 0,550 \\
\hline 9 & 29,35 & 68,40 & 0,560 \\
\hline 10 & 28,55 & 68,10 & 0,565 \\
\hline 10 & 29,45 & 68,30 & 0,567 \\
\hline Média & 29,27 & 68,27 & 0,560 \\
\hline $\mathbf{S}$ & 1,01 & 0,93 & 0,01 \\
\hline$\overline{C . V}$ & 3,44 & 1,36 & 0,88 \\
\hline
\end{tabular}

$\mathrm{s}=$ desvio padrão; c.v = coeficiente de variação

$\left(^{*}\right)$ valores médio de 3 repetições, sendo 2 repetições para cada árvore. 


\section{APÊNDICE 4.}

Análise da variância e teste $F$ para o teor de lignina, teor de holocelulose e densidade básica da madeira das 10 árvores - E. grandis x E. urophylla P4299

$\mathrm{GL}=$ grau de liberdade $\mathrm{SQ}=$ soma de quadrados $\mathrm{QM}=$ quadrado médio Prob = probabilidade

Análise de variância e teste $\mathrm{F}$ para o parâmetro teor de lignina total da madeira

\begin{tabular}{lrrrrr}
\hline & GL & SQ & QM & F & Prob>F \\
\hline Árvores & 9 & 8,1142 & 0,9016 & 1,24 & 0,3687 \\
Resíduo & 10 & 7,2662 & 0,7266 & & \\
\hline Total & 19 & 15,3804 & & & \\
\hline
\end{tabular}

Análise de variância e teste F para o parâmetro teor de holocelulose da madeira

\begin{tabular}{lrrrrr}
\hline & GL & SQ & QM & F & Prob>F \\
\hline Árvores & 9 & 11,6944 & 1,2994 & 1,24 & 0,3699 \\
Resíduo & 10 & 10,4939 & 1,0494 & & \\
\hline Total & 19 & 22,1883 & & & \\
\hline
\end{tabular}

Análise de variância e teste $\mathrm{F}$ para o parâmetro densidade básica da madeira

\begin{tabular}{lrlclr}
\hline & GL & SQ & QM & F & Prob>F \\
\hline Árvores & 9 & 0,0057 & 0,00063 & 1,52 & 0,2604 \\
Resíduo & 10 & 0,0041 & 0,00041 & & \\
\hline Total & 19 & 0,0098 & & & \\
\hline
\end{tabular}




\section{APÊNDICE 5.}

\section{Análise da variância e teste $F$ para o teor de lignina, teor de holocelulose e densidade básica da madeira das 10 árvores - E. grandis x E. urophylla C085}

$\mathrm{GL}=$ grau de liberdade $\mathrm{SQ}=$ soma de quadrados $\mathrm{QM}=$ quadrado médio Prob = probabilidade

Análise de variância e teste $\mathrm{F}$ para o parâmetro teor de lignina total da madeira

\begin{tabular}{lrrrrr}
\hline & GL & \multicolumn{1}{c}{ SQ } & QM & F & Prob>F \\
\hline Árvores & 9 & 10,3161 & 1,1462 & 1,28 & 0,3521 \\
Resíduo & 10 & 8,9679 & 0,8968 & & \\
\hline Total & 19 & 19,2840 & & & \\
\hline
\end{tabular}

Análise de variância e teste $\mathrm{F}$ para o parâmetro teor de holocelulose da madeira

\begin{tabular}{lrrrrr}
\hline & GL & \multicolumn{1}{c}{ SQ } & \multicolumn{1}{c}{ QM } & F & Prob>F \\
\hline Árvores & 9 & 4,2205 & 0,4689 & 0,39 & 0,9162 \\
Resíduo & 10 & 12,1498 & 1,2150 & & \\
\hline Total & 19 & 16,3703 & & & \\
\hline
\end{tabular}

Análise de variância e teste $\mathrm{F}$ para o parâmetro densidade básica da madeira

\begin{tabular}{lrcccc}
\hline & GL & SQ & QM & F & Prob>F \\
\hline Árvores & 9 & 0,00016 & 0,000018 & 0,64 & 0,7456 \\
Resíduo & 10 & 0,00029 & 0,000029 & & \\
Total & 19 & 0,00045 & & & \\
\hline
\end{tabular}




\section{APÊNDICE 6.}

\section{Análise da variância e teste $F$ para densidade básica da madeira e composição química da amostra composta para os híbridos E. grandis x E. urophylla P4299 e C085}

$\mathrm{GL}=$ grau de liberdade $\mathrm{SQ}=$ soma de quadrados $\mathrm{QM}=$ quadrado médio Prob = probabilidade

Análise de variância e teste $\mathrm{F}$ para o parâmetro densidade básica da madeira

\begin{tabular}{lrrrrr}
\hline & GL & SQ & QM & F & Prob>F \\
\hline Material & 1 & 0,0054 & 0,00540 & 132,24 & 0,0003 \\
Resíduo & 4 & 0,0002 & 0,00004 & & \\
\hline Total & 4 & 0,0056 & & & \\
\hline
\end{tabular}

Análise de variância e teste $\mathrm{F}$ para o parâmetro lignina total da madeira

\begin{tabular}{lrrrrr}
\hline & GL & SQ & QM & F & Prob>F \\
\hline Material & 1 & 0,4004 & 0,4004 & 2,62 & 0,1808 \\
Resíduo & 4 & 0,6113 & 0,1528 & & \\
\hline Total & 5 & 1,0117 & & & \\
\hline
\end{tabular}

Análise de variância e teste F para o parâmetro extrativos totais da madeira

\begin{tabular}{lccccc}
\hline & GL & SQ & QM & F & Prob>F \\
\hline Material & 1 & 0,7776 & 0,7776 & 2,07 & 0,2237 \\
Resíduo & 4 & 1,5033 & 0,3758 & & \\
\hline Total & 5 & 2,2809 & & & \\
\hline
\end{tabular}

Análise de variância e teste $\mathrm{F}$ para o parâmetro holocelulose da madeira

\begin{tabular}{lrrrrr} 
& GL & SQ & QM & $F$ & Prob>F \\
\hline Material & 1 & 0,6468 & 0,6468 & 1,93 & 0,3904 \\
Resíduo & 4 & 2,7934 & 0,6984 & & \\
\hline Total & 5 & 3,4403 & & & \\
\hline
\end{tabular}

